\title{
WestVirginiaUniversity
}

THE RESEARCH REPOSITORY @ WVU

Graduate Theses, Dissertations, and Problem Reports

2013

\section{Investigation of the Dual-Fuel Conversion of a Direct Injection Diesel Engine}

John S. Smallwood

West Virginia University

Follow this and additional works at: https://researchrepository.wvu.edu/etd

\section{Recommended Citation}

Smallwood, John S., "Investigation of the Dual-Fuel Conversion of a Direct Injection Diesel Engine" (2013). Graduate Theses, Dissertations, and Problem Reports. 3410.

https://researchrepository.wvu.edu/etd/3410

This Thesis is protected by copyright and/or related rights. It has been brought to you by the The Research Repository @ WVU with permission from the rights-holder(s). You are free to use this Thesis in any way that is permitted by the copyright and related rights legislation that applies to your use. For other uses you must obtain permission from the rights-holder(s) directly, unless additional rights are indicated by a Creative Commons license in the record and/ or on the work itself. This Thesis has been accepted for inclusion in WVU Graduate Theses, Dissertations, and Problem Reports collection by an authorized administrator of The Research Repository @ WVU. For more information, please contact researchrepository@mail.wvu.edu. 


\title{
Investigation of the Dual-Fuel Conversion of a Direct Injection Diesel Engine
}

\author{
John S. Smallwood \\ Thesis Submitted to the \\ Benjamin M. Statler College of Engineering and Mineral Resources \\ at West Virginia University \\ in Partial Fulfillment of the Requirements \\ for the Degree of
}

Master of Science

in

Mechanical Engineering

Mridul Gautam, Ph.D., Chair

Greg Thompson, Ph.D.

Hailin Li, Ph.D.

Department of Mechanical and Aerospace Engineering

Morgantown, West Virginia

2013

Keywords: Dual-Fuel, Alternative Fuels, CNG, Engine, Emissions 


\section{Abstract \\ Investigation of the Dual-Fuel Conversion of a Direct Injection Diesel Engine}

\section{John S. Smallwood}

The transportation sector is the second largest energy-consuming sector in the United States. With heavy-duty vehicles comprising $20 \%$ of the sector and petroleum products being used as $93 \%$ of the sector's fuel, alternatives fuels continue to be investigated to offset petroleum usage. Natural gas is increasingly being considered as a fuel source due to its abundance in the Marcellus Shale Formation. Compressed natural gas $(\mathrm{CNG})$ is a promising energy source for dual-fuel combustion. It appears to benefit the environment and the economy. With the ability to reduce oxides of nitrogen (NOx) emissions, carbon dioxide $\left(\mathrm{CO}_{2}\right)$ emissions, and particulate matter (PM) emissions, dual-fuel operation is environmentally viable. CNG costs less than petroleum derived diesel and would enable the United States to reduce its dependence on oil imports. Thus, dual-fuel operation promises to be economically practical.

Dual-fuel operation reduces the amount of diesel fuel used during combustion and replaces it with an energy-equivalent amount of CNG. CNG is injected into the intake air stream during the intake stroke of the dual-fuel converted diesel engine's four-stroke cycle. CNG is utilized as the main energy source while diesel fuel is direct injected to initiate the ignition process due to its compression ignition characteristics. The objective of this work was to investigate dual-fuel combustion characteristics and resultant emissions to determine if the partial replacement of diesel fuel with CNG is an applicable technology in the transportation industry. To fulfill this objective, a dual-fuel capable 2005 Mercedes OM-460LA 12.8 liter engine outfitted with incylinder pressure and exhaust emissions measurement capabilities was operated at steady-state conditions. Combustion characteristics and resultant emissions were compared between the dualfuel and diesel operations. To certify a dual-fuel conversion kit with the Environmental Protection Agency's (EPA's) Clean Alternative Fuel Conversion Program, research and development work was also completed on a 2005 Mack AC-460P 12.0 liter engine. Exhaust emissions were collected over steady-state and transient conditions. In-use operation cost comparisons and fuel efficiencies between dual-fuel operation and diesel-only operation were completed with the certified conversion kit.

The combustion characteristics that most affected emission formations were decreased combustion efficiencies $(\leq 39.9 \%)$ and decreased maximum in-cylinder gas temperatures $(\leq$ $15.2 \%)$. With the dual-fuel conversion kit meeting certification requirements, NOx emissions decreased for steady-state $(10.1 \%)$ and transient $(7.29 \%)$ operations while PM emissions increased for steady-state (14.2\%) operation and decreased for transient (27.4\%) operation. $\mathrm{CO}_{2}$ emissions decreased for steady-state $(8.87 \%)$ and transient $(7.81 \%)$ operations while carbon monoxide (CO) emissions increased for steady-state $(754 \%)$ and transient $(836 \%)$ operations. Non-methane hydrocarbon (NMHC) emissions increased for steady-state (34.4\%) and transient $(59.3 \%)$ operations while methane hydrocarbon (MHC) emissions were prominent due to the combustion of CNG for steady-state (4.05 g/bhp-hr) and transient $(7.95 \mathrm{~g} / \mathrm{bhp}-\mathrm{hr})$ operations. The reduction of $\mathrm{CO}_{2}$ emissions is outweighed by the increase in MHC emissions due to a GWP increase of $35 \%$ for the steady-state SET and $85.2 \%$ for the transient FTP. 
Dual-fuel operation yielded operation cost savings of $\$ 17,932 /$ year based on a 2.27 -year return of investment timeframe. Though brake specific fuel consumption (BSFC) increased $(\leq 24.2 \%)$ and miles per gallon (MPG) efficiencies decreased $(\leq 18.1 \%)$, dual-fuel operation still yielded desirable cost savings due to the low price of CNG. Dual-fuel operation cost savings proved to be most effective when the vehicle was operated on highways and accumulated high yearly mileages. The dual-fuel conversion kit successfully showed compliance with the EPA's emissions standards and marketable cost savings. 


\section{Table of Contents}

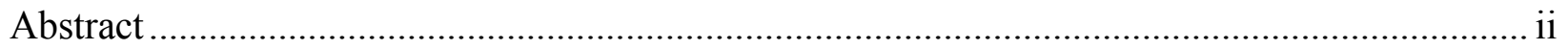

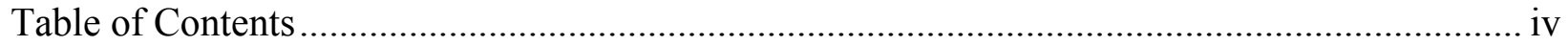

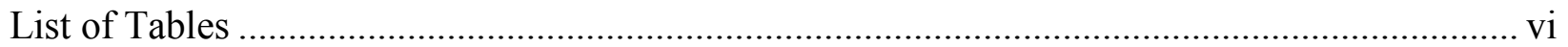

List of Figures .............................................................................................................. vii

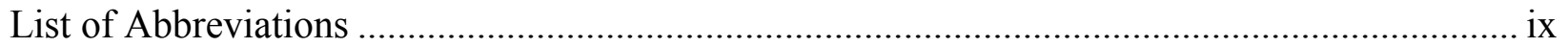

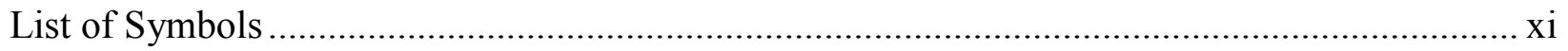

Acknowledgments............................................................................................................ xii

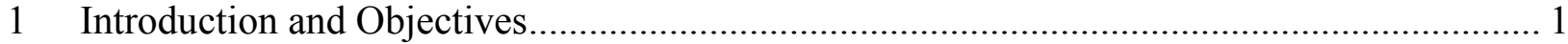

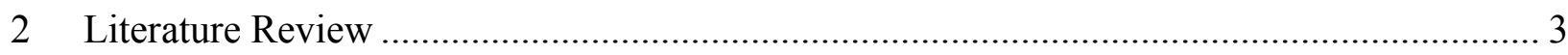

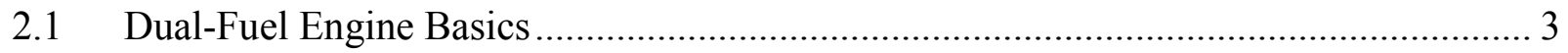

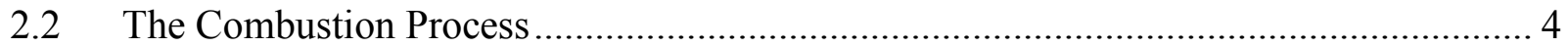



2.4 Particulate Matter Emissions................................................................................. 20

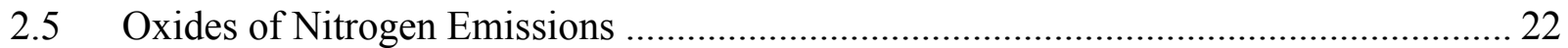

2.6 Carbon Monoxide and Carbon Dioxide Emissions......................................................... 24

2.7 EPA's Clean Alternative Fuel Conversion Program....................................................... 25

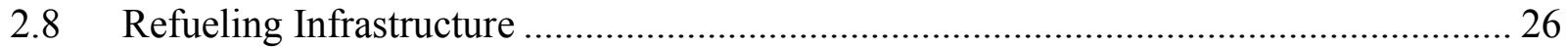

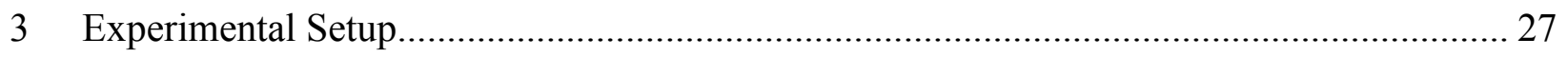

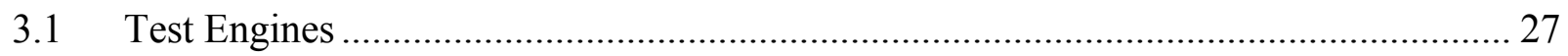

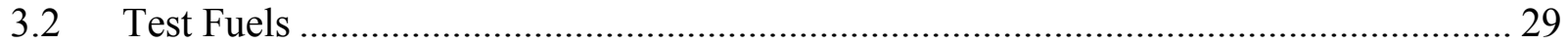

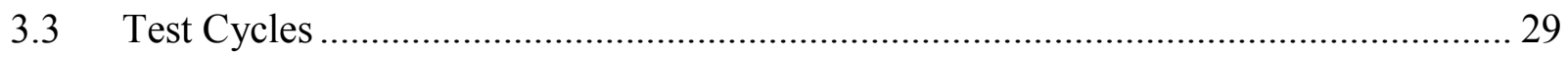

$3.4 \quad$ Test Plan ............................................................................................................ 31

3.4.1 Combustion and Emission Formation............................................................ 32

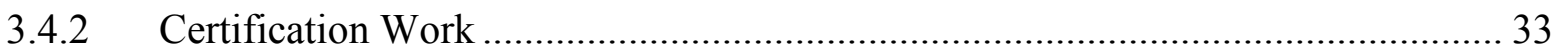

3.4.3 Cost Comparison and MPG Efficiencies .......................................................... 33

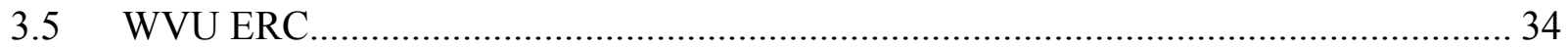

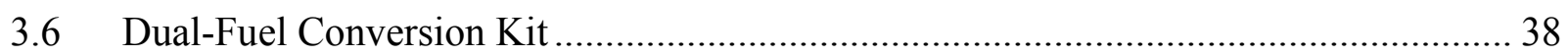

3.7 In-Cylinder Pressure Analysis and Calculations .......................................................... 40

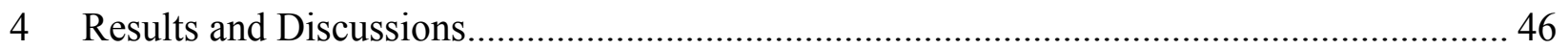

4.1 Combustion and Exhaust Emissions .......................................................................... 46 


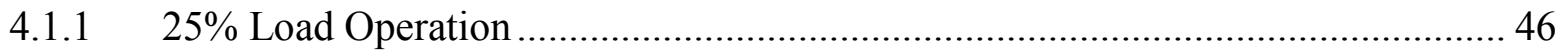

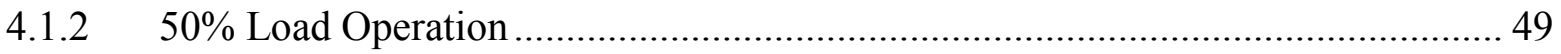

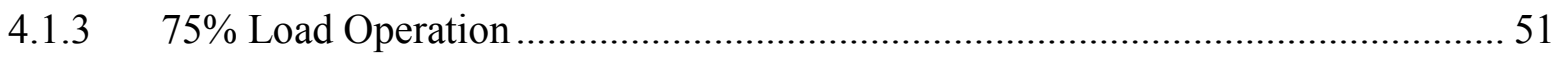

4.1.4 100\% Load Operation ....................................................................................... 53

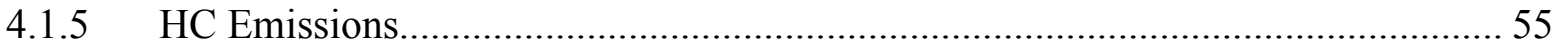

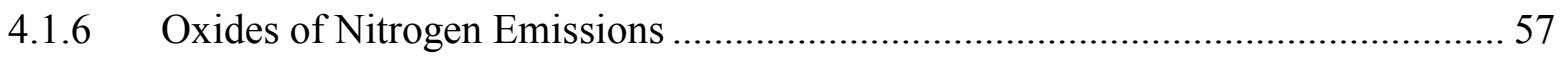

4.1.7 Carbon Monoxide and Carbon Dioxide Emissions …………………….................. 61

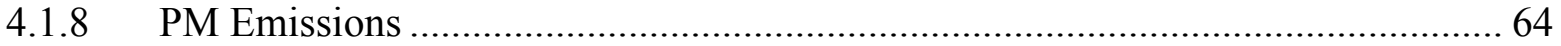

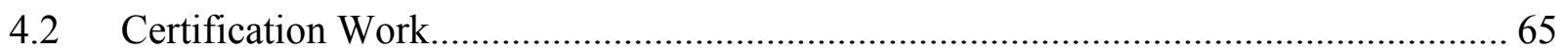

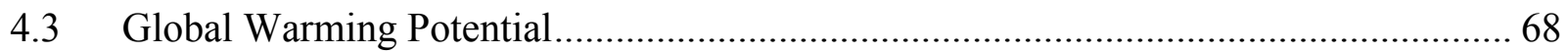

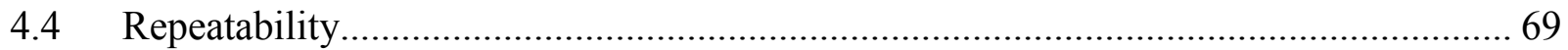

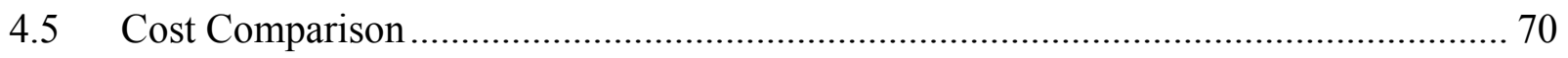

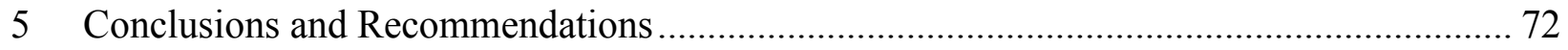

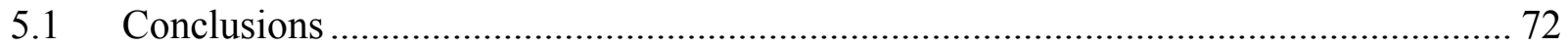

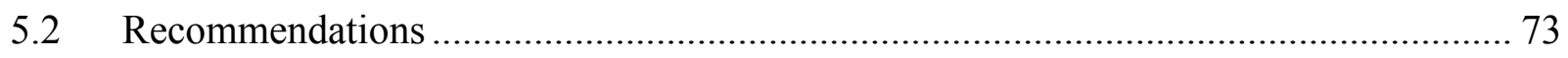

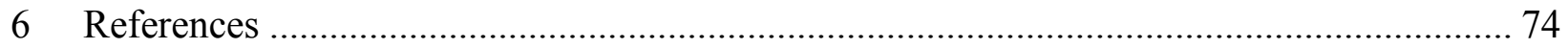

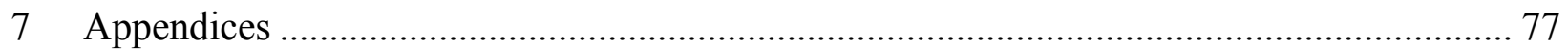




\section{List of Tables}

Table 1 - 2004-2007 EPA Heavy-Duty Engine Emissions Standards .......................................... 26

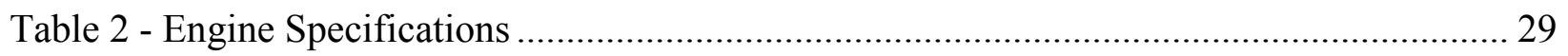

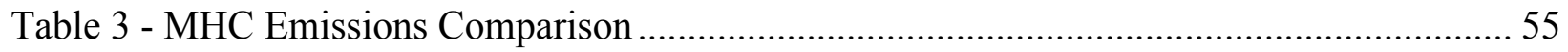

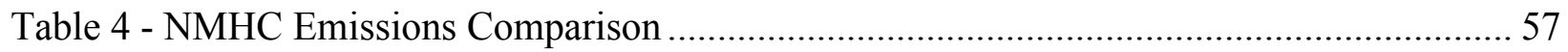

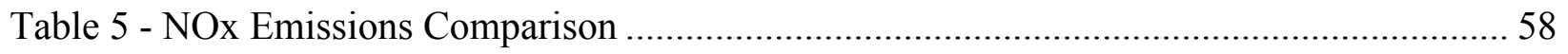

Table 6 - Maximum and Average Calculated In-Cylinder Gas Temperatures Comparison.......... 59

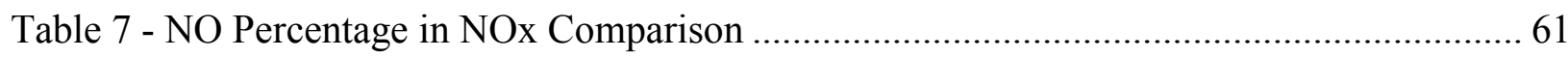



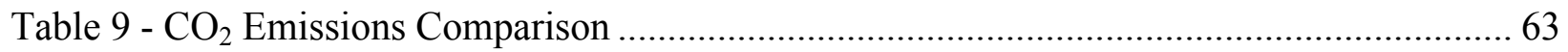

Table 10 - FTP Transient Operation Emissions (Haltermann Diesel Fuel) ..................................... 65

Table 11 - SET Steady-State Operation Composite Emissions (Haltermann Diesel Fuel) .......... 66

Table 12 - SET Steady-State Operation Composite Emissions (Haltermann Diesel Fuel, No

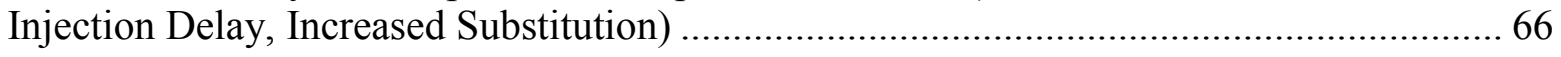

Table 13 - SET Steady-State Operation Composite Emissions (Haltermann Diesel Fuel, Altering

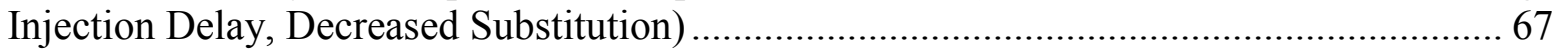

Table 14 - FTP Transient Operation Emissions (Haltermann Diesel Fuel, Altering Injection

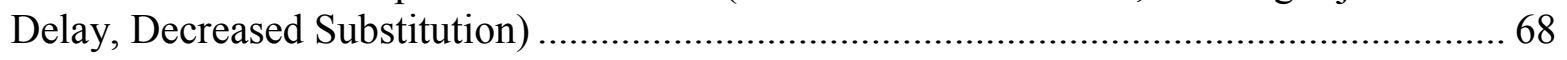

Table 15 - Certified Dual-Fuel Conversion Kit Operation Emissions Compared to Diesel-Only

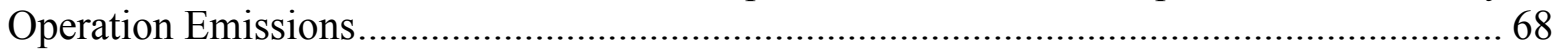

Table 16 - Mean, Standard Deviation, and COV of RPT Tests for Engine Data .......................... 77

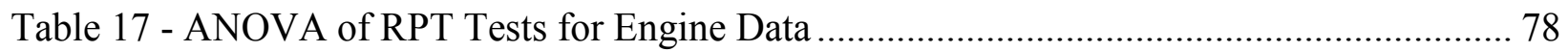

Table 18 - Mean, Standard Deviation, and COV of RPT Tests for In-Cylinder Pressure Data ... 79

Table 19 - Mean, Standard Deviation, and COV of RPT Tests for In-Cylinder Pressure Data

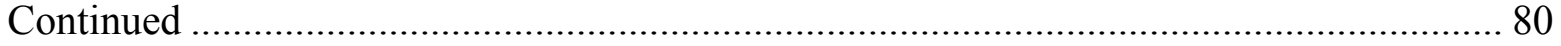



Table 21 - ANOVA of RPT Tests for In-Cylinder Pressure Data Continued ................................ 82

Table 22 - Mean, Standard Deviation, and COV of Operating Conditions .................................... 83

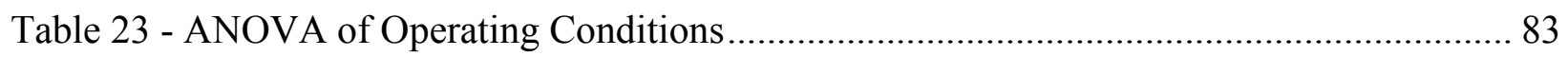

Table 24 - Mean, Standard Deviation, and COV of Certification Work ....................................... 83

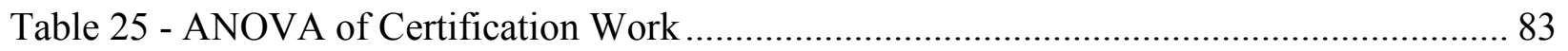

Table 26 - Mean, Standard Deviation, and COV of Repeated FTPs ........................................... 84

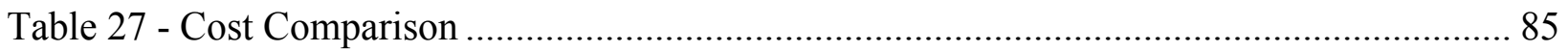




\section{List of Figures}

Figure 1 - Heat Release Rate Diagram Indicating Combustion Phases [7] ............................... 5

Figure 2 - Heat Release Rate Diagram Indicating Light Load Dual-Fuel Combustion [2] ........... 6

Figure 3 - Heat Release Rate Diagram Indicating Heavy Load Dual-Fuel Combustion [2] ......... 6

Figure 4 - Exhaust Gas Concentration of Unconverted $\mathrm{CH}_{4}$ Emissions and $\mathrm{CO}$ versus Fuel/Air

Equivalence Ratio for Dual-Fuel Operation [8] ...................................................... 8

Figure 5 - Flame Spread Limits Versus Pilot Diesel Injection Quantity for Dual-Fuel Operation [8]

Figure 6 - In-Cylinder Pressure and Heat Release Rate for Diesel-Only Operation and Dual-Fuel

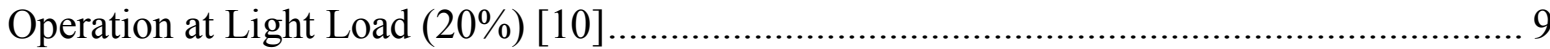

Figure 7 - In-Cylinder Pressure and Heat Release Rate for Diesel-Only Operation and Dual-Fuel

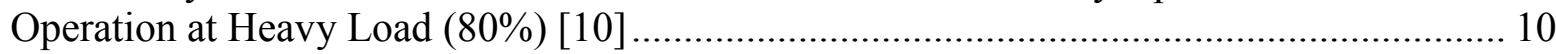

Figure 8 - Maximum In-Cylinder Gas Temperature Versus Fuel/Air Equivalence Ratio in the

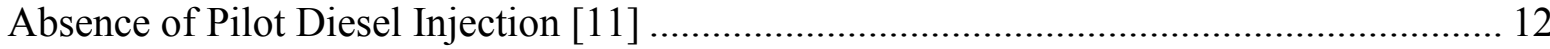

Figure 9 - Maximum In-Cylinder Gas Heat Transfer Versus Fuel/Air Equivalence Ratio in the Absence of Pilot Diesel Injection [11] ................................................................. 12

Figure 10 - Maximum In-Cylinder Gas Pre Ignition Energy Release Versus Fuel/Air Equivalence Ratio in the Absence of Pilot Diesel Injection [11] .................................................... 13

Figure 11 - Maximum Gas Charge Temperature Versus Diluents Concentration in Intake [11]. 14

Figure 12 - Ignition Delay and Exhaust Temperature versus $\mathrm{CH}_{4}$ Concentration in Intake [11]. 15

Figure 13 - Light Load In-Cylinder Pressure with CNG Substitution [12] ............................. 15

Figure 14 - Light Load Heat Release Rate with CNG Substitution [12] ................................. 16

Figure 15 - Heavy Load In-Cylinder Pressure with CNG Substitution [12] ............................. 17

Figure 16 - Heavy Load Heat Release Rate with CNG Substitution [12] ............................... 18

Figure 17 - HC Emissions from Diesel-Only Operation and Dual-Fuel Operation [14]............. 20

Figure $18-\mathrm{NO}_{2} / \mathrm{NOx}$ Concentration for Dual-Fuel and Diesel-Only Operation [18] ................ 23

Figure 19 - NOx Emissions For Diesel-Only Operation And Dual-Fuel Operation [17]............ 24

Figure 20 - CO Emissions For Diesel-Only Operation And Dual-Fuel Operation [10]............. 25

Figure 21 - 2005 Mercedes OM-460LA ................................................................................ 28

Figure 22 - 2005 Mack AC-460P.................................................................................. 28

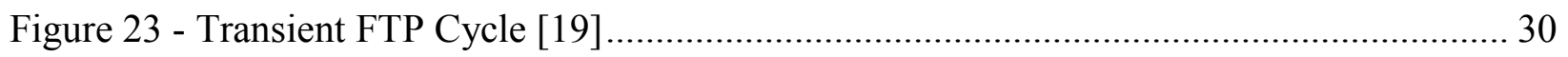

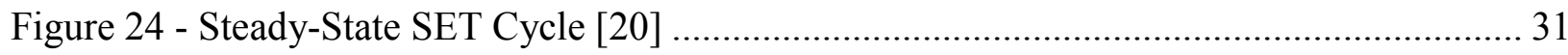

Figure 25 - WVU's ERC Title 40 CFR Part 1065 Emissions Sampling System ........................ 35

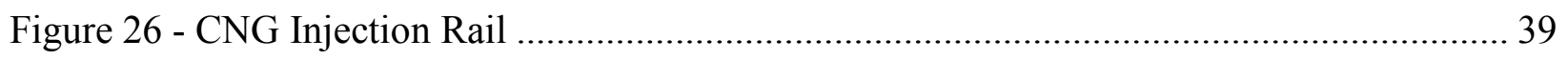




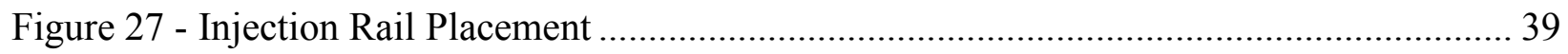

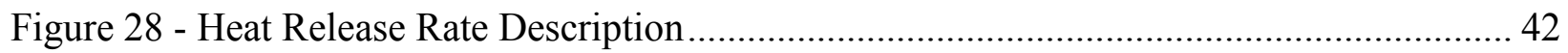

Figure 29 - Fuel Flow Linear Regression for 2005 Mercedes OM-460LA Steady-State DieselOnly Operation

Figure 30 - Fuel Flow Linear Regression for 2005 Mercedes OM-460LA Steady-State Dual-Fuel Operation ....................................................................................................... 44

Figure 31 - Intake Air Flow Linear Regression for 2005 Mercedes OM-460LA Steady-State

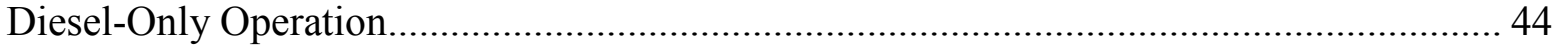

Figure 32 - Intake Air Flow Linear Regression for 2005 Mercedes OM-460LA Steady-State

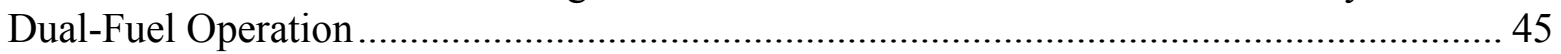

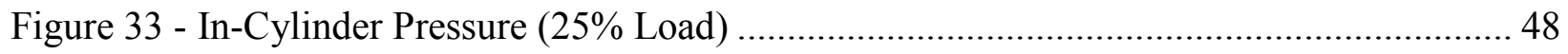

Figure 34 - Heat Release Rate (25\% Load) ............................................................................. 49



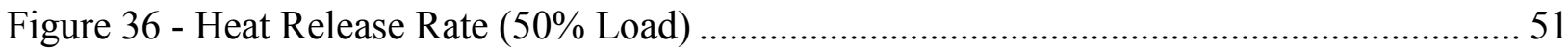

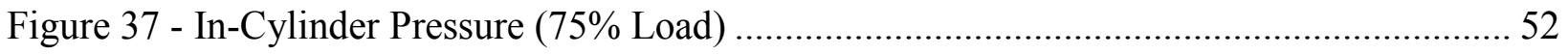

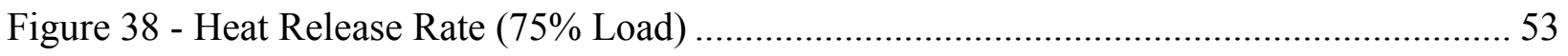

Figure 39 - In-Cylinder Pressure (100\% Load) .................................................................... 54

Figure 40 - Heat Release Rate (100\% Load) ............................................................................ 55

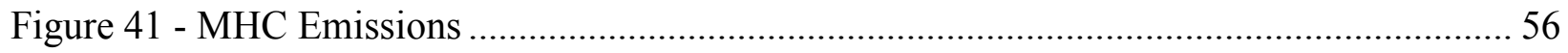

Figure 42 - NMHC Emissions Comparison........................................................................... 57

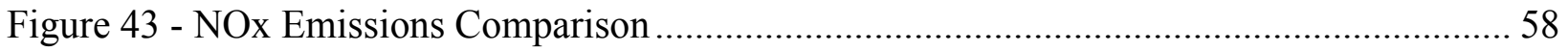

Figure 44 - NO Emissions Comparison ............................................................................. 59

Figure 45 - Calculated In-Cylinder Gas Temperatures At 25\% Load .......................................... 60

Figure 46 - Calculated In-Cylinder Gas Temperatures At 100\% Load .......................................... 61

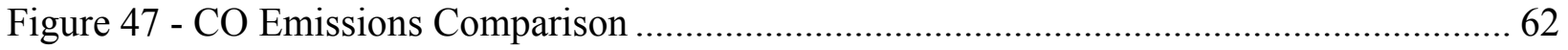

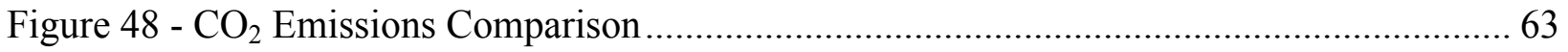

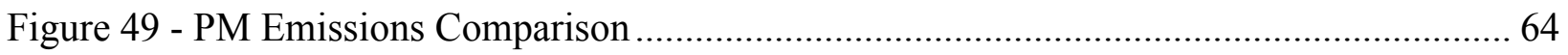




\section{List of Abbreviations}

\begin{tabular}{|c|c|}
\hline ATDC & After Top Dead Center \\
\hline $\mathrm{BDC}$ & Bottom Dead Center \\
\hline BSFC & Break Specific Fuel Consumption \\
\hline BTDC & Before Top Dead Center \\
\hline BTE & Brake Thermal Efficiency \\
\hline $\mathrm{C}$ & Carbon \\
\hline CAA & Clean Air Act \\
\hline CAFEE & Center for Alternative Fuels, Engines, and Emissions \\
\hline CEGR & Cooled Exhaust Gas Recirculation \\
\hline CFR & Code of Federal Regulations \\
\hline $\mathrm{CH}_{4}$ & Methane \\
\hline CLD & Chemiluminescence Detector \\
\hline $\mathrm{CNG}$ & Compressed Natural Gas \\
\hline $\mathrm{COV}$ & Coefficient of Variation \\
\hline $\mathrm{CO}_{2}$ & Carbon Dioxide \\
\hline CVS & Constant Volume Sampling \\
\hline DAQ & Data Acquisition \\
\hline DC & Direct Current \\
\hline DOC & Diesel Oxidation Catalyst \\
\hline ECU & Electronic Control Unit \\
\hline EGR & Exhaust Gas Recirculation \\
\hline EOC & End of Combustion \\
\hline EPA & Environmental Protection Agency \\
\hline ERC & Engines Research Center \\
\hline FID & Flame Ionization Detector \\
\hline GE & General Electric \\
\hline GWP & Global Warming Potential \\
\hline $\mathrm{H}_{2}$ & Hydrogen \\
\hline $\mathrm{H}_{2} \mathrm{O}$ & Water \\
\hline $\mathrm{HC}$ & Hydrocarbon \\
\hline $\mathrm{HCHO}$ & Formaldehyde \\
\hline $\mathrm{He}$ & Helium \\
\hline LHV & Lower Heating Value \\
\hline LNG & Liquefied Natural Gas \\
\hline MAP & Manifold Air Pressure \\
\hline MAT & Manifold Air Temperature \\
\hline MHC & Methane Hydrocarbon \\
\hline MPG & Miles Per Gallon \\
\hline MPDGE & Miles Per Diesel Gallon Equivalent \\
\hline $\mathrm{N}$ & Monatomic Nitrogen \\
\hline $\mathrm{N}_{2}$ & Diatomic Nitrogen \\
\hline
\end{tabular}




$\begin{array}{ll}\text { NDIR } & \text { Non-Dispersive Infrared Analyzer } \\ \text { NFPA } & \text { National Fire Protection Agency } \\ \text { NMHC } & \text { Non-Methane Hydrocarbon } \\ \mathrm{NO} & \text { Nitrogen Oxide } \\ \mathrm{NO}_{2} & \text { Nitrogen Dioxide } \\ \mathrm{NOx} & \text { Oxides of Nitrogen } \\ \mathrm{O}_{2} & \text { Oxygen } \\ \mathrm{O}_{3} & \text { Ozone } \\ \mathrm{OBD} & \text { On-Board Diagnostics } \\ \mathrm{OEM} & \text { Original Equipment Manufacturer } \\ \mathrm{OH} & \text { Hydroxide } \\ \mathrm{Pb} & \text { Lead } \\ \mathrm{PM} & \text { Particulate Matter } \\ \mathrm{PPM} & \text { Parts Per Million } \\ \mathrm{RPM} & \text { Revolutions Per Minute } \\ \mathrm{SO} & \text { Sulfur Dioxide } \\ \mathrm{SO} & \text { Sulfate } \\ \text { SOC } & \text { Start of Combustion } \\ \text { SOF } & \text { Soluble Organic Fraction } \\ \text { SOI } & \text { Start of Injection } \\ \text { SOL } & \text { Solid Fraction } \\ \text { TDC } & \text { Top Dead Center } \\ \text { THC } & \text { Total Hydrocarbon } \\ \text { UV } & \text { Ultra-Violet } \\ \text { VGT } & \text { Variable Geometry Turbocharger } \\ \text { VOC } & \text { Volatile Organic Compound } \\ \text { WVU } & \text { West Virginia University }\end{array}$




\section{List of Symbols}

\begin{tabular}{|c|c|}
\hline$\dot{m}_{\text {fuel }}$ & Mass Flow of Fuel \\
\hline $\mathrm{P}$ & In-Cylinder Pressure \\
\hline $\mathrm{P}_{\mathrm{IVC}}$ & In-Cylinder Pressure at Intake Valve Closing \\
\hline$P_{\text {std }}$ & Pressure Standard \\
\hline $\mathrm{P}_{\Theta}$ & In-Cylinder Pressure at Crank Angle \\
\hline$\Delta \mathrm{P}$ & Change in In-Cylinder Pressure \\
\hline$Q_{\text {gross }}$ & Gross Heat Release \\
\hline$Q_{\text {net }}$ & Net Heat Release \\
\hline $\mathrm{Q}_{\text {wall }}$ & Heat Release to Wall \\
\hline $\mathrm{T}_{\mathrm{g}}$ & Mean In-Cylinder Gas Temperature \\
\hline $\mathrm{T}_{\mathrm{IVC}}$ & In-Cylinder Gas Temperature at Intake Valve Closing \\
\hline $\mathrm{T}_{\text {std }}$ & Standard Temperature \\
\hline$\Delta \mathrm{T}_{\mathrm{g}}$ & Change in Mean In-Cylinder Gas Temperature \\
\hline$\Delta \mathrm{T}_{\text {th }}$ & Change in Mean In-Cylinder Gas Temperature due to Thermodynamic Properties \\
\hline$\Delta \mathrm{T}_{\mathrm{ht}}$ & Change in Mean In-Cylinder Gas Temperature due to Heat Transfer to Walls \\
\hline$\Delta \mathrm{T}_{\mathrm{rt}}$ & Change in Mean In-Cylinder Gas Temperature due Pre-Ignition Energy Release \\
\hline$\Delta \mathrm{T}_{\mathrm{re}}$ & Change in Mean In-Cylinder Gas Temperature due to Residual Gases \\
\hline $\mathrm{V}$ & Cylinder Volume \\
\hline $\mathrm{V}_{\mathrm{d}}$ & Displacement Volume \\
\hline $\mathrm{V}_{\text {IVC }}$ & Cylinder Volume at Intake Valve Closing \\
\hline $\mathrm{V}_{\Theta}$ & Cylinder Volume at Crank Angle \\
\hline$\gamma$ & Specific Heat Ratio \\
\hline$\eta_{\mathrm{v}}$ & Volumetric Efficiency \\
\hline$\Theta$ & Crank Angle \\
\hline$\phi$ & Equivalence Ratio \\
\hline$\Delta \phi$ & Change in Equivalence Ratio \\
\hline$\tau$ & Ignition Delay \\
\hline$\Delta \tau$ & Change in Ignition Delay \\
\hline
\end{tabular}




\section{Acknowledgments}

I would like to thank Dr. Mridul Gautam for giving me the opportunity to complete my master's degree. Your guidance throughout my graduate career is greatly appreciated. I would like to thank Ross Ryskamp for assisting me with this project from start to finish. I appreciate your expertise and insight about the operation of the ERC. I would like to thank Dan Carder for giving me the opportunity to work on this project and offering assistance and knowledge at all times. I would like to thank Brad Ralston for the long hours spent in the engine lab towards this project. I would like to thank Dr. Thompson for helping me organize my test plan and answering my project concerns. I would like to thank Marc Besch and Arvind Thiruvengadam for taking the time to answer my questions. I would like to thank Dr. Hailin Li for his knowledge and experience with dual-fuel engines. I would like to thank all of the other graduate students who offered assistance towards this project. I would like to thank Terry Smallwood, Brian Smallwood, Mary Bauer, Emily Minehart, Briley Bauer, Atley Bauer, Gene Strouse, and Julie DeHaven for supporting me in everything I have ever wanted to accomplish. 


\section{Introduction and Objectives}

The effects of hydrocarbon (HC) combustion emissions on air quality is not a new problem. In 1306, coal burning was banned from London, England. Within the United States, the Clean Air Act (CAA) was signed into legislation in 1963 to control air pollution and the Environmental Protection Agency (EPA) was created in 1970 to protect human health and the environment. Through the enforcement of regulations from 1970 to 2002, aggregate emissions of six principle pollutants \{carbon monoxide (CO), oxides of nitrogen (NOx), volatile organic compounds (VOCs), sulfur dioxide $\left(\mathrm{SO}_{2}\right)$, particulate matter $(\mathrm{PM})$, and lead $\left.(\mathrm{Pb})\right\}$ were reduced by $48 \%$ while vehicle miles traveled increased by $155 \%$ and energy consumption increased by $42 \%$ [1].

The diesel engine represents the dominant portion of the heavy-duty transportation sector and will continue to be so in the foreseeable future due to its desirable energy conversion efficiency, durability, and reliability. The EPA began to control PM and NOx emissions standards for heavy-duty diesel engines in 1988. Today's emissions standards require exhaust after-treatment systems to meet the stringent 2007 and later emissions standards. In 2010, the EPA created the Clean Alternative Fuel Conversion Program to help consumers address concerns about fuel costs, energy security, and emissions. The EPA prohibits modification to the original configuration of a vehicle or engine by enforcing the CAA's prohibition against tampering laws. If a clean alternative fuel conversion manufacturer demonstrates compliance with the program, the EPA grants them an exemption from the CAA's prohibition against tampering laws. The manufacturer is then allowed to market and sell their product to the public.

One option to operate a diesel engine on a clean alternative fuel is a dual-fuel conversion kit. By application of the kit, diesel injection is reduced while an energy-equivalent amount of compressed natural gas $(\mathrm{CNG})$ is introduced to be ignited by the autoignition characteristics of the diesel fuel. The engine retains its diesel operation characteristics and gains the ability to substitute a clean alternative gaseous fuel for power output. A conversion requires the vehicle to be outfitted with CNG tanks, a CNG injection system, a filler arm, and a dual-fuel electronic control unit (ECU). The conversion kit investigated in this study is marketed for inside useful life engines (explained in Section 2.7). To comply with the program, when the dual-fuel conversion kit is operated on an original equipment manufacturer (OEM) diesel engine, it must meet the 
emissions standards of the particular OEM engine's production year, pass an on-board diagnostics (OBD) scan, and demonstrate durability.

Dual-fuel operation on fumigated single-cylinder research engines operating at steady-state conditions comprises a majority of the current body of research. Although a steady-state test is required to show compliance with the EPA, the dual-fuel conversion kit has to operate in a transient mode to show EPA emissions compliance and be useable in transportation applications.

The objective of this work was to investigate dual-fuel combustion characteristics and resultant emissions to determine if the partial replacement of diesel fuel with $\mathrm{CNG}$ is an applicable technology in the transportation industry. To complete this objective, a dual-fuel capable 2005 Mercedes OM-460LA 12.8 liter engine outfitted with in-cylinder pressure and exhaust emissions measurement capabilities was operated at steady-state conditions. Combustion characteristics and resultant emissions were compared between the dual-fuel and diesel-only operations. To certify a dual-fuel conversion kit under the EPA's Clean Alternative Fuel Conversion Program, research and development work was also completed on a 2005 Mack AC-460P 12.0 liter engine. Exhaust emissions were collected over steady-state and transient conditions. In-use operation cost comparisons and fuel efficiencies between dual-fuel operation and diesel-only operation were completed with the certified conversion kit. 


\section{Literature Review}

Much of the work towards dual-fuel research has been completed on single-cylinder research engines at steady-state conditions. This work offers insight into in-cylinder pressure analysis and emissions formation. The EPA's Clean Alternative Fuel Conversion Program allows dual-fuel conversion manufacturers to certify and sell their products to the public with an exemption from the CAA prohibition against tampering laws. This requires development of a dual-fuel conversion kit that can meet the EPA's stringent emissions standards while operating in steadystate and transient conditions. While meeting these standards, the dual-fuel conversion kit has to produce marketable fuel consumption for the end user. The following presents related work in regards to dual-fuel combustion and its resultant emissions. An understanding of this work can be applied to the combustion and resultant emissions of a certifiable dual conversion kit, determine the adjustments needed to show compliance with the EPA, and be marketable to the public.

\subsection{Dual-Fuel Engine Basics}

A dual-fuel engine retains the same engine structure as a common four-stroke diesel engine but modifies its combustion methods. A dual-fuel engine has the ability to operate on diesel alone, as in the conventional diesel cycle, or diesel and a gaseous fuel simultaneously. This study considers $\mathrm{CNG}$ as the gaseous fuel but other common gaseous fuels including hydrogen $\left(\mathrm{H}_{2}\right)$ and liquefied natural gas (LNG) can be utilized. During dual-fuel operation, a majority of the energy release comes from the combustion of $\mathrm{CNG}$ which is ignited through timed injection of a pilot fuel [2]. CNG is inducted with intake air during the intake stroke and is compressed during the compression stroke. The CNG/air mixture does not autoignite due to CNG's low cetane number. To ignite the $\mathrm{CNG} /$ air mixture, a pilot quantity of diesel is injected into the cylinder before the piston reaches top dead center (TDC) and autoignites under compression. The ignited pilot diesel fuel acts as an ignition source for the remaining $\mathrm{CNG}$ /air mixture within the combustion chamber [3]. The combustion of the pilot diesel and CNG converts the chemical energies of both fuels to heat, consequently raising the temperature and pressure within the cylinder and driving the piston downward to complete the power stroke. Dual-fuel engines are comparable to spark ignited engines due to the premixing of air and the primary fuel source in the cylinder before combustion [4]. At the same time, the engine cannot operate without compression ignition of the pilot diesel making it comparable to a diesel engine [4]. 
With a dual-fuel engine, conventional diesel operation is not compromised. This allows the flexibility to switch between dual-fuel operation and diesel-only operation. This study evaluated a conventional diesel-only engine with a dual-fuel conversion kit. The engine comes from the OEM designed to operate with diesel as its only energy source and thereafter a conversion kit is installed to allow the engine to operate with dual-fuel capabilities. There are numerous strategies for operating a compression-ignited engine by dual-fuel combustion [5]. The methods are distinguished by the introduction techniques of $\mathrm{CNG}$ and control strategies to reduce diesel injection to a pilot quantity.

Different CNG injection techniques include: sequential port injection, post intercooler injection, direct injection, pre-turbo injection, and intake manifold injection. One control strategy is to intercept the diesel injection signal, reduce the signal to inject a pilot quantity of diesel, and inject an energy-equivalent amount of $\mathrm{CNG}$ to reach the desired engine output. Another control strategy involves emulating the throttle signal to the OEM's ECU so it will inject a pilot quantity of diesel from its predetermined fueling maps. The controller then injects the proper energyequivalent amount of $\mathrm{CNG}$ to reach the desired engine output.

\subsection{The Combustion Process}

The combustion process during diesel-only operation consists of four stages which can be identified on a heat release rate diagram presented in Figure 1 [6]. The first stage, ignition delay (a-b on Figure 1), is the duration between the start of diesel injection and the start of combustion [6]. Fuel injected during this stage follows a sequence of physical and chemical steps: atomization (forms a spray of droplets due to jet velocity), vaporization (forms a vapor due to heat transfer from the aerodynamic drag of droplet), fuel vapor mixing with air, and precombustion reactions leading to autoignition (oxidation of $\mathrm{HCs}$ causing multiple areas of localized ignition) [6]. The second stage, premixed combustion (b-c on Figure 1), is the combustion of diesel mixed with air to its proper flammability limits during the ignition delay stage [6]. This stage occurs rapidly with high pressure rise rates and heat release rates. The characteristic noise emitted from a diesel engine is a result of the pressure rise rates occurring during this stage.

The third stage, rate-controlled combustion (c-d on Figure 1), is the combustion of diesel that is injected after the premixed combustion phase [6]. Fuel injected during this stage follows all of 
the physical and chemical steps outlined in the ignition delay stage but is controlled by the rate of diesel injection subsequently mixing with air [6]. The fourth stage, late combustion (d-e on Figure 1), is the combustion of products left over from the stages before [6]. These products include unburned fuel, soot, and fuel rich combustion products [6].

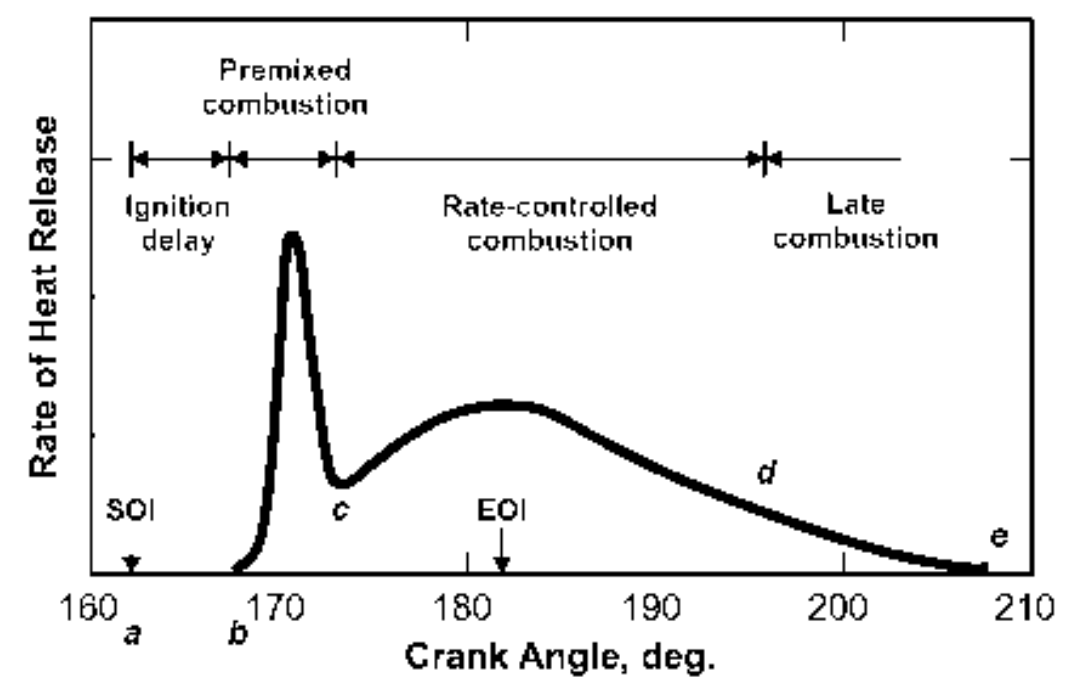

Figure 1 - Heat Release Rate Diagram Indicating Combustion Phases [7]

The combustion process during dual-fuel operation is dependent on the pilot diesel characteristics, the CNG characteristics, and the amount of diesel substituted by CNG. The combustion energy release rate of a dual-fuel engine can be considered as three overlapping components, which can be observed in Figure 2 and Figure 3, where:

- Component I is the energy release from the pilot diesel combustion

- Component II is the energy release from the CNG component that is in the immediate vicinity of the pilot diesel combustion

- Component III is the energy release from the pre-ignition reaction activity of the CNG and flame propagation from the combustion of the pilot diesel and CNG within its immediate vicinity to the $\mathrm{CNG} /$ air mixture outside of the immediate vicinity of the pilot diesel combustion [2].

As can be observed in Figure 2, a majority of the energy release during dual-fuel combustion at light load conditions comes from Component I and Component II [2]. This combustion energy comes from the immediate vicinity of the pilot diesel [2]. In this vicinity there is ignition and rapid combustion of the pilot diesel [2]. Also, there is combustion of the lean CNG/air mixtures 
within the combusting pilot diesel and in close proximity to this zone due to high surrounding temperatures [2]. Marginal energy release during dual-fuel combustion at light-load conditions comes from Component III, the CNG/air mixture located away from the pilot diesel [2].

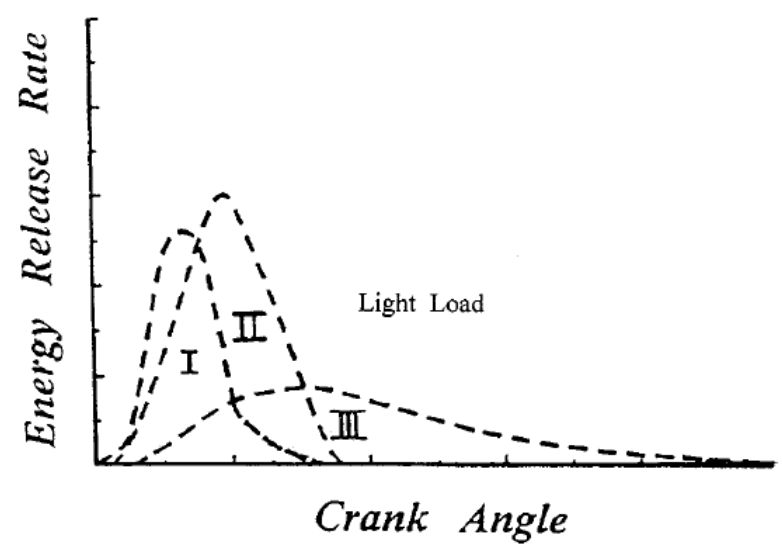

Figure 2 - Heat Release Rate Diagram Indicating Light Load Dual-Fuel Combustion [2]

As can be observed in Figure 3, a majority of the energy release during dual-fuel combustion at heavy loads comes from Component II and Component III [2]. This combustion energy comes from the immediate vicinity of the pilot diesel and areas away from the pilot diesel vicinity [2]. Under heavy load conditions, the concentration of CNG increases resulting in a less lean $\mathrm{CNG}$ /air mixture as compared to light load conditions [2]. The higher concentration of CNG allows a larger energy release from zones away from the pilot region when compared to the decreased concentration of gaseous fuel used at light load conditions [2]. The higher concentrations of $\mathrm{CNG}$ also allows for better flame propagation from the pilot diesel ignition regions [2]. This allows for larger energy release from $\mathrm{CNG}$ /air mixtures away from the pilot zone.

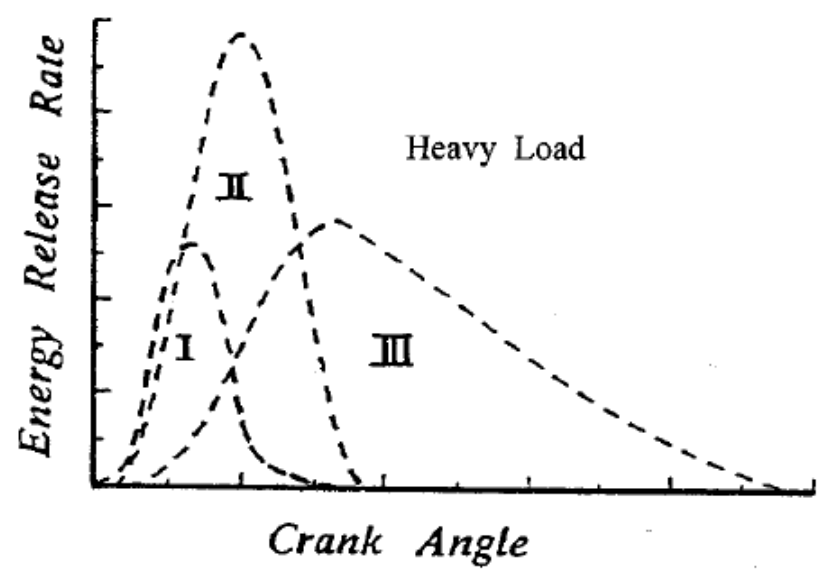

Figure 3 - Heat Release Rate Diagram Indicating Heavy Load Dual-Fuel Combustion [2] 
As the engine transitions from light load to heavy load, the energy release from combustion transitions from the immediate vicinity of the pilot diesel to areas further away from the pilot diesel vicinity. In dual-fuel combustion, the turbulent flame propagation through the CNG/air mixture is initiated from the autoignition of the pilot diesel [8]. At heavy load conditions, turbulent flame propagation reaches the $\mathrm{CNG}$ /air mixture further out in the cylinder. At light load conditions, turbulent flames cannot propagate fast and far enough to ignite CNG/air mixtures further out in the cylinder [8]. Flame propagation can be improved by increasing CNG concentrations and increasing the pilot diesel quantity, both of which increase the fuel/air equivalence ratio [8].

To determine whether sufficient flame propagation is taking place, exhaust emissions of methane $\left(\mathrm{CH}_{4}\right)$ and $\mathrm{CO}$ can be analyzed. During dual-fuel combustion of the pilot diesel and CNG (largely composed of $\mathrm{CH}_{4}$ ), oxidation of $\mathrm{CH}_{4}$ generally forms formaldehyde ( $\mathrm{HCHO}$ ), followed by $\mathrm{CO}$, followed by the formation of $\mathrm{CO}_{2}$ and water $\left(\mathrm{H}_{2} \mathrm{O}\right)$ [8]. Figure 4 shows the concentrations of unconverted $\mathrm{CH}_{4}$ emissions and $\mathrm{CO}$ emissions in the exhaust with regions broken into different fuel/air equivalence ratios [8]. Combustion that takes place in Region I consists of small concentrations of CNG within the cylinder resulting in low fuel/air equivalence ratios [8]. The large concentrations of unconverted $\mathrm{CH}_{4}$ emissions in the exhaust indicate the inability of flame propagation to reach the CNG/air mixture away from the pilot diesel vicinity [8]. The small amounts of $\mathrm{CO}$ emissions is due to the combustion of the pilot diesel without complete oxidation to $\mathrm{CO}_{2}$ due to lower combustion temperatures observed during dual-fuel operation [8].

Combustion that takes place in Region II has increased concentrations of CNG within the cylinder resulting in increased fuel/air equivalence ratios [8]. There are still large concentrations of unconverted $\mathrm{CH}_{4}$ emissions in the exhaust indicating that flame propagation still cannot reach the CNG/air mixture away from the pilot diesel vicinity [8]. This is supported by the emissions of unburned $\mathrm{CH}_{4}$ observed at low loads especially when the $\mathrm{CH}_{4}$ concentration in the mixture is low [9]. The increased amounts of $\mathrm{CO}$ emissions are from mechanisms similar to Region I and pre-ignition reactions of the $\mathrm{CNG}$ /air mixture [8]. Combustion that takes place in Region III is fueled by higher concentrations of $\mathrm{CNG}$ within the cylinder resulting in increased fuel/air equivalence ratios [8]. The decreasing concentration of unconverted $\mathrm{CH}_{4}$ emissions in the exhaust indicates that flame propagation is reaching further into the CNG/air mixture [8]. The 
decreased amount of $\mathrm{CO}$ emissions indicates more complete combustion which allows $\mathrm{CH}_{4}$ emissions to oxidize more completely to $\mathrm{CO}_{2}[8]$.

Combustion that takes place in Region IV has further increased concentrations of CNG within the cylinder resulting in increased fuel/air equivalence ratios [8]. The minimum concentration of unconverted $\mathrm{CH}_{4}$ emissions in the exhaust indicates that flame propagation is more completely reaching the entire $\mathrm{CNG}$ /air mixture within the cylinder [8]. The minimum amount of $\mathrm{CO}$ emissions indicates complete combustion with the $\mathrm{CH}_{4}$ emissions able to oxidize almost completely to $\mathrm{CO}_{2}$ [8]. These results indicate that flame propagation can be improved by increasing $\mathrm{CNG}$ concentrations and therefore the fuel/air equivalence ratio [9].

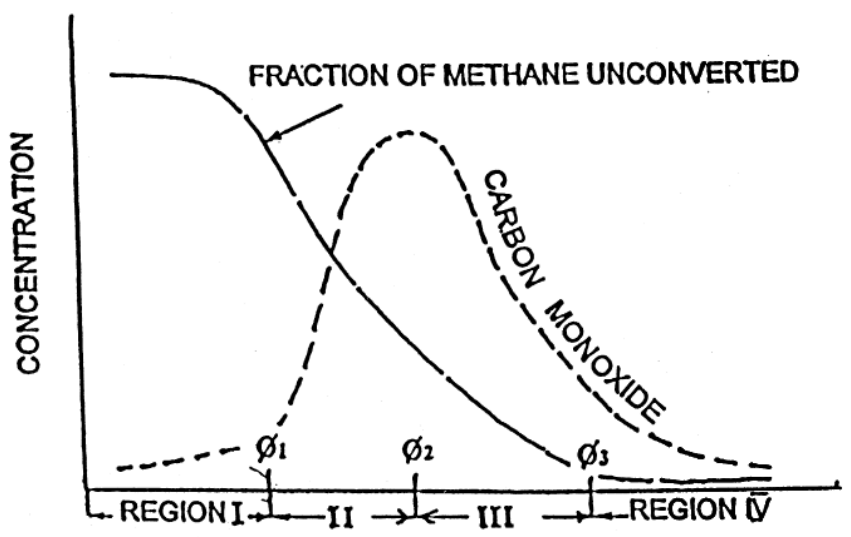

Figure 4 - Exhaust Gas Concentration of Unconverted $\mathrm{CH}_{4}$ Emissions and $\mathrm{CO}$ versus Fuel/Air Equivalence Ratio for Dual-Fuel Operation [8]

The minimum concentration of CNG homogeneously mixed with air in which flame propagation reaches all of the mixture within the cylinder is considered the flame spread limit [8]. Figure 5 shows the flame-spread limits during dual-fuel combustion with increasing pilot diesel injection quantity [8]. As the pilot diesel quantity is increased, the flame spread limit decreases due to the creation of larger pilot diesel vicinities, along with more ignition centers, resulting in reduced distances needed for flame propagation [8]. These factors, along with higher temperatures in the pilot diesel vicinity due to the larger energy release, allows for improved flame propagation [8]. Results indicate that flame propagation can be improved by increasing the pilot injection quantity. 




Figure 5 - Flame Spread Limits Versus Pilot Diesel Injection Quantity for Dual-Fuel Operation [8]

An example of in-cylinder pressure and heat release rate for diesel-only operation and dual-fuel operation can be observed in Figure 6 and Figure 7 [10]. Deviations between diesel-only operation and dual-fuel operation at all loading conditions begins to occur during the compression stroke. The in-cylinder pressure obtained during dual-fuel operation during the compression stroke is less than the value obtained during diesel-only operation [10]. These values increasingly deviate as the piston ascends towards TDC in the compression stoke.

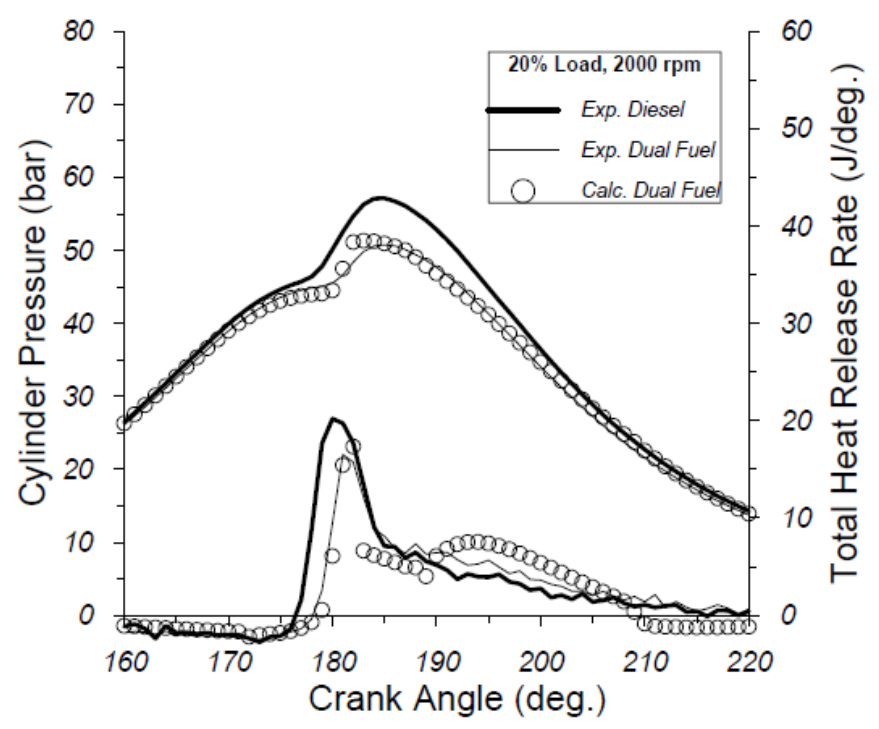

Figure 6 - In-Cylinder Pressure and Heat Release Rate for Diesel-Only Operation and Dual-Fuel Operation at Light Load (20\%) [10]

Since the CNG/air mixture has a higher specific heat than air alone, it takes more energy to produce the same in-cylinder pressure rise resulting in lower compression pressures during dualfuel operation [10]. As load increases, increased amounts of CNG are inducted into the cylinder increasing its concentration in the intake mixture [10]. This results in further deviations in 
compression pressures which can be observed by comparing Figure 6 and Figure 7 [10]. After the combustion event has taken place and the piston descends from TDC to bottom dead center (BDC), the deviation between in-cylinder pressure curves for dual-fuel operation and diesel-only operation converge.

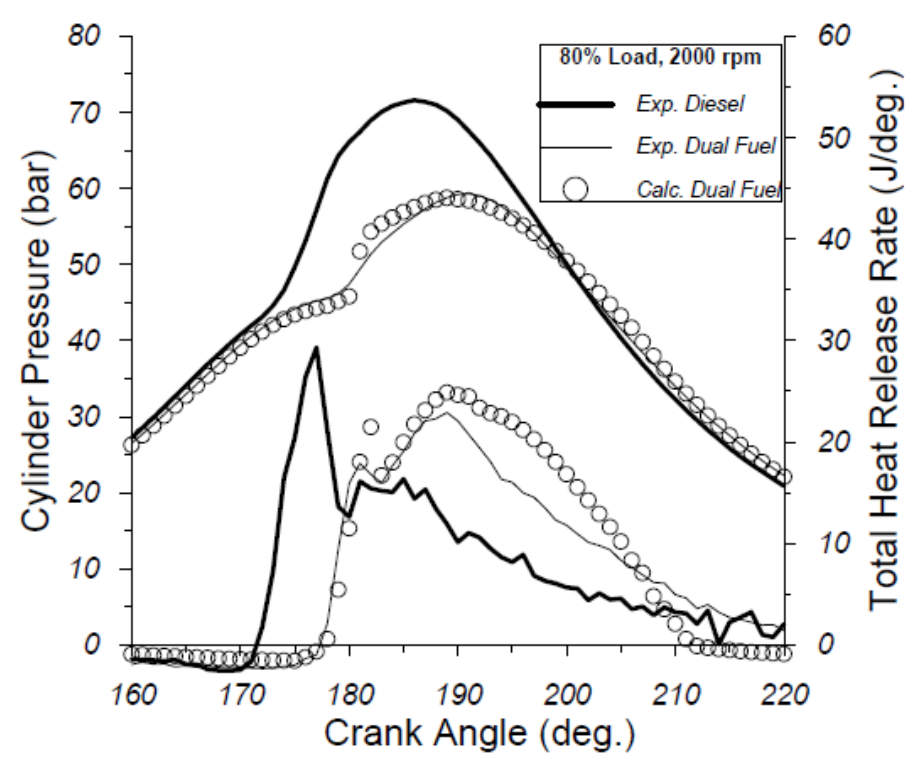

Figure 7 - In-Cylinder Pressure and Heat Release Rate for Diesel-Only Operation and Dual-Fuel Operation at Heavy Load (80\%) [10]

Ignition delay in a compression ignition engine has the ability to affect the combustion event following ignition, emissions generated, and the overall performance of the engine [11]. The introduction of CNG during the intake stroke and the subsequent reduction in diesel injection to a pilot quantity affects the ignition delay of a dual-fuel operating engine as compared to its diesel-only counterpart. This indicates that the processes taking place at the end of the compression stroke leading to ignition proceeds in a different fashion for dual-fuel operation in comparison to diesel-only operation [11]. Factors that effect this process and subsequently effect the ignition delay during dual-fuel operation include: charge temperature and pressure, preignition energy release, heat transfer, fuel/air equivalence ratio, and residual gases [11]. The ignition delay $(\tau)$ and its change due to dual-fuel operation $(\Delta \tau)$ can be approximated by [11]:

$\tau+\Delta \tau=A(P+\Delta P)^{a}(\phi+\Delta \phi)^{b} \exp \left(\frac{c}{T_{g}+\Delta T_{g}}\right)$

Equation 1 
In Equation 1, $\mathrm{P}$ is the mean in-cylinder pressure during the diesel-only compression stroke, $\Delta \mathrm{P}$ is the modification of the in-cylinder pressure during the dual-fuel compression stroke, $\mathrm{T}_{\mathrm{g}}$ is the in-cylinder gas temperature during the diesel-only compression stroke, $\Delta \mathrm{T}_{\mathrm{g}}$ is the modification of the in-cylinder gas temperature during the dual-fuel compression stroke, $\phi$ is the overall fuel/air equivalence ratio during the diesel-only compression stroke, and $\Delta \phi$ is the modification of the overall fuel/air equivalence ratio during the dual-fuel compression stroke [11]. A, a, and b are experimentally obtained constants [11]. In Equation 1, in-cylinder gas temperature exponentially affects the ignition delay making it the most significant component. The modification of the cylinder temperature during the dual-fuel compression stroke can be approximated by [11]:

$\Delta T_{g}=\Delta T_{t h}+\Delta T_{r e}+\Delta T_{h t}+\Delta T_{r t}$

Equation 2

In Equation 2, $\Delta \mathrm{T}_{\text {th }}$ is the change in in-cylinder gas temperature due to the thermodynamic and physical properties of the $\mathrm{CNG}$ /air mixture, $\Delta \mathrm{T}_{\mathrm{re}}$ is the change in in-cylinder gas temperature due to the presence of residual gases, $\Delta \mathrm{T}_{\mathrm{ht}}$ is the change in in-cylinder gas temperature due to heat transfer to the cylinder walls, and $\Delta \mathrm{T}_{\mathrm{rt}}$ is the change in in-cylinder gas temperature due to preignition energy release [11]. If these values produce a reduction in the in-cylinder temperature during the dual-fuel compression stroke, their effect will exponentially increase the ignition delay when compared to diesel-only operation.

The change in the in-cylinder gas temperature due to the thermodynamic and physical properties of the $\mathrm{CH}_{4}$ /air mixture with the addition of $\mathrm{CH}_{4}$ can be observed in Figure 8 [11]. As the fuel/air equivalence ratio increases with the increased quantity of $\mathrm{CH}_{4}$ induction, the maximum gas incylinder gas temperature during compression in the absence of pilot diesel injection decreases [11]. This effect correlates directly to the lower compression pressures observed in Figure 6 and Figure 7 during pre-ignition dual-fuel compression [11]. As the fuel/air equivalence ratio increases, the specific heat of the $\mathrm{CH}_{4}$ /air mixture also increases requiring more energy to produce a temperature change, resulting in decreasing maximum in-cylinder gas temperatures during the dual-fuel compression stroke. 


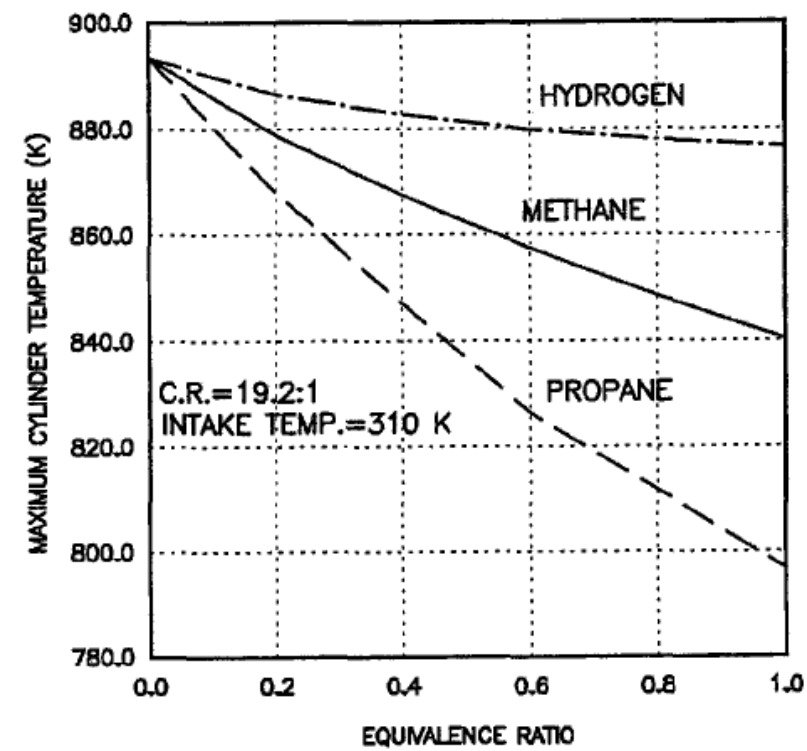

Figure 8 - Maximum In-Cylinder Gas Temperature Versus Fuel/Air Equivalence Ratio in the Absence of Pilot Diesel Injection [11]

The change in in-cylinder gas temperature due to heat transfer to the walls from the $\mathrm{CH}_{4} / \mathrm{air}$ mixture can be observed in Figure 9 [11]. As the fuel/air equivalence ratio increases with increased quantity of $\mathrm{CH}_{4}$ induction, the maximum heat transferred away from the $\mathrm{CH}_{4} /$ air mixture during compression in the absence of the pilot diesel injection decreases [11]. This indicates that during the dual-fuel compression stroke, heat is transferred to the $\mathrm{CH}_{4} /$ air mixture from the cylinder walls.

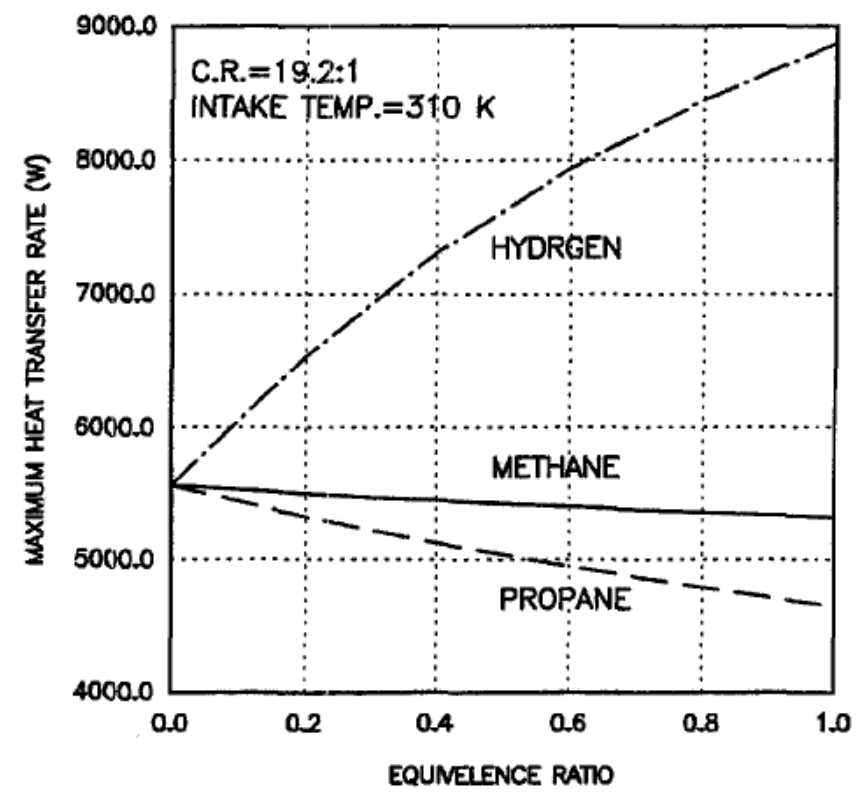

Figure 9 - Maximum In-Cylinder Gas Heat Transfer Versus Fuel/Air Equivalence Ratio in the Absence of Pilot Diesel Injection [11] 
The change in in-cylinder gas temperature due to pre-ignition energy release from the $\mathrm{CH}_{4} /$ air mixture can be observed in Figure 10 [11]. During the compression stroke, the $\mathrm{CH}_{4} /$ air mixture experiences increasing temperatures and pressures causing chemical reactions to take place [2]. These reactions are exothermic, releasing heat to the surrounding $\mathrm{CH}_{4} /$ air mixture and incylinder gas [11]. As the fuel/air equivalence ratio is increased, the maximum energy release is also increased until reaching a peak value with the fuel/air equivalence ratio in the lean region [11]. $\mathrm{CH}_{4} /$ air mixtures permit chemical reactions to occur up to some lean value, then begin to decline as the mixture progresses towards a stoichiometric to rich mixture [11]. The chemical reactions that take place are in absence of a pilot diesel injection and can produce partial oxidation products such as $\mathrm{HCHO}$ and $\mathrm{CO}$ [2].

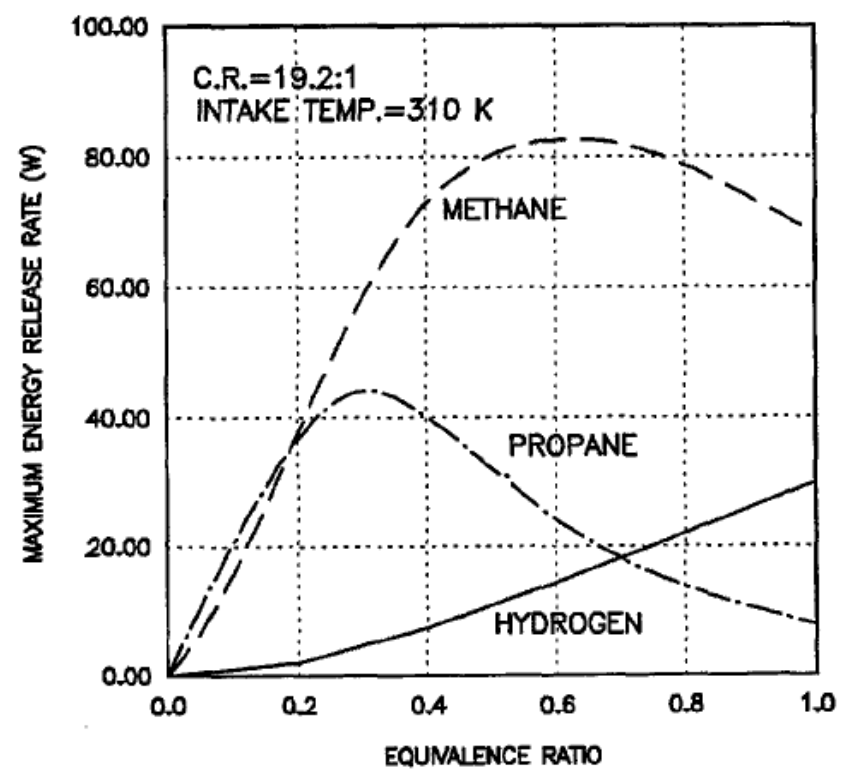

Figure 10 - Maximum In-Cylinder Gas Pre Ignition Energy Release Versus Fuel/Air Equivalence Ratio in the Absence of Pilot Diesel Injection [11]

The change in in-cylinder gas temperature due to the presence of residual gases within the $\mathrm{CH}_{4} /$ air mixture can be observed in Figure 11[11]. Nitrogen $\left(\mathrm{N}_{2}\right)$ has a specific heat similar to air meaning it requires similar amounts of energy addition to cause a temperature change. As $\mathrm{N}_{2}$ is inducted into the cylinder and compressed, it has very little effect on the maximum in-cylinder gas charge temperature [11]. At temperatures experienced during compression, $\mathrm{CO}_{2}$ has a higher specific heat than air therefore their mixture has a higher specific heat than air alone. $\mathrm{As}^{\mathrm{CO}_{2}}$ is inducted into the cylinder and compressed, it reduces the maximum in-cylinder gas charge temperature [11]. 




Figure 11 - Maximum Gas Charge Temperature Versus Diluents Concentration in Intake [11]

The ignition delay and corresponding exhaust temperature versus intake $\mathrm{CH}_{4}$ concentration for dual-fuel operation can be observed in Figure 12 [11]. At light to medium loads (low to medium $\mathrm{CH}_{4}$ concentration in the intake), ignition delay increases with the addition of $\mathrm{CH}_{4}$ in the intake concentration [11]. At these loads, the reduction in charge temperature due to the presence of $\mathrm{CH}_{4}$ in the charge mixture is the driving factor for increased ignition delay [11]. The effects of residual gases, heat transfer, and pre-ignition reactions do not significantly affect the charge temperature at these loads [11]. This decrease in in-cylinder temperature has an adverse exponential effect on Equation 1 and can be observed experimentally in Figure 12 [11]. The ignition delay increases until it reaches a maximum value at the initiation of high load, and then it begins to decrease [11]. At high loads, flame propagation reaches all points within the cylinder resulting in more complete combustion and higher exhaust temperatures. Higher exhaust temperatures result in higher residual gas temperatures which survive to the next combustion event [11]. Higher residual gas temperatures are accompanied by more pre-ignition chemical activity and subsequent energy release [11]. At these loads, the increase in charge temperature is driven by the increase in residual gas temperature and pre-ignition chemical activity [11]. This increase in temperature has a positive exponential effect on Equation 1 and can be observed experimentally in Figure 12 [11]. 


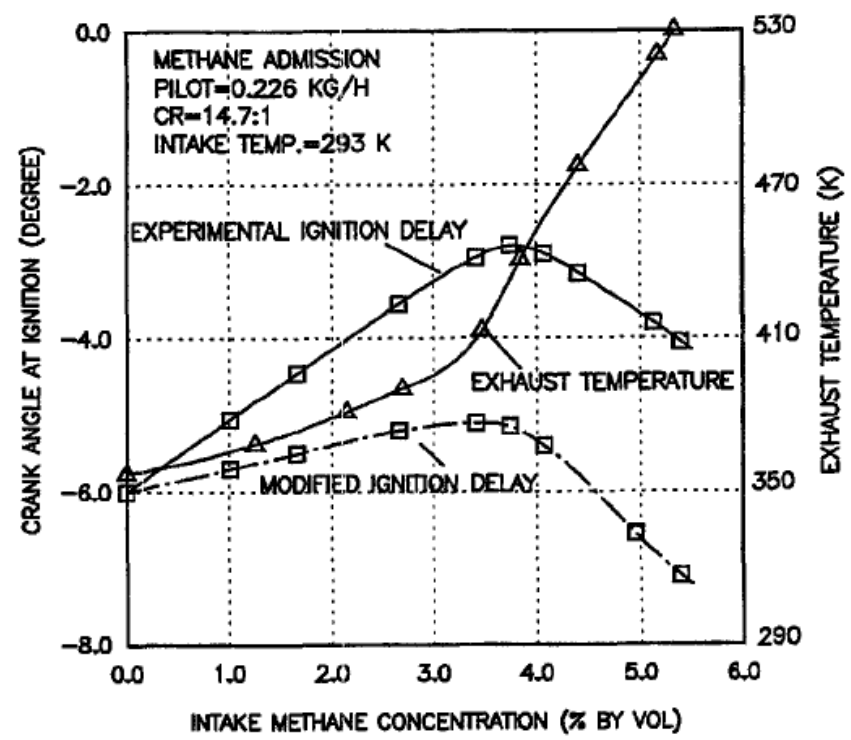

Figure 12 - Ignition Delay and Exhaust Temperature versus $\mathrm{CH}_{4}$ Concentration in Intake [11]

To fully understand dual-fuel combustion it is best to analyze in-cylinder pressure and heat release rates for dual-fuel operation compared to diesel-only operation at different engine loads and corresponding substitution ratios with the pilot diesel injection quantity held constant. The effect of dual-fuel operation on in-cylinder pressure and heat release rate at light loads can be observed in Figure 13 and Figure 14 [12]. At light loads, the reduction in charge temperature due to the presence of $\mathrm{CNG}$ is the driving factor for increased ignition delay during dual-fuel operation observed in Figure 13 and Figure 14 [12]. After the initiation of combustion, the premixed in-cylinder pressure during dual-fuel operation decreased with the increase of CNG substitution.

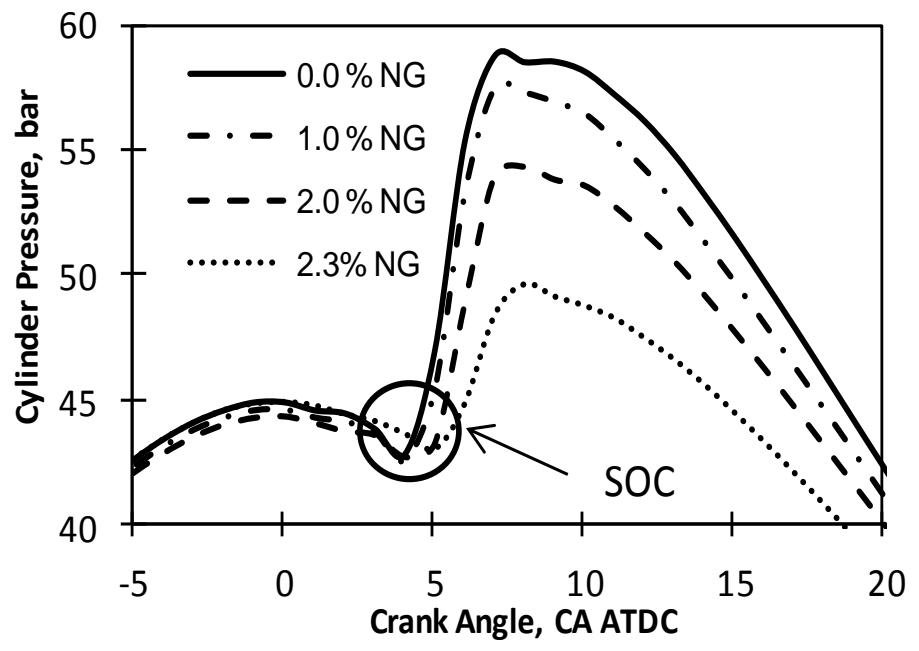

Figure 13 - Light Load In-Cylinder Pressure with CNG Substitution [12] 
At light loads, a majority of the combustion energy released comes from combustion of the pilot diesel and CNG/air mixture that is in the immediate vicinity of the pilot diesel combustion [2]. This causes peak in-cylinder pressures and heat release rates to take part in the premixed combustion region. With increased amounts of $\mathrm{CNG}$ admitted into the cylinder during the intake stroke, less air is inducted. With less air for the pilot diesel to utilize for combustion, combustion taking place in the immediate vicinity of the pilot diesel, and less diesel fuel available because of its reduction, the peak in-cylinder pressure decreased with the increase of CNG [2]. This effect also decreases and delays the heat release rate during premixed combustion as observed in Figure 14 [12]. With flame-spread limits not reaching into the cylinder, much of the CNG is not combusted causing the diffusion combustion region of dual-fuel combustion to be similar to diesel-only combustion.

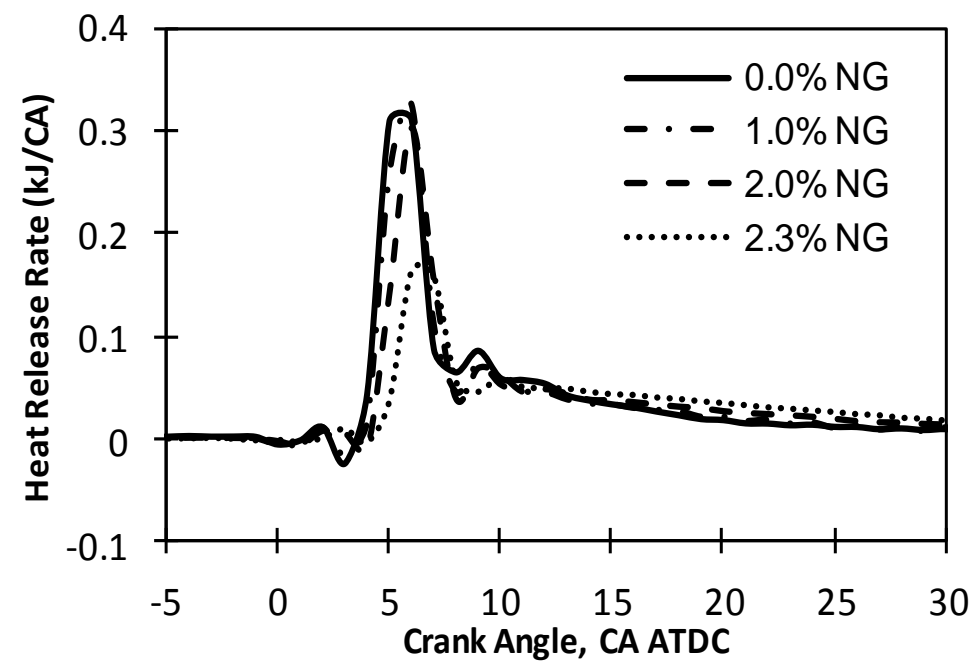

Figure 14 - Light Load Heat Release Rate with CNG Substitution [12]

The effect of CNG substitution on in-cylinder pressure and heat release rate at heavy loads can be observed in Figure 15 and Figure 16 [12]. At heavy loads, an increase in residual gas temperature causes pre-ignition chemical activity, which counteracts the reduction in charge temperature due to the presence of CNG in the charge mixture [11]. As can be observed in Figure 15 and Figure 16 this counteraction does not completely eliminate the increase in ignition delay when comparing dual-fuel operation to diesel-only operation at high loads [12]. With the increased amount of diesel injection for premixed combustion during diesel-only operation, premixed in-cylinder pressures for dual-fuel operation remain lower than diesel-only operation [12]. Due to an increase in residual gas temperature causing pre-ignition chemical activity, the 
in-cylinder pressure rise rate during premixed combustion is higher for dual-fuel operation when compared to diesel-only operation at high loads. This allows for higher heat release rates for dual-fuel operation when compared to diesel-only operation during premixed combustion at heavy loads.

During diffusion combustion the in-cylinder pressure observed during dual-fuel operation becomes greater than that observed during diesel-only operation [12]. At heavy load conditions turbulent flame propagation reaches the gaseous fuel-air mixture further into the cylinder [2]. An increase in in-cylinder pressure during diffusion combustion is observed when comparing dualfuel operation to diesel-only operation because large amounts of $\mathrm{CNG}$ is being reached with flame propagation. Also, dual-fuel operation heat release rates during diffusion combustion are higher than diesel-only operations heat release rates [12]. At high loads, dual-fuel operation heat release rates during late combustion are lower than diesel-only operations heat release rate [12]. The increased CNG concentrations experienced during high loads allows the flame propagation to reach most parts of the cylinder during diffusion combustion leaving less unburned fuel, soot, and fuel rich combustion products to be combusted during late stages.

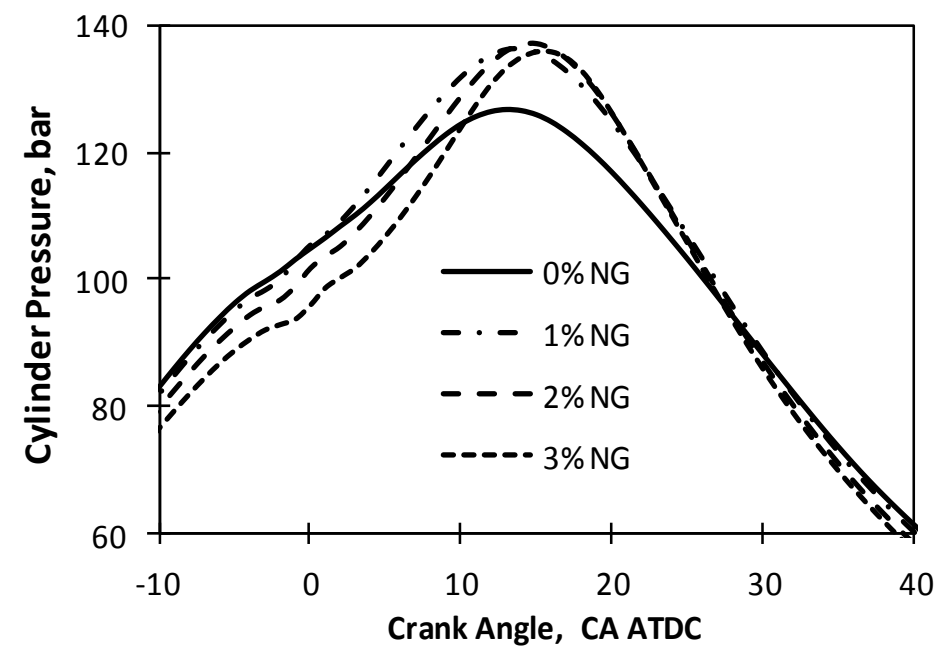

Figure 15 - Heavy Load In-Cylinder Pressure with CNG Substitution [12]

Dual-fuel operation is known to exhibit combustion knock at high loads. Combustion knock takes place when a larger than normal in-cylinder pressure rise rate occurs during combustion causing an audible "knocking" sound within the engine. At increased loads, higher exhaust temperatures result in higher residual gas temperatures which survive to the next combustion 
event [11]. Higher residual gas temperatures are accompanied by increased pre-ignition chemical activity and subsequent energy release during the compression stroke [13]. Under knocking conditions, there is a high level of pre-ignition reactions occurring in the immediate surroundings of the pilot diesel ignition vicinity which are accelerated by the ignition of the pilot diesel region [13]. This allows $\mathrm{CNG} /$ air mixtures further away from the pilot diesel ignition vicinity to reach autoignition conditions [13]. The result is the entire charge combusting at once causing a large in-cylinder pressure rise rate.

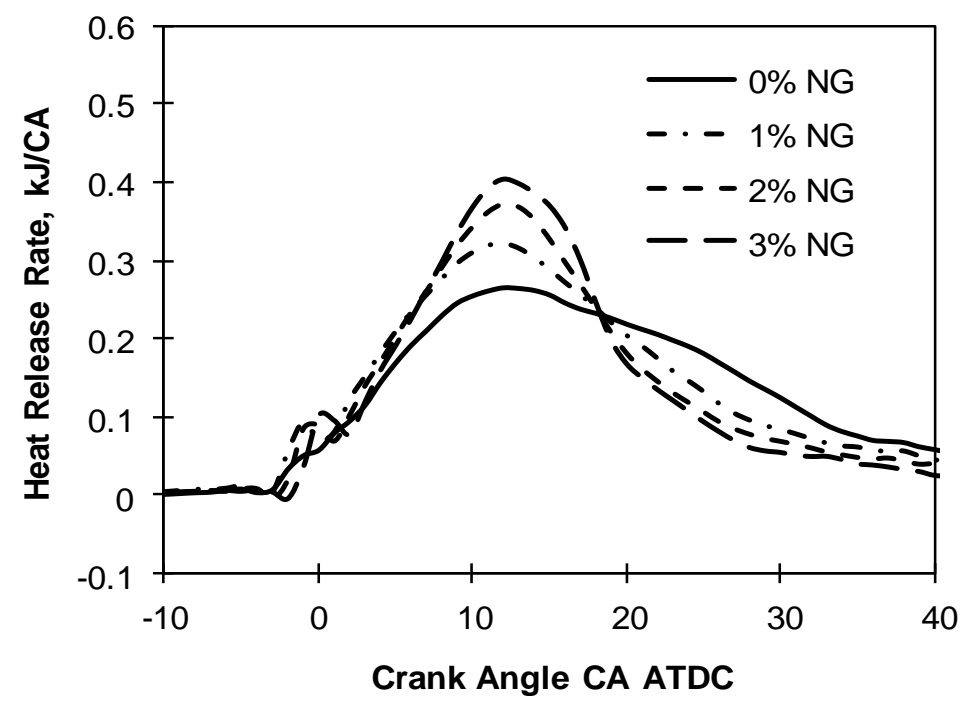

Figure 16 - Heavy Load Heat Release Rate with CNG Substitution [12]

\subsection{Hydrocarbon Emissions}

$\mathrm{HC}$ emissions present in the exhaust of a diesel engine are species resulting from the combustion of the fuel and/or lubricating oil present in the combustion chamber [6]. Unburned HC constituents can be found in the gaseous and solid phase within a diesel exhaust sample [6]. During exhaust sampling, $\mathrm{HC}$ constituents ranging from $\mathrm{CH}_{4}$ to heavier molecular weight $\mathrm{HCs}$ remaining in the vapor phase are considered gaseous $\mathrm{HC}$ emissions [6]. Higher molecular weight HCs which condense to a solid are considered PM emissions and will be discussed in Section 2.4 [6]. $\mathrm{HC}$ emissions form when the following factors take place during combustion: over-lean fuel/air mixtures, over-rich fuel/air mixtures, quenching, and misfire [6].

In a developed fuel/air mixture, ignition will occur in a slightly lean-of-stoichiometric region [6]. Ignition will not occur nor will a flame front propagate through regions where the fuel/air mixture is over-lean [6]. $\mathrm{HC}$ emissions are prominent from over-leaning during the ignition delay 
period of the combustion process [6]. During ignition delay the amount of fuel that is injected has more time to mix with the surrounding air causing increasingly lean conditions [6]. As ignition delay increases, over-leaning becomes increasingly prominent resulting in an increase of $\mathrm{HC}$ emissions [6]. Late in the combustion process, when the fuel injector closes, the injector sac volume is filled with fuel [6]. This fuel eventually vaporizes, enters the cylinder, and mixes slowly with air [6]. The slow mixing with air causes over-rich conditions and excess HC emissions [6]. Increased HC emission due to over-rich conditions can also be observed during engine acceleration when over-fueling conditions may occur trying to meet load demands [6].

During cool engine operating conditions, fuel injection spray may impinge on the cylinder wall and condense [6]. The condensed fuel may survive the combustion process without being completely burned resulting in increased $\mathrm{HC}$ emissions [6]. During engine operation, if combustion does not occur this is called a misfire. During a misfire, the fuel/air mixture is not ignited therefore exiting the engine through the exhaust. An increase in misfires during engine operation will cause an increase in $\mathrm{HC}$ emissions [6]. As engine load is increased, $\mathrm{HC}$ emissions are decreased with indication of more complete combustion, due to higher mean in-cylinder gas temperatures.

A comparison between $\mathrm{HC}$ emissions from diesel-only and dual-fuel operation with respect to engine load can be observed in Figure 17 [14]. As load is increased, HC emissions for diesel operation and dual-fuel operation decrease [14]. At all loads, HC emissions from dual-fuel operation are higher than those emitted during diesel-only operation, especially during light loads [14]. During diesel-only operation, ignition delay is largest at light loads and decreases as load increases [10]. This trend corresponds to $\mathrm{HC}$ emissions realizing that over-lean fuel/air mixtures are experienced during light load conditions at combustion events corresponding with increased ignition delay. 


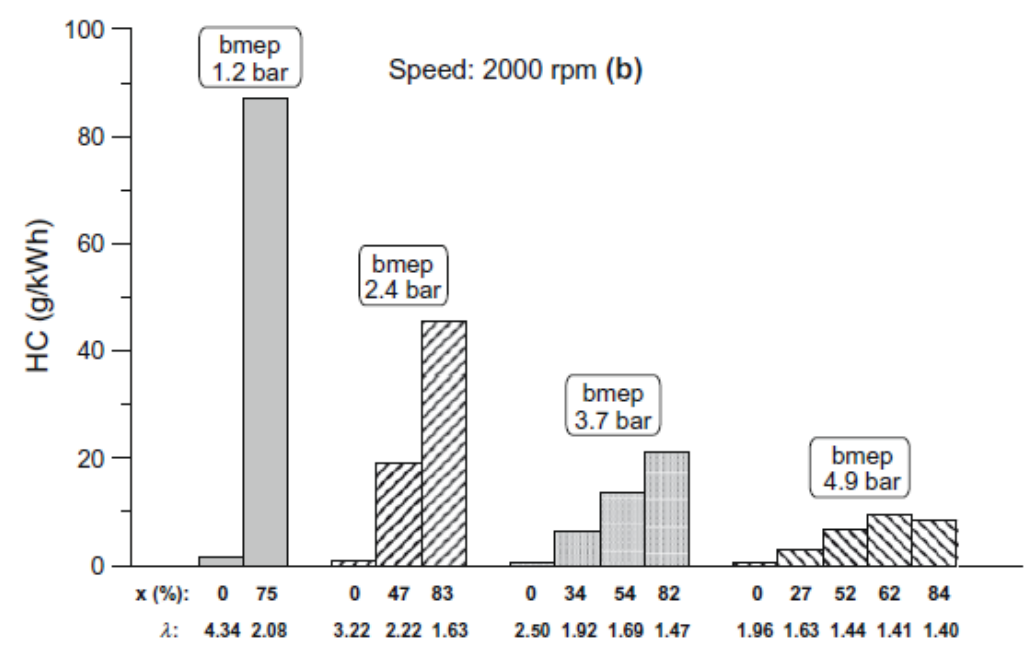

Figure 17 - HC Emissions from Diesel-Only Operation and Dual-Fuel Operation [14]

During dual-fuel operation, ignition delay is smallest at light loads and increases as load increases, which would positively affect $\mathrm{HC}$ emissions [10]. Though ignition delay plays a role in $\mathrm{HC}$ emissions for dual-fuel combustion, the significant factor is incomplete combustion due to flame-spread limits. During dual-fuel operation, as load is increased, fuel/air equivalence ratios begin to increase from fuel lean conditions toward stoichiometric conditions which favors flame propagation [14]. A large majority of $\mathrm{HC}$ emissions during dual-fuel operation is unburned $\mathrm{CH}_{4}$ which is the major constituent in CNG. As stated in Section 2.2, during dual-fuel combustion at light loads, combustion takes place in the pilot diesel region and its near vicinity [2]. Flame spread limits restrict flame propagation from burning the $\mathrm{CNG}$ /air mixture further away from the pilot diesel region resulting in large $\mathrm{HC}$ emissions composed mainly of $\mathrm{CH}_{4}$.

\subsection{Particulate Matter Emissions}

When atmospheric air is used to dilute raw exhaust at a temperature of $52^{\circ} \mathrm{C}$ or less and filtered, anything collected on the filter is considered PM [6]. PM emissions are composed of elemental carbon (C) on which organic compounds have been absorbed [6]. PM emissions are considered to have a bimodal size distribution: nuclei mode particles and accumulation mode particles [15]. Nuclei mode particles are combustion generated soot spherules which are characterized by a number-mean diameter of $10 \mathrm{~nm}$ to $20 \mathrm{~nm}$ [6]. Accumulation mode particles are agglomerated soot spherules which are characterized by a number-mean diameter of $100 \mathrm{~nm}$ to $180 \mathrm{~nm}$ [6].

PM emissions are composed of solid fraction (SOL), soluble organic fraction (SOF), and sulfate particles $\left(\mathrm{SO}_{4}\right)$ [15]. SOL is formed inside the combustion chamber and is composed of 
elemental $\mathrm{C}$ and ash [15]. Elemental carbon is formed in locally fuel rich zones within the combustion chamber where oxygen $\left(\mathrm{O}_{2}\right)$ is not present to convert all $\mathrm{C}$ to $\mathrm{CO}_{2}$ [16]. Due to the global lean mixture within the combustion chamber, a significant amount of $\mathrm{C}$ particles can remix with $\mathrm{O}_{2}$ and be consumed [16]. Those that are not consumed are exhausted as part of the SOL portion of PM emissions. Ash is formed from the wear of engine components and additives to fuel or lubrication oil [15]. As PM exits the combustion chamber of the engine, it is mixed with cool dilution air within the dilution tunnel [15]. At this point, organic material derived from fuel and engine lubricating oil condenses and absorbs onto the surface of $\mathrm{C}$ particles forming the SOF portion of PM [15].

Under heavy load conditions where high exhaust temperatures are present, organic material derived from fuel and engine lubricating oil does not condense and therefore does not absorb onto carbon particles to form significant SOF [16]. Under light load conditions where low exhaust temperatures are observed, organic material derived from fuel and engine lubricating oil condenses to form SOF [16]. Factors that affect PM emissions are fueling quantities, combustion duration, cylinder temperatures, and injection [16]. Increased combustion durations allow more time for elemental $\mathrm{C}$ to remix with $\mathrm{O}_{2}$ and burn completely to $\mathrm{CO}_{2}$ [16]. Higher cylinder temperatures enhances the oxidation of $\mathrm{C}$ to $\mathrm{CO}_{2}$. Higher injection pressure allows the fuel to vaporize and mix with oxygen more effectively, therefore combusting at higher temperatures and producing less PM emissions [16].

Dual-fuel combustion is known to produce lower PM emissions when compared to diesel-only combustion at similar operating conditions [17]. CNG produces less particulate matter compared to diesel fuel when combusted due to $\mathrm{CNG}$ containing less $\mathrm{C}$ than diesel. As load increases for diesel-only operation, soot emissions decrease due to the increase in combustion efficiencies and in-cylinder gas temperatures enhancing the oxidation of $\mathrm{C}$ to $\mathrm{CO}_{2}$. Soot emissions decline with load for dual-fuel operation because diesel pilot injection quantities are held constant while gaseous fuel concentrations in the intake increase to meet power demands [17]. Considering the $\mathrm{C}$ content of $\mathrm{CNG}$, most elemental $\mathrm{C}$ can find adequate amount of $\mathrm{O}_{2}$ to oxidize to $\mathrm{CO}_{2}$. Therefore most PM comes from locally rich regions during pilot diesel combustion. As loads increase, increased in-cylinder temperatures and combustion durations are experienced while pilot diesel injection is held nearly constant resulting in a decrease of PM. 


\subsection{Oxides of Nitrogen Emissions}

A majority of NOx emissions produced in a diesel engine are derived from $\mathrm{N}_{2}$ found in the inducted air. Some fuel blends can possess $\mathrm{N}_{2}$ but in such small quantities that they do not become a major contribution of NOx formation [16]. NOx emissions in diesel engines consist mainly of nitrogen oxide (NO) and nitrogen dioxide $\left(\mathrm{NO}_{2}\right)$. $\mathrm{NO}_{2}$ can compose $10 \%$ to $30 \%$ of the NOx emissions in a diesel engine while NO is the remaining contribution [6]. At the high temperatures experienced during combustion, diatomic nitrogen $\left(\mathrm{N}_{2}\right)$ found in the intake air, breaks down to monatomic nitrogen $(\mathrm{N})$ which is reactive [16]:

$N_{2}=2 N$

Equation 3

$\mathrm{O}_{2}$ and water vapor $\mathrm{H}_{2} \mathrm{O}$ found in the intake air and combustion products break down to become reactive at the high temperatures experienced during combustion [16]:

$\mathrm{O}_{2}=20$

Equation 4

$\mathrm{H}_{2} \mathrm{O}=\mathrm{OH}+\frac{1}{2} \mathrm{H}_{2}$

Equation 5

At near stoichiometric fuel-air mixtures the formation of NO usually occurs from the following reactions [6]:

$O+N_{2}=N O+N$

Equation 6

$\mathrm{N}+\mathrm{O}_{2}=\mathrm{NO}+\mathrm{O}$

Equation 7

$N+O H=N O+H$

Equation 8

These reactions occur in the combustion flame and the post-flame gases present from combustion [6]. The resultant gases from early premixed combustion are compressed as the piston ascends towards TDC causing higher temperatures than experienced directly after combustion [6]. Due to the higher temperatures and time for reactions to take place, NO formation occurring in the post-flame gases is greater than NO formation occurring in the combustion flame [6]. In either the combustion flame and the compressing post flame gases, NO can be converted to $\mathrm{NO}_{2}$ by the following reaction [6]:

$\mathrm{NO}+\mathrm{HO}_{2}=\mathrm{NO}_{2}+\mathrm{OH}$

Equation 9 
If the temperature remains high following this reaction then $\mathrm{NO}_{2}$ will immediately convert back to NO by the following reaction [6]:

$\mathrm{NO}_{2}+\mathrm{O}=\mathrm{NO}+\mathrm{O}_{2}$

Equation 10

If the temperature is reduced after the reaction takes place in Equation 9 then the reaction taking place in Equation 10 will not take place and $\mathrm{NO}_{2}$ will be formed [6]. This tends to happen at light loads where flame quenching can occur due to lower combustion temperatures [6]. The concentration of $\mathrm{NO}_{2}$ in $\mathrm{NOx}$ emissions is higher for dual fuel operation due to flame quenching as can be observed in Figure 18 [18]. Figure 19 shows the NOx emissions with respect to load for diesel-only operation and dual-fuel operation [17]. NOx emissions increase for dual-fuel operation and diesel-only operation due to larger temperatures experienced during combustion at higher loads. It can be observed that NOx emissions are larger for diesel-only operation compared to dual-fuel operation and this difference becomes more evident at high loads [17].

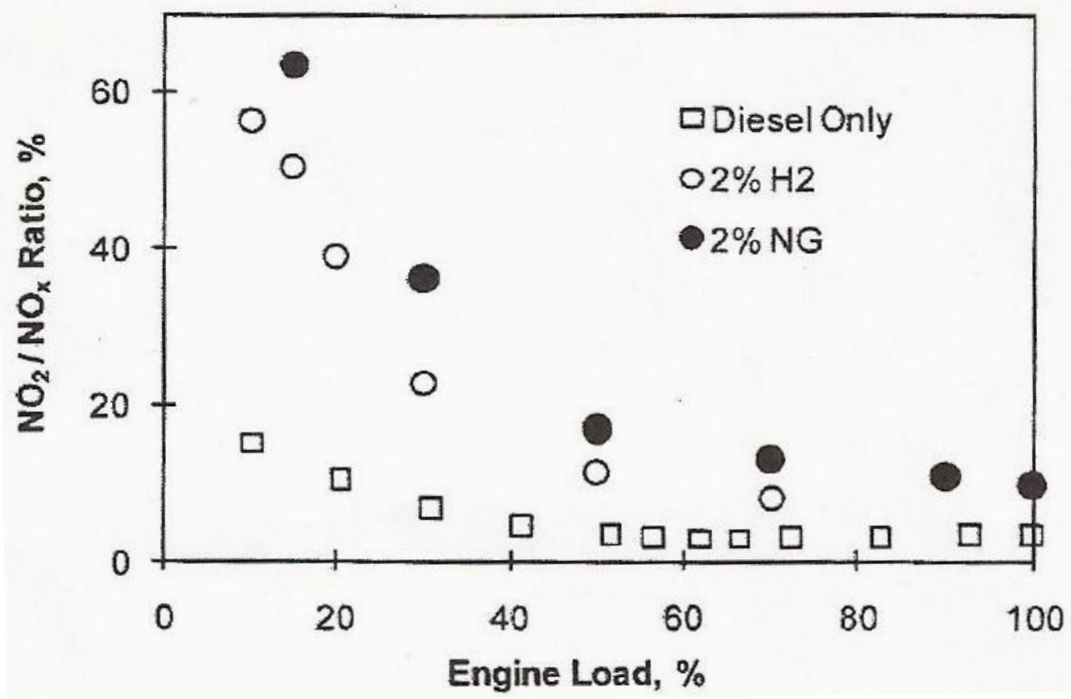

Figure 18 - $\mathrm{NO}_{2} / \mathrm{NOx}$ Concentration for Dual-Fuel and Diesel-Only Operation [18]

NOx is well known to be affected by high charge temperature and high $\mathrm{O}_{2}$ concentration [17]. During dual-fuel operation the charge temperature is reduced due to the cool CNG being inducted into the combustion chamber during the intake stroke. Also, the $\mathrm{O}_{2}$ concentration is reduced because it is displaced by the induction of CNG during the intake stroke. At high loads, NOx emissions from dual-fuel operation are increasing at a lower rate than diesel-only operation due to the large amounts of cool CNG being inducted into the cylinder displacing the amount of $\mathrm{O}_{2}$ being inducted with air [17]. Lower combustion temperatures experienced during dual-fuel 
operation also play an important role in NOx formation. Due to lower in-cylinder pressures and temperatures experienced during dual-fuel combustion (until high loads are reached), there is a decrease in NOx formation when comparing to diesel-only operation.

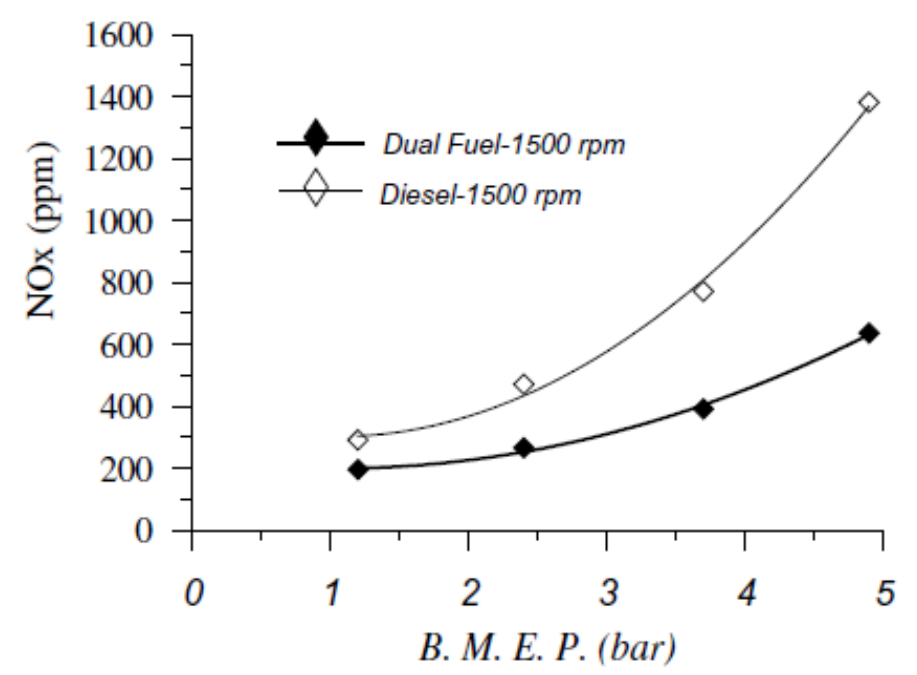

Figure 19 - NOx Emissions For Diesel-Only Operation And Dual-Fuel Operation [17]

\subsection{Carbon Monoxide and Carbon Dioxide Emissions}

$\mathrm{CO}$ emissions are intermediate products from incomplete combustion of a HC fuel [15]. Incomplete combustion which aids the formation of $\mathrm{CO}$ is present due to the lack of $\mathrm{O}_{2}$, the proper temperature for oxidation to occur, and the residence time for oxidation to occur [15]. During complete combustion, $\mathrm{CO}$ proceeds towards $\mathrm{CO}_{2}$ by the following reaction [16]:

$\mathrm{CO}+\frac{1}{2} \mathrm{O}_{2}=\mathrm{CO}_{2}+\mathrm{Heat}$

Equation 11

If the reaction taking place in Equation 11 has a lack of oxidants, temperature, or residence time, $\mathrm{CO}$ will not form into $\mathrm{CO}_{2}$ and remains in its present form [15]. $\mathrm{CO}$ emissions are commonly produced from fuel rich mixtures. Diesel engines operate with lean combustion and excess amounts of air for $\mathrm{CO}$ to oxidize to $\mathrm{CO}_{2}$, meaning $\mathrm{CO}$ emissions are relatively low [15]. Though diesel engines operate with lean combustion there are still locally rich regions which produce $\mathrm{CO}$ emissions. Figure 20 shows CO emissions with respect to load for diesel-only operation and dual-fuel operation [10]. CO emissions decrease with load for dual-fuel operation and dieselonly operation due to higher temperatures experienced during combustion and increased residence time due to longer combustion durations increasing the oxidation of CO. 
It can be observed that $\mathrm{CO}$ emissions are greater for dual-fuel operation compared to diesel-only operation and this difference becomes more evident at light loads [10]. As stated in Section 2.2, during dual-fuel combustion at light loads, combustion takes place in the pilot diesel region and its near vicinity [2]. Flame spread limits restrict flame propagation from burning the $\mathrm{CNG}$ /air mixture further away from the pilot diesel region resulting in increased $\mathrm{CO}$ emissions due to incomplete combustion [2]. As loads increase, flame propagation reaches further into the cylinder allowing for more complete oxidation of $\mathrm{CO}$ into $\mathrm{CO}_{2}$ [2]. $\mathrm{CO}_{2}$ emissions are lower at all modes of dual-fuel operation when compared to diesel-only operation [10]. With lower $\mathrm{O}_{2}$ concentration in the cylinder due to its displacement during $\mathrm{CNG}$ induction and lower combustion temperatures, $\mathrm{CO}$ does not completely oxidize to $\mathrm{CO}_{2}$ following Equation 11. This is evident by the increased $\mathrm{CO}$ emissions observed during dual-fuel operation when compared to diesel-only operation.

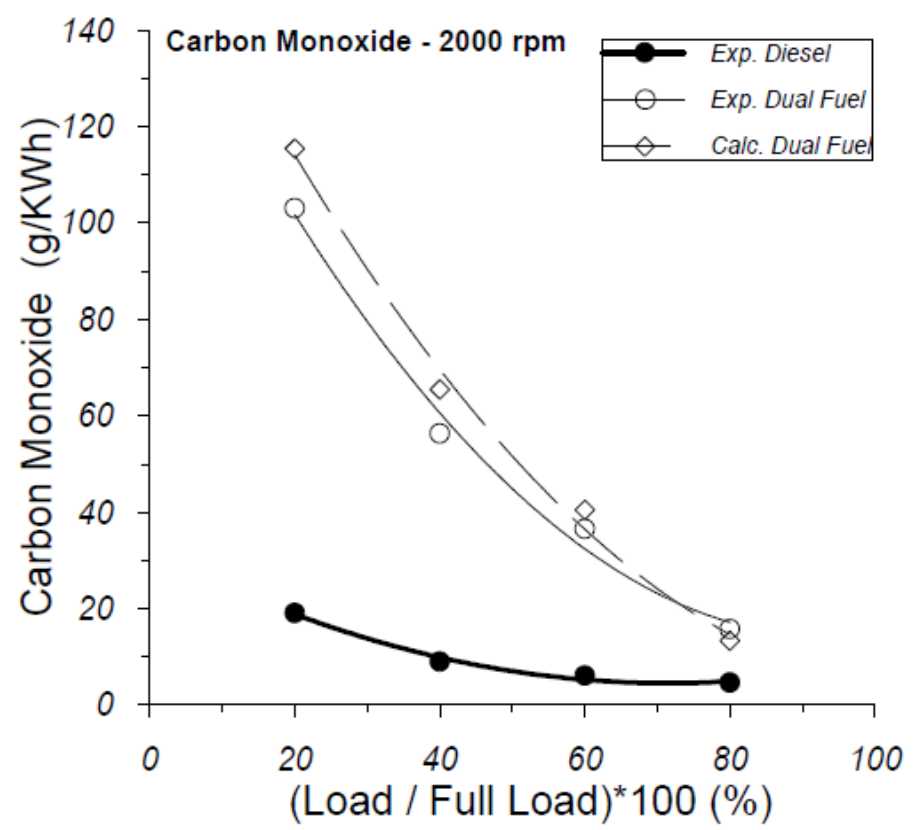

Figure 20 - CO Emissions For Diesel-Only Operation And Dual-Fuel Operation [10]

\subsection{EPA's Clean Alternative Fuel Conversion Program}

The EPA's Clean Alternative Fuel Conversion Program was designed to grant clean alternative fuel conversion manufacturers an exemption from the CAA prohibition against tampering laws. The dual-fuel conversion kit used for this research was being certified for intermediate age compliance meaning the engines model year was less than or equal to the current calendar year minus two years and within useful life $(435,000$ miles or 22,000 hours). To comply with the 
program the dual-fuel conversion kit had to meet emissions standards, OBD attestation, and durability attestations. To comply with emissions standards, the engine had to be tested to the OEM emissions standards found in Table 1. Testing included transient FTPs and steady-state SET tests. An OBD scan had to be completed with the engine in dual-fuel operation to determine if the dual-fuel conversion kit affected the OEM OBD system. The dual-fuel conversion manufacturer had to attest the conversion kit was reliable using good engineering judgment.

Table 1 - 2004-2007 EPA Heavy-Duty Engine Emissions Standards

\begin{tabular}{cc}
\hline 2004-2007 Emissions Standards & \\
\hline NMHC + NOx (g/bhp-hr) & 2.50 \\
\hline NMHC (g/bhp-hr) & 0.500 \\
\hline PM (g/bhp-hr) & 0.100 \\
\hline CO $(\mathrm{g} / \mathrm{bhp}-\mathrm{hr})$ & 15.5 \\
\hline
\end{tabular}

\subsection{Refueling Infrastructure}

There are approximately 1,000 CNG stations within the Unites States compared to the 118,756 retail gasoline stations, most of which offer diesel fuel [32]. To become a competitive infrastructure, the CNG industry would benefit from developing $10 \%$ to $20 \%$ of the traditional liquid refueling stations, or between 16,000 and 32,000 CNG stations [32]. The average cost of a station is from $\$ 600,000$ to $\$ 1,000,000$ varying with unique components such as gas dryers and high pressure storage systems [32]. If the industry is to meet the growth explained above, there will need to be an expansion of existing companies and entering of new companies [32]. These companies include compressor manufacturers, compressor suppliers, compressor packagers, engineering and construction, and CNG retailers [32]. 


\section{Experimental Setup}

The objective of this work was to investigate dual-fuel combustion characteristics and its resultant emissions to determine if the partial substitution of diesel fuel with $\mathrm{CNG}$ is a viable technology for the transportation industry. Two engines originally designed for diesel-only operation were outfitted with a dual-fuel conversion kit intended to certify with the EPA's Clean Alternative Fuel Conversion Program. For the investigation, steady-state and transient tests were completed at the West Virginia University (WVU) Center for Alternative Fuels, Engines, and Emission's (CAFEE's) Engine Research Center (ERC) by comparing dual-fuel operation to diesel-only operation. Operational costs and miles per gallon (MPG) efficiencies were analyzed by in-use operation comparisons between dual-fuel operation and diesel-only operation.

\subsection{Test Engines}

A 2005 Mercedes OM-460LA engine (Figure 21) and a 2005 Mack AC-460P engine (Figure 22) were used for this project. Both engines represent modern on-road heavy-duty diesel engines which meet the 2004-2007 EPA Heavy-duty Engine Emissions Standards found in Table 1. The 2005 Mercedes OM-460LA engine was used for in-cylinder pressure analysis and exhaust emissions measurements during steady-state operation. The 2005 Mack AC-460P engine was used to measure steady-state and transient operation exhaust emissions. The 2005 Mack AC$460 \mathrm{P}$ engine was also used to show the operating characteristics a dual-fuel conversion kit must obtain to meet the EPA's Clean Alternative Fuel Conversion Program. Once meeting the EPA's certification requirements, the 2005 Mack AC-460P engine was used to show in-use operational costs and MPG efficiencies of an EPA certified dual-fuel conversion kit. A comparison of engine specifications can be found in Table 2 . 


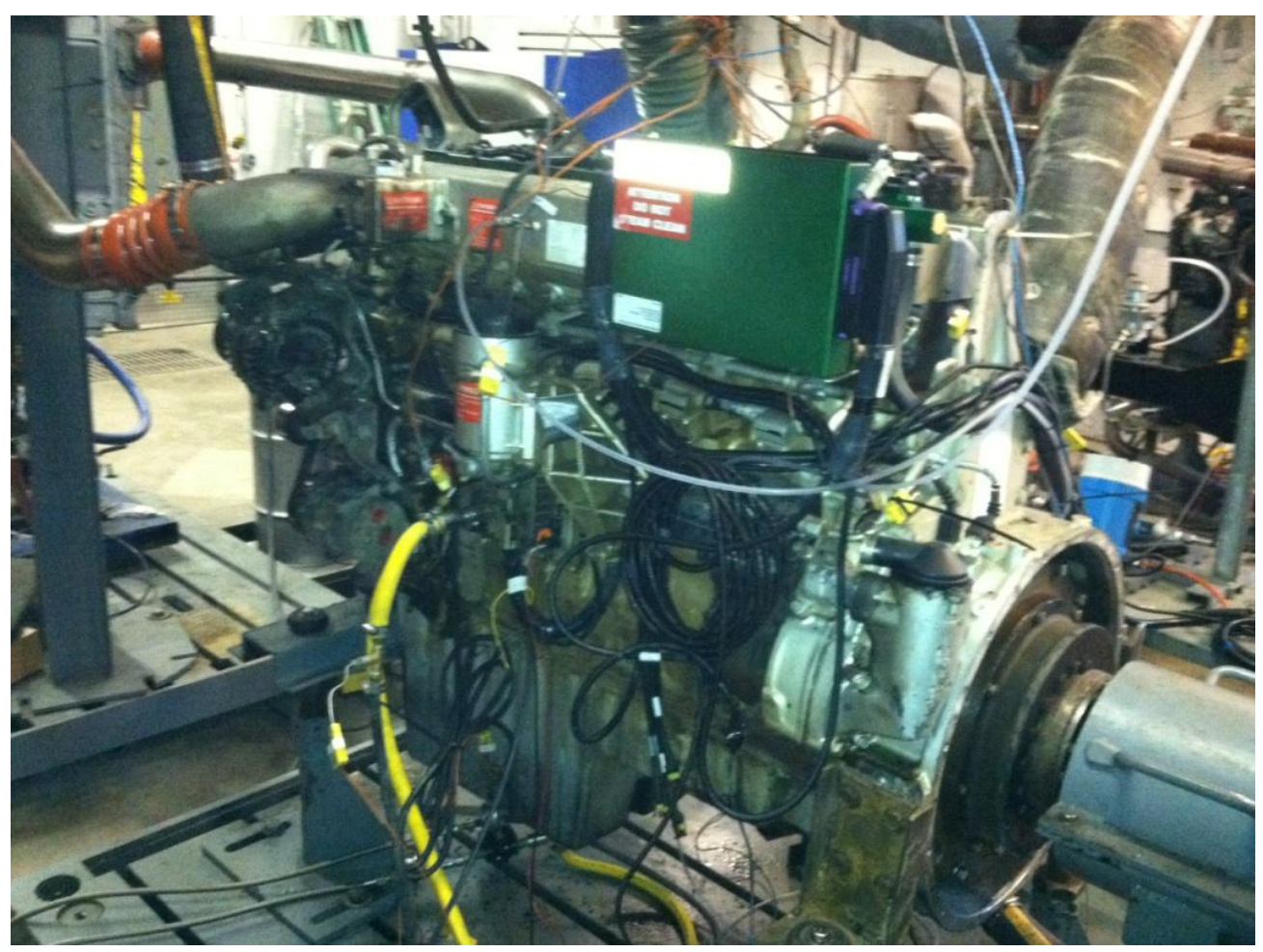

Figure 21 - 2005 Mercedes OM-460LA

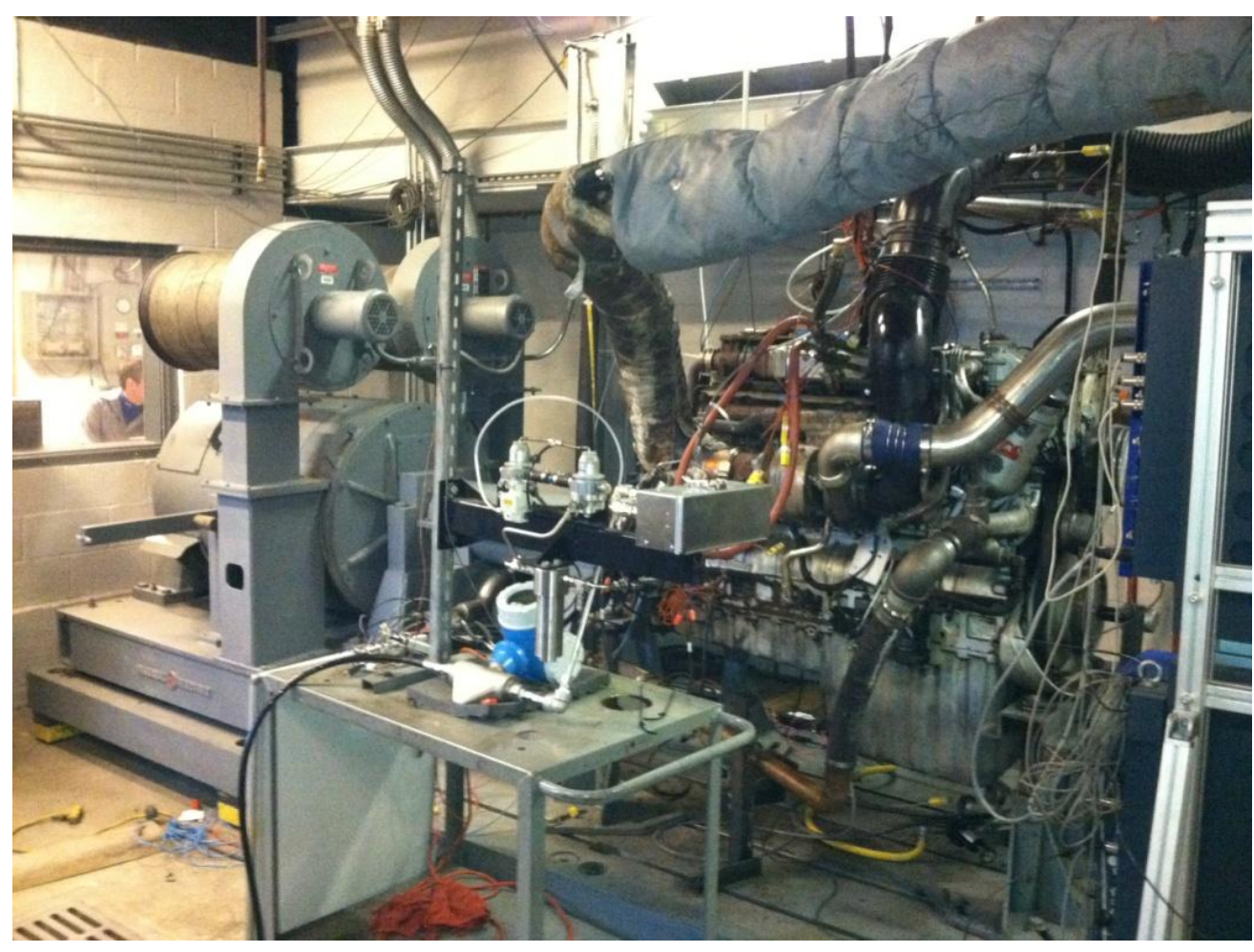

Figure 22 - 2005 Mack AC-460P 
Table 2 - Engine Specifications

\begin{tabular}{ccc}
\hline Manufacturer & Mercedes & Mack \\
\hline Year & 2005 & 2005 \\
\hline Model & OM-460LA & AC-460P \\
\hline Cylinders & 6 & 6 \\
\hline Displacement (L) & 12.8 & 12.0 \\
\hline Rated Power (hp) & 410 & 480 \\
\hline Rated Torque (ft-lb) & 1550 & 1660 \\
\hline Bore (in) & 5.040 & 4.875 \\
\hline Stroke (in) & 6.540 & 6.500 \\
\hline Compression Ratio & $17.75: 1$ & $16.00: 1$ \\
\hline Diesel Injection Methods & Unit Pump & Unit Pump \\
\hline Aspiration & VGT & VGT \\
\hline Emissions Control & Cooled EGR & Cooled EGR \\
\hline
\end{tabular}

\subsection{Test Fuels}

The diesel fuel used for transient and steady-state certification work on the 2005 Mack AC-460P was Haltermann Solutions Ultra Low Sulfur 2007 Certification diesel fuel. The CNG used for dual-fuel certification work was Matheson Chemically Pure $\mathrm{CH}_{4}\left(99.5 \% \mathrm{CH}_{4}\right)$. These fuels were chosen to show compliance with the EPA's Clean Alternative Fuels Conversion Program. The diesel fuel used for steady-state in-cylinder pressure analysis on the 2005 Mercedes OM-460LA was Guttmann Oil diesel fuel. The CNG used for dual-fuel in-cylinder pressure analysis was the same Matheson Chemically Pure $\mathrm{CH}_{4}$ used for certification testing. Certification diesel fuel was only used for certification testing due to its high cost. To show repeatability with the Mack AC460P, a series of repeatability tests were exercised on Guttmann Oil diesel fuel and Matheson Chemically Pure $\mathrm{CH}_{4}$.

\subsection{Test Cycles}

The test cycles used for this project were a transient Federal Test Procedure (FTP), a steady-state Supplemental Emissions Test (SET), and a steady-state repeatability (RPT) test. The transient FTP has four sections simulated in the following order: the New York Non Freeway (NYNF), the Los Angeles Non Freeway (LANF), the Los Angeles Freeway (LAFY), and a repetition of the NYNF. The NYNF section simulates frequent stopping and starting in city conditions. The LANF simulates infrequent stopping and starting in city conditions. The LAFY models highway conditions with traffic. A graphical depiction of the transient FTP cycle can be observed in 
Figure 23 [19]. The steady-state SET has 13 different modes including an idle and four load points each exercised at three different engine speeds. The load points include $25 \%, 50 \%, 75 \%$, and $100 \%$ load. A graphical depiction of the steady-state SET can be observed in Figure 24 with the mode number circled [20]. The actual torque and speed values used in the transient FTP and steady-state SET are determined from an engine map. A map is a test completed where the engine incrementally operates from low idle to high idle at $100 \%$ throttle. Each test cycle is controlled by a computer and must pass regression requirements after every test indicating the speed and torque control demanded by the computer was produced by the engine.

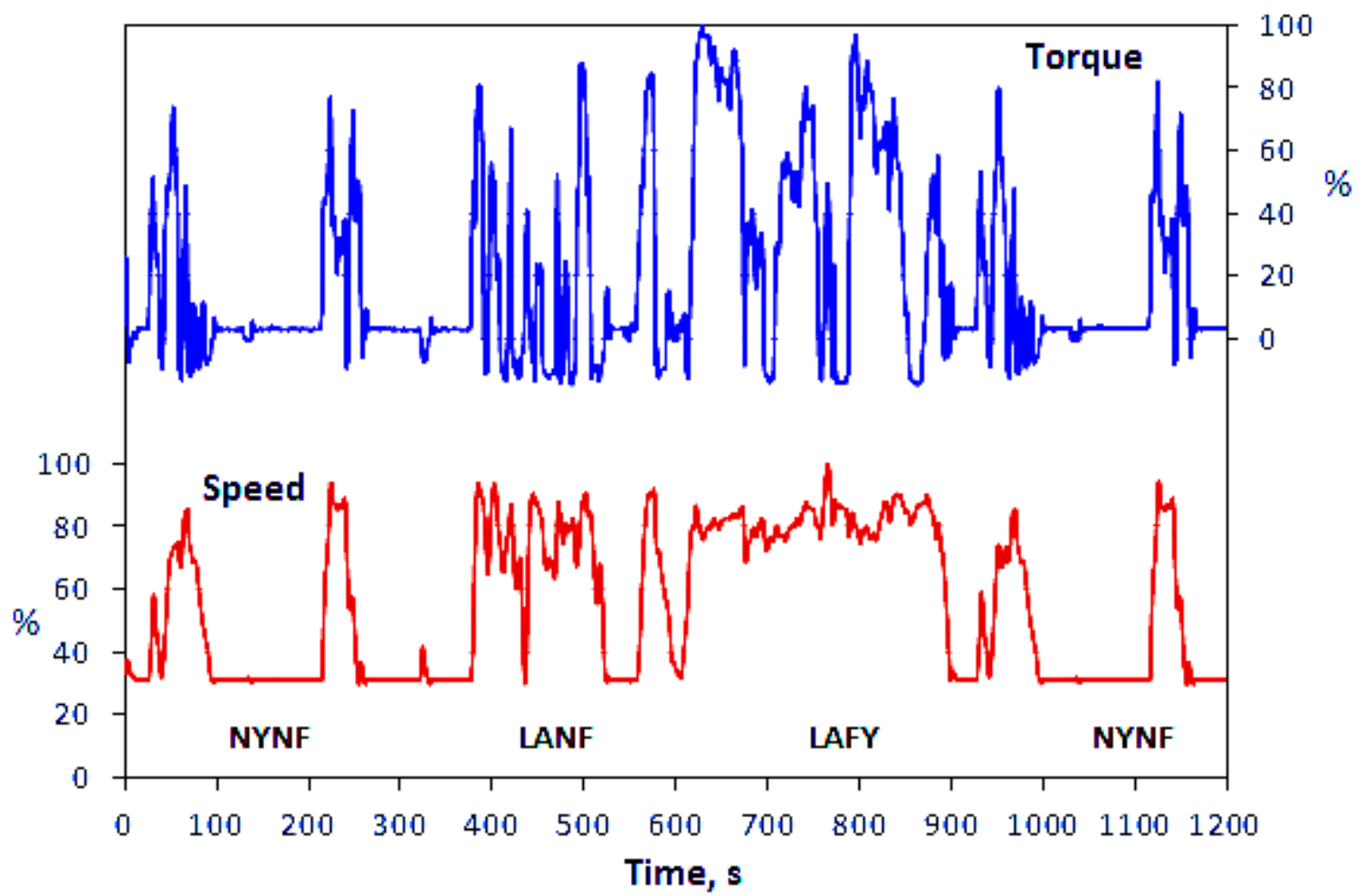

Figure 23 - Transient FTP Cycle [19] 


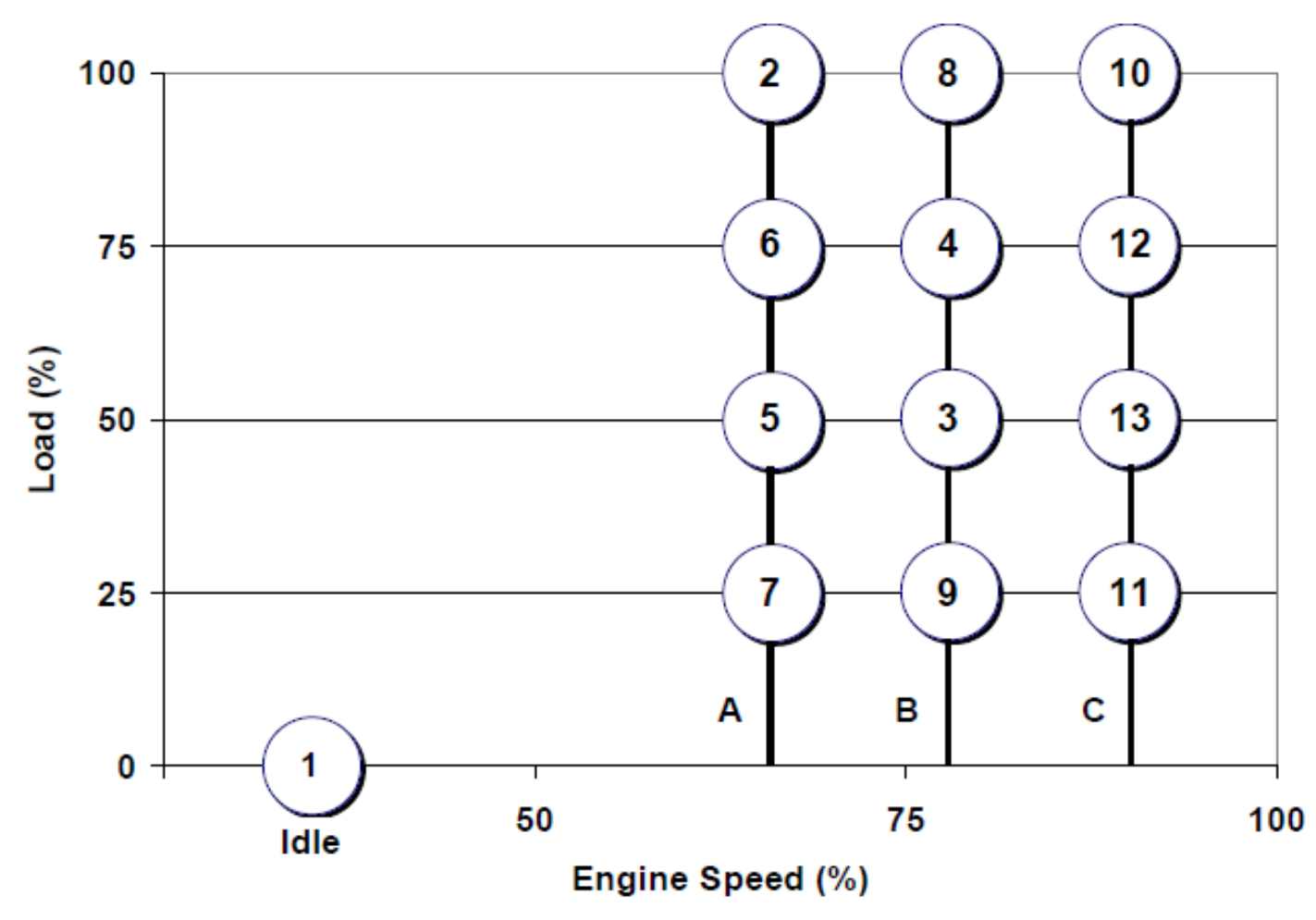

Figure 24 - Steady-State SET Cycle [20]

The RPT test was developed to check for steady-state repeatability of emissions and in-cylinder pressure data measured from the 2005 Mercedes OM-460LA. The test consisted of six modes all at the same engine speed and torque. The engine was switched between dual-fuel operation and diesel-only operation every other mode resulting in three modes in diesel-only operation and three modes in dual-fuel operation.

\subsection{Test Plan}

Testing was completed for diesel-only operation and dual-fuel operation. Both engines came from the OEM designed to be operated in diesel-only operation. The purpose of the dual-fuel conversion kit is to take a diesel-only OEM operated engine and convert it to dual-fuel operation without significantly degrading performance and emissions. With this being said, the engine was baseline tested in diesel-only operation and then tested in dual-fuel operation to compare the results. Between each test is a 20-minute ignition off soak period which allows the analyzers to be zeroed and spanned, the PM filter to be changed, and the engine to reach similar starting operating conditions for each test. Fuel costs and MPG efficiencies were obtained from in-use operation and compared. 


\subsubsection{Combustion and Emission Formation}

Steady-state testing used to collect in-cylinder pressure data and resultant emissions formation was completed in a single day. At the beginning of the day, a cold-start RPT test was completed to bring the engine to normal operating conditions. With the engine operating at normal conditions, a second RPT test was completed to check the repeatability of the engine operating in diesel-only operation and dual-fuel operation. Then, a steady-state SET was exercised for dieselonly operation and a second SET for dual-fuel operation while collecting in-cylinder pressure and emissions. A final RPT test was exercised at the end of the day too bracket the steady-state SETs and provide additional statistical significance.

To determine the repeatability of the engine during diesel-only operation and dual-fuel operation, the mean, standard deviation, and coefficient of variation were calculated for the RPT tests combined. This was completed for the in-cylinder pressure data and emissions data. To determine if the engine was repeatable due to operating condition changes, an analysis of variance between each RPT test was completed. A 95\% confidence interval was assumed to determine if the tests were similar. If the analysis of variance test returned a probability value (pvalue) greater than 0.05 then the null hypothesis was accepted and there were no significant operating condition variations. If the analysis of variance determined the tests were significantly different, the coefficient of variation of the means was calculated. Coefficient of variation was not calculated for crank angle location parameters determined from the in-cylinder pressure analysis, due to the accuracy of the encoder and magnitude of the values. The most important factors affecting daily engine operation over a series of tests include barometric pressure, intake absolute humidity, and intake temperature. To determine if these values changed significantly over the test day, an analysis of variance was completed for the operating conditions between each RPT test. Also the mean, standard deviation, and coefficient of variation were calculated for the operating conditions of the RPT tests combined to offer additional insight.

PM data was collected for each mode during the RPT test and the steady-state SET. PM sampling times were not long enough to collect adequate amounts of PM on the filter for gravimetric analysis yielding incomparable results. This resulted in incomplete modal analysis of PM data. PM data was obtained through developmental testing completed for sponsors. This data utilized the same dual-fuel controller settings as used during the RPT tests and steady-state SETs but were not repeated to show statistical significance. 


\subsubsection{Certification Work}

Before certification testing was completed, a series of transient FTPs were exercised to determine if the engine and emissions were repeatable during dual-fuel operation and diesel-only operation. This work was completed operating the engine on Guttman Oil diesel fuel rather than Haltermann Solutions certification fuel because of cost burdens. A cold-start transient FTP was completed to bring the engine to normal operating conditions. Three hot-start FTPs were then completed for dual-fuel operation and diesel-only operation to show engine and emissions repeatability. The mean, standard deviation, and coefficient of variation were calculated for the emission measurements to show statistical significance.

Research and development tests completed for certification work were not repeated due to time limitations. Tests were completed over a series of days so an analysis of variance was completed for barometric pressure, intake absolute humidity, and intake temperature to determine if operating conditions could have affected emissions results. An analysis of variation of emissions due to changes in operating conditions could not be completed because there were no group of tests with similar engine configurations exercised on different days.

When completing certification testing for the EPA, a certain test sequence must be followed. The test sequence includes a cold-start transient FTP, a hot-start transient FTP, and a steady-state SET. The official certification testing sequence using Haltermann Solutions certification diesel fuel was completed with the same dual-fuel control strategy used for the transient FTP repeatability tests. The same sequence was then repeated for diesel-only operation. With the results of these baseline tests, it was determined adjustments had to be to the dual-fuel conversion kits ECU for the engine to meet the EPA's emissions standards. The tests exercised and the adjustments made are presented in Section 4.2.

\subsubsection{Cost Comparison and MPG Efficiencies}

After the 2005 Mack AC-460P met the EPA's Clean Alternative Fuel Conversion Program certification requirements, it was in-use tested to determine fuel cost savings and MPG efficiencies. The tests included a fully loaded trailer (80,000 lbs gross weight) and a demonstration route. The engine was baseline tested over the route in diesel-only operation and then tested in dual-fuel operation. For both modes of operation, mileage and fuel usage was logged. Demonstration I was a 350-mile route largely composed of highway driving. Demonstration II was a 98-mile route composed of highway driving and rural driving. 
Demonstration III was a 520-mile route largely composed of highway driving. Each test used the cost of diesel fuel as $\$ 3.90 /$ gallon and the cost of CNG as $\$ 2.06 /$ diesel gallon equivalent (DGE). Each test assumed the dual-fuel conversion kit cost $\$ 40,000$ with a $\$ 300 /$ year maintenance costs.

\subsection{WVU ERC}

WVU's ERC was used for the engine testing completed in this research. The laboratory is Title 40 Code of Federal Regulations (CFR) Part 1065 compliant with the ability to perform the EPA's required transient FTP and steady-state SET. The 2005 Mercedes OM-460LA and the 2005 Mack AC-460P were operated on a General Electric (GE) $800 \mathrm{hp}$ direct current (DC) engine dynamometer with the ability to provide and absorb power at speeds up to 3000 revolutions per minute (RPM). A diagram of the intake air and emissions sampling system can be found in Figure 25. Intake and dilution air are ducted into the laboratory from the outside through a high efficiency particulate air (HEPA) filter. Intake and dilution air are initially conditioned together with the ability to be cooled, dehumidified, heated, or humidified. Intake and dilution air are then split with dilution air sent to the constant volume sampling (CVS) tunnel and intake air sent through intake ducting to the engine. Intake air can be conditioned further by humidification. 


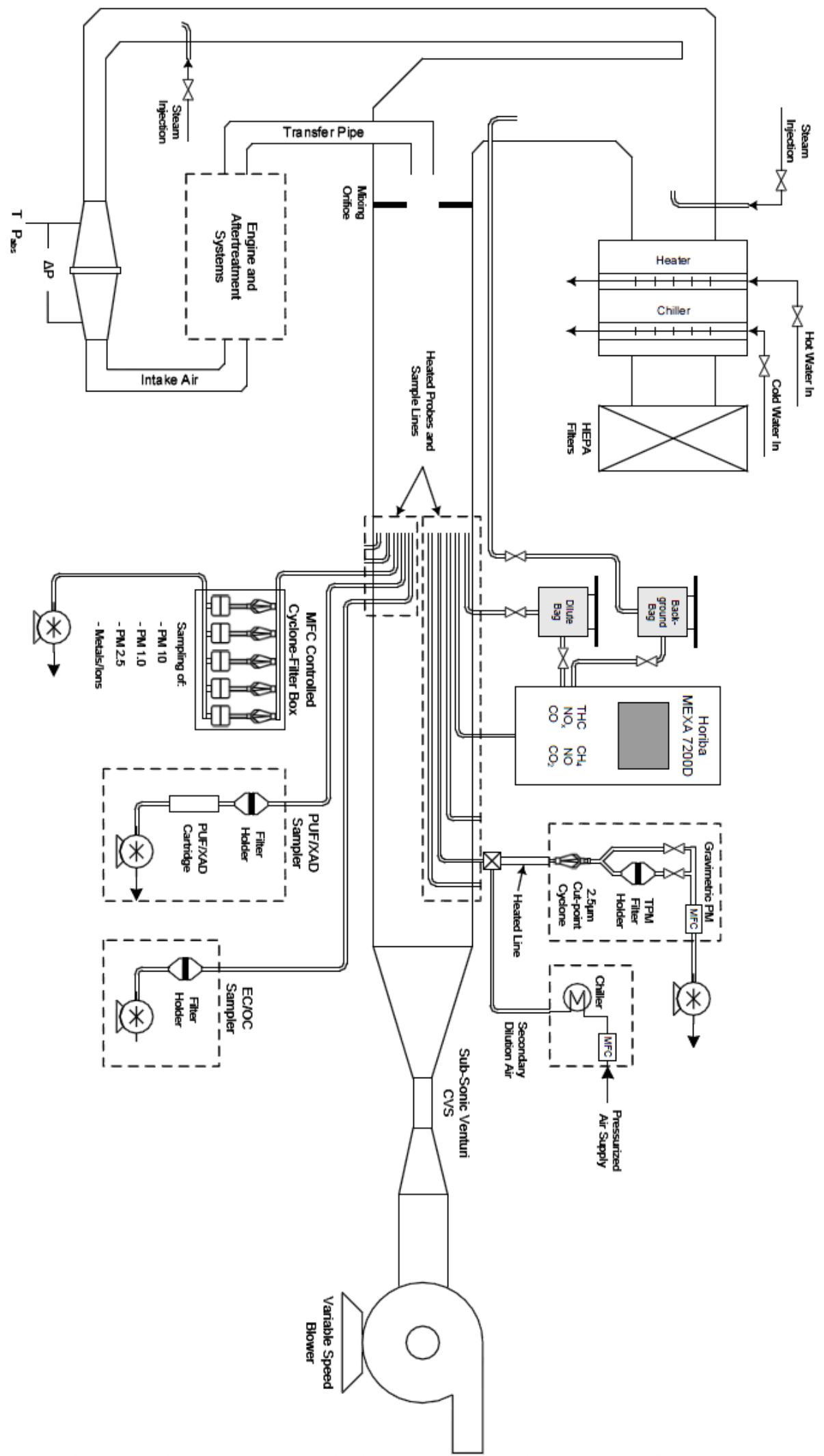

Figure 25 - WVU's ERC Title 40 CFR Part 1065 Emissions Sampling System 
Before intake air is inducted into the engine, it passes through a laminar flow element (LFE) to measure intake flow rate. Knowing the differential pressure across the flow obstruction, Bernoulli's Theorem and continuity provide the means to calculate the flow rate of the intake air. Dilution air is pulled through the CVS dilution tunnel by a variable speed blower. Exhaust from the engine is ducted to the CVS tunnel and mixed with the dilution air. A mixing orifice is used to increase mixing of exhaust with dilution air. The diluted exhaust flow stabilizes as it passes through the CVS tunnel and is then sampled. The remaining diluted exhaust gas flows through a sub-sonic venturi, where measurements similar to the LFE are taken to determine the diluted exhaust flow rate.

All gaseous emissions are measured by the Horiba Mexa-7200D Motor Exhaust Gas Analyzer. The gaseous emissions of interest where total $\mathrm{HCs}$ (THCs), $\mathrm{CH}_{4} \mathrm{HCs}(\mathrm{MHCs}), \mathrm{CO}, \mathrm{CO}_{2}, \mathrm{NOx}$, and NO. To measure these emissions, three primary analyzers within the exhaust gas analyzer were used including: flame ionization detection (FID), chemiluminescence detection (CLD), and a non-dispersive infrared analyzer (NDIR). Two FID's were used to measure THC emissions and MHC emissions separately. THC emissions are passed through a flame within the FID which is combusted by a $\mathrm{H}_{2}$ /helium (He) mixture and air. Ions are formed and their electrical charge is measured by an electrometer. The measured electrical charge is proportional to the $\mathrm{HC}$ emissions concentration in the exhaust gas sample [21]. To determine MHC emissions, a THC sample is passed through a non- $\mathrm{CH}_{4} \mathrm{HC}(\mathrm{NMHC})$ cutter (heated catalyst) which ideally removes all $\mathrm{HC}$ emissions except for MHC emissions. This sample is then passed through another FID to determine the amount of MHC emissions present in the exhaust. NMHC emissions are determined by subtracting $\mathrm{MHC}$ emissions from $\mathrm{THC}$ emissions. HC measurements are measured wet.

Two NDIR's were used to measure $\mathrm{CO}$ emissions and $\mathrm{CO}_{2}$ emissions separately. Within a NDIR, exhaust gases pass through a sample cell while a reference gas of known concentration occupies a reference cell. Infrared light is bandpass filtered to a specific frequency and passed through the sample and reference cells within the NDIR [22]. The reference cell does not absorb light due to the nitrogen composition within it. As light exits the sample cell, it is composed of less energy due to the absorption of light by the sample gas. The ratio of detected energy from both cells is related to the sample concentration [22]. Separate NDIR's are used to measure CO emissions and 
$\mathrm{CO}_{2}$ emissions due to different wavelength detections. $\mathrm{CO}$ emissions and $\mathrm{CO}_{2}$ emissions measurements are measured dry.

Two CLD's were used to measure $\mathrm{NO}$ and $\mathrm{NO}_{2}$ separately. When $\mathrm{NO}$ and $\mathrm{O}_{3}$ react, they produce chemiluminescence (light from a chemical reaction) [22]. This light is bandpass filtered to a specific frequency that a photomultiplier expects to see [22]. A photomultiplier has the ability to detect small quantities of light and produce a magnified signal which is proportional to the amount of $\mathrm{NO}$ emissions detected by the CLD. The CLD will not detect $\mathrm{NO}_{2}$ emissions. To measure NO emissions, a sample is passed through the CLD and reacted with $\mathrm{O}_{3}$ producing a signal proportional to the amount of $\mathrm{NO}$ present. $\mathrm{O}_{3}$ is produced by ultraviolet (UV) irradiation of $\mathrm{O}_{2}$ in a quartz tube [22]. To determine total $\mathrm{NOx}$ emissions, an $\mathrm{NO}_{2}$ to $\mathrm{NO}$ converter must be used. An $\mathrm{NO}_{2}$ to $\mathrm{NO}$ converter is a catalyst which converts $\mathrm{NO}_{2}$ to $\mathrm{NO}$. The sample is passed through the converter and through another CLD which determines total NOx emissions within the sample. To determine $\mathrm{NO}_{2}$ emissions in the sample, $\mathrm{NO}$ emissions are subtracted from $\mathrm{NOx}$ emissions. NO emissions are measured dry while total NOx emissions are measured wet to benefit the $\mathrm{NO}_{2}$ to $\mathrm{NO}$ converter.

PM emissions are measured gravimetrically in a Class 1000 climate controlled clean room. PM is considered anything that is captured from an exhaust sample on a filter at $47^{\circ} \mathrm{C} \pm 5^{\circ} \mathrm{C}$. A exhaust sample is drawn from the CVS tunnel and transported by a heated line. Flowrate controlled secondary dilution air is dehumidified and mixed with the primary sample heated line. The sample is then passed through a cyclone which removes $2.5 \mu \mathrm{m}$ and bigger particles at a $50 \%$ efficiency. The cyclone is $99 \%$ efficient at removing $1 \mu \mathrm{m}$ and bigger particles. Particles of this size are not considered produced by the engine so they are removed. These particles may come from buildup on the CVS tunnel walls or the exhaust ducting walls from previous tests. The sample is then passed over a $47 \mathrm{~mm}$ filter which is to be weighed gravimetrically. The sample is diluted with secondary dilution air so filter face PM loading is not exceeded. Also, the sample is diluted to control filter face temperature and maintain filter face velocity.

A background bag is sampled prior to exhaust mixing in the CVS tunnel. At the end of every test this bag is evacuated through the Horiba Mexa to determine background emissions. To determine background PM, a test is completed by passing a continuous background sample over the filter face. These emissions are then subtracted from the emissions produced during the test. Similar 
to the background bag, a dilute bag is sampled during engine operation over the entire test cycle. At the end of the test the bag is evacuated through the Horiba Mexa to determine cycle-averaged emissions. This is completed for a comparison to the cycle average emissions and is not required by the CFR.

Matheson Chemically Pure $\mathrm{CH}_{4}$ was stored outside of the ERC with transfer lines bringing the fuel to the engine. The flowrate of natural gas was measured by an Endress Hauser Gas Flow Meter (Model 8DFO8-AG15AAAABAON). Diesel fuel was stored in a 33 gal drum. Diesel fuel was conditioned by an AVL Temperature Control Unit (Model 753CH). The flowrate of diesel fuel was measured by an AVL Fuel Mass Flow Meter (Model 7351CST) . Both flow meters operated on the Coriolis Principle. Within a coriolis meter is u-shaped tubing which begins to oscillate when excited by an outside force. Without fluid flow the tubing oscillates uniformly which is picked up by sensors located at the inlet and outlet of the tubing. As fluid flows through the tubing, the inlet and outlet oscillations change at different phase rates. The magnitude of the oscillations is proportional to volume flowrate of the fluid through the meter. The frequency of the oscillations is proportional to the density of the fluid flowing through the meter.

\subsection{Dual-Fuel Conversion Kit}

The purpose of the dual-fuel conversion kit is to operate an OEM heavy-duty diesel engine partially on an alternative fuel source to ideally reduce emissions and save the operator fuel expenses. The kit includes a sequential port CNG injection rail, a dual-fuel ECU, a CNG storage system, knock sensors, and a filler arm. The sequential port CNG injection rail (Figure 26) is outfitted with two CNG injectors per cylinder capable of meeting the fueling requirements of the engine. The injection rail is placed in between the existing intake manifold and cylinder head with the injector nozzles flowing towards the intake valves as can be observed in Figure 27. The rail is outfitted with temperature/pressure sensors for input into the dual-fuel ECU. 


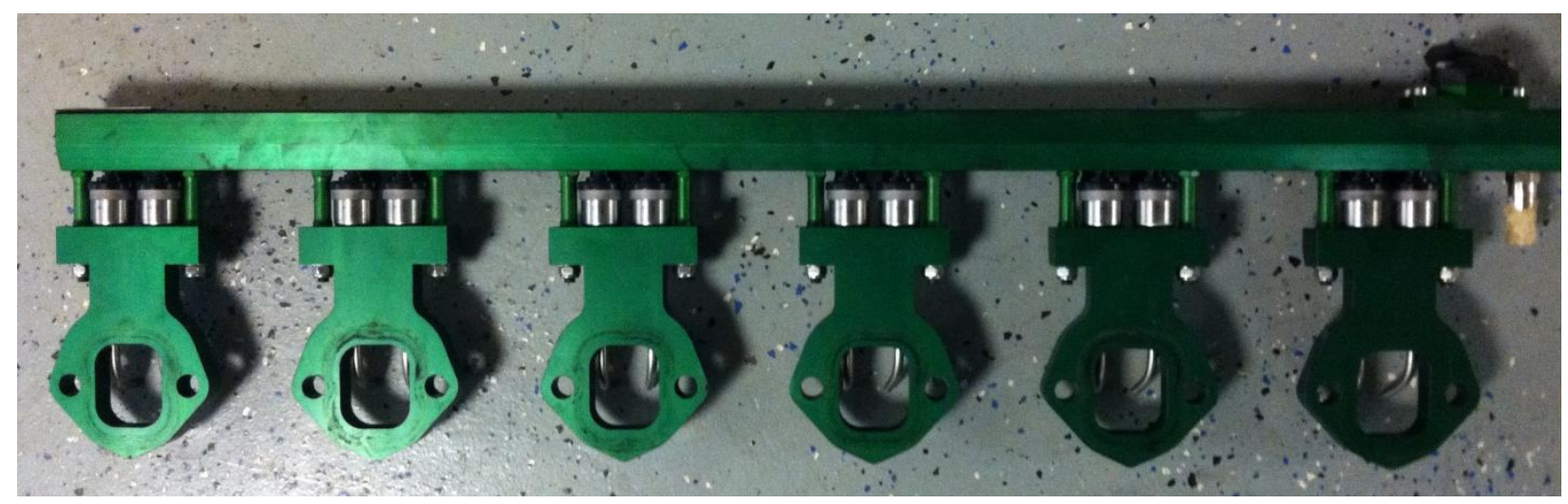

Figure 26 - CNG Injection Rail

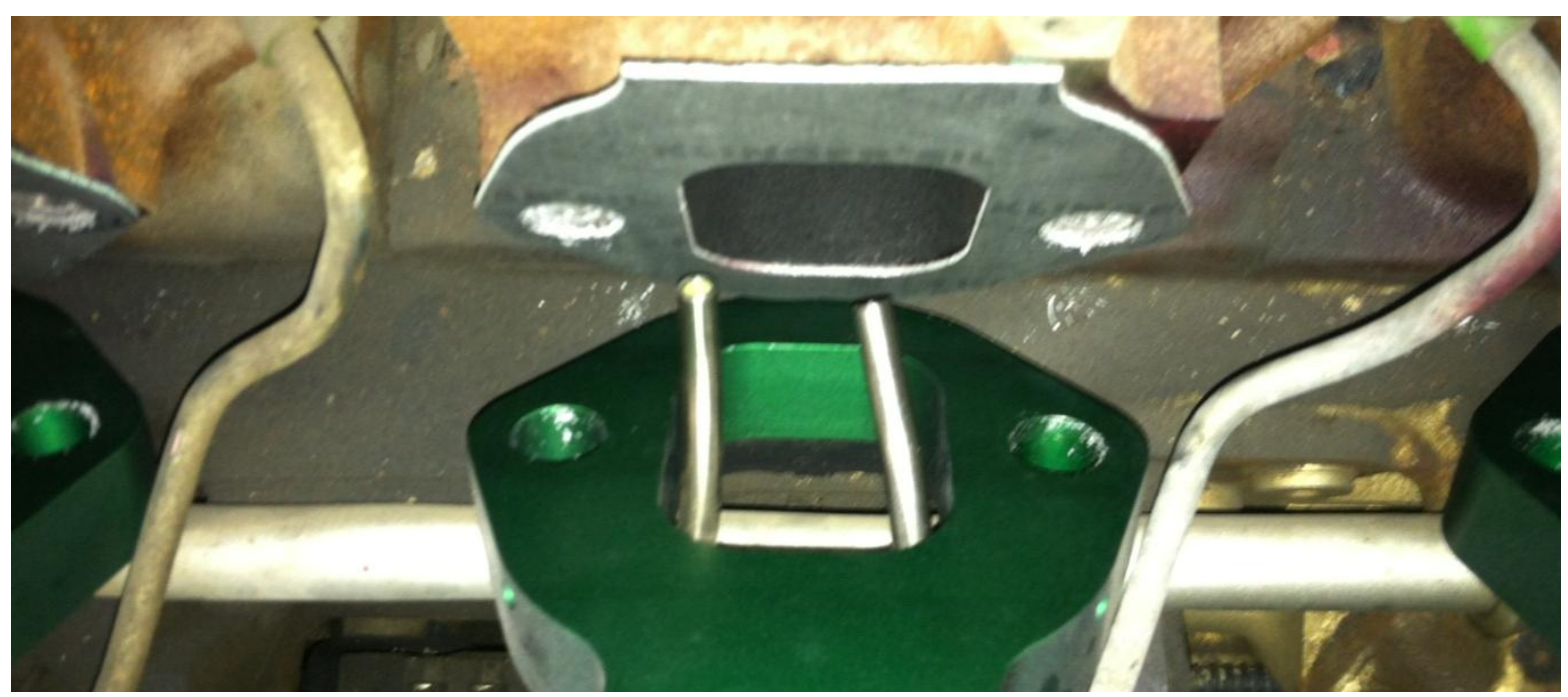

Figure 27 - Injection Rail Placement

Gaskets are provided with the kit to seal the intake manifold to injection rail surface while OEM intake manifold gaskets seal the cylinder head to injection rail surface. Tank mounting and configurations come in multiple different options with the largest holding 75 DGE of CNG and adding $1985 \mathrm{lbs}$ to the truck when full. The filler arm contains a variable CNG pressure regulator (up to 125 psi to the injection rail), NGV-1 fill nozzle (slow fill), NGV-2 fill nozzle (fast fill), manual and electronic safety shut-off valves, a high pressure filler gauge, a back flow prevention valve, and a coalescing filter. All plumbing and accessories meets the National Fire Protection Agency (NFPA) vehicular gaseous fuel systems code (NFPA-52). Two knock sensors are placed on the side of the engine block, one measuring audible knock from the rearward three cylinders $(6,5$, and 4$)$ and the other measuring audible knock from the forward three cylinders $(3,2$, and $1)$. 
The dual-fuel ECU determines the substitution parameters that allow the engine to operate in duel fuel mode. The dual-fuel ECU is connected between the OEM ECU and the wiring providing signals to the diesel fuel injectors. The dual-fuel ECU intercepts the OEM ECU diesel fuel injection length signal, reduces it, and injects an equivalent amount of CNG for combustion. This approach does not require access to the OEM ECU preserving its control over all other engine operating factors including exhaust gas recirculation (EGR) and variable geometry turbocharger (VGT). As the intake valve opens and air is inducted into the cylinder, the CNG injector is opened allowing the predetermined amount of CNG to flow into the cylinder. Considering the diesel injection signal will be provided by the OEM ECU after CNG is injected into the cylinder, the amount of $\mathrm{CNG}$ is determined from the interception of the previously firing cylinder in the ignition sequence.

Due to the high autoignition characteristics of $\mathrm{CNG}$, diesel fuel injection is still needed to operate the engine. The substitution maps are proprietary information but manifold air pressure (MAP), manifold air temperature (MAT), and CNG temperature determine the amount of substitution. If audible knocking occurs, the substitution is immediately reduced. If the dual-fuel

kit determines system malfunctions or the user decides they want to operate in diesel-only operation, the dual-fuel ECU will hibernate without altering the diesel injection signals. The cost of the dual-fuel conversion kit is approximately $\$ 40,000$ with variations due to accessories and configurations.

\subsection{In-Cylinder Pressure Analysis and Calculations}

In-cylinder pressure was measured on a 2005 Mercedes OM-460LA engine. This engine was chosen for in-cylinder pressure analysis due to its use of one cylinder head per cylinder and its constant throttle valve (used for engine braking) location. A bronze sleeve was press fitted into the constant throttle valve guide where the pressure transducer would be inserted. The pressure transducer was then inserted into the bronze guide giving direct access to in-cylinder pressure within the combustion chamber. A Kistler $6125 \mathrm{C}$ dynamic pressure transducer was used to measure in-cylinder pressure. Due to the piezoelectric effect, when a dynamic pressure is exerted on the sensor it outputs a charge that is amplified by a Kistler 5010 charge amplifier to a usable voltage signal. This voltage signal is then processed by the data acquisition (DAQ) system. 
Intake and exhaust temperatures are measured in the intake and exhaust runners respectively. A BEI encoder was mounted to a serpentine pulley driven by the crankshaft measuring engine speed and crankshaft location. The DAQ software developed by Nuszkowski for his dissertation was utilized [20]. The following discussion describes the methods Nuszkowski's program incorporates. The DAQ utilized a $2300 \mathrm{~Hz}$ low pass filter to reduce high frequency combustion noise. The dynamic pressure measured in the cylinder has to be referenced to an actual pressure to determine the absolute pressure in the cylinder. This was done by assuming a constant polytropic process throughout the compression and expansion processes. To determine the appropriate correction pressure to relate the actual pressure signal too, the MAP was used. The polytropic coefficient was adjusted to relate the pressure signal when the intake valve closes to the actual MAP. To further analyze the combustion process, the heat release rate in the combustion chamber must be calculated. Using the first law of thermodynamics and assuming an ideal gas, uniform temperature, and uniform pressure the net heat release rate is given in Equation 12 [20].

$\left(\frac{d Q}{d \theta}\right)_{n e t}=\left(\frac{\gamma}{\gamma-1}\right) P \frac{d V}{d \theta}+\left(\frac{1}{\gamma-1}\right) V \frac{d P}{d \theta}$

Equation 12

$\mathrm{Q}$ is the heat released, $\gamma$ is the specific heat ratio, $\mathrm{P}$ is the pressure, $\mathrm{V}$ is the cylinder volume, and $\theta$ is the crank angle location. When heat transfer to the walls is considered, the net heat release rate becomes the gross heat release as given in Equation 13 [20].

$\left(\frac{d Q}{d \theta}\right)_{n e t}=\left(\frac{\gamma}{\gamma-1}\right) P \frac{d V}{d \theta}+\left(\frac{1}{\gamma-1}\right) V \frac{d P}{d \theta}+\left(\frac{d Q}{d \theta}\right)_{\text {wall }}$

Equation 13

A graph of a typical heat release rate can be observed in Figure 28. The start of combustion (SOC) is considered the first measurable quantity of combustion in the cylinder. The end of combustion (EOC) is considered the point in which the maximum total heat was released. The total gross heat released during a cycle of engine operation is the summation of the heat released during each step in crank angle from SOC to EOC found by Equation 14 [20].

$Q_{\text {gross }}=\sum_{S O C}^{E O C} d Q_{\text {gross }}$

Equation 14

Insight into ignition delay was found by intercepting the diesel injection signal. The dual-fuel ECU had the ability to relate the crank angle in which the diesel injection signal was sent to the diesel injector. Due to time lag between the signal and the injector opening, this value could not 
be used to determine actual injection delay but could offer insight. To determine the mean incylinder gas temperature involves making the ideal gas assumption and knowing the properties of the gas at two states. The result is Equation 15 which uses the intake valve closure as one state and the cylinder conditions at any crank angle as the other state.

$T_{\theta}=\frac{P_{\theta} V_{\theta} T_{I V C}}{P_{I V C} V_{I V C}}$

Equation 15

$\mathrm{P}_{\theta}$ represents the in-cylinder pressure at any crank angle, $\mathrm{V}_{\theta}$ represents the cylinder volume at any crank angle, $\mathrm{T}_{\mathrm{IVC}}$ represents the mean in-cylinder gas temperature at intake valve closure, $\mathrm{P}_{\mathrm{IVC}}$ represents the in-cylinder pressure at intake valve closure, and $\mathrm{V}_{\text {IVC }}$ represents the cylinder volume at intake valve closure.

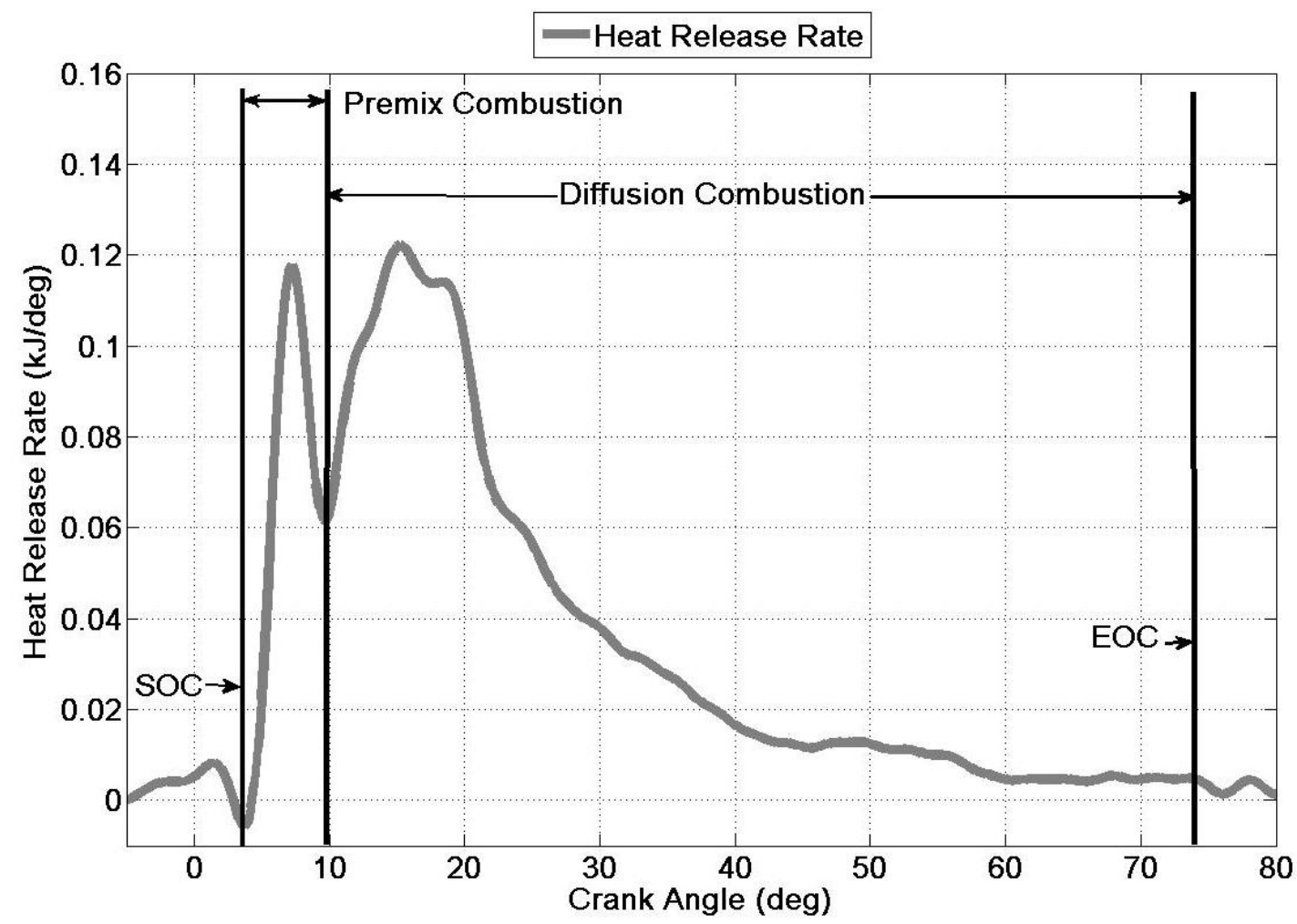

Figure 28 - Heat Release Rate Description

To determine how efficiently the energy of the fuel was converted into power output of the engine, the thermal efficiency was calculated by Equation 16 where $\dot{m}_{\text {fuel }}$ represents the mass flowrate of fuel and LHV represents the lower heating value (LHV) of the fuel [20].

$\eta_{\text {therm }}=\frac{\text { Power }}{\dot{m}_{\text {fuel }}(L H V)}$

Equation 16 
To determine if the in-cylinder pressure analysis was yielding correct results, the volumetric intake air flow and mass flow of the fuel were calculated and compared to the laboratory values. The volumetric air flow was calculated using Equation 17 where $\eta_{\mathrm{v}}$ is the volumetric efficiency $P_{\text {std }}$ is the standard pressure, $T_{\text {std }}$ is the standard temperature, and $V_{d}$ is the displacement volume of the engine [20]. The mass flow of fuel was calculated using Equation 18 [20].

$\dot{V}=\frac{\eta_{v}(\text { Engine Speed }) V_{d}}{2}\left(\frac{M A P}{P_{\text {std }}}\right)\left(\frac{T_{\text {std }}}{M A T}\right)$

Equation 17

$\dot{m}_{\text {fuel }}=\frac{Q_{\text {gross }}(\text { Engine Speed })}{2(\text { LHV })}$

Equation 18

A linear regression passing through the origin was completed for the volumetric air flow and mass flow of fuel for calculated and laboratory based values for four load points and a single engine speed. The results can be found in Figure 29, Figure 30, Figure 31, and Figure 32.

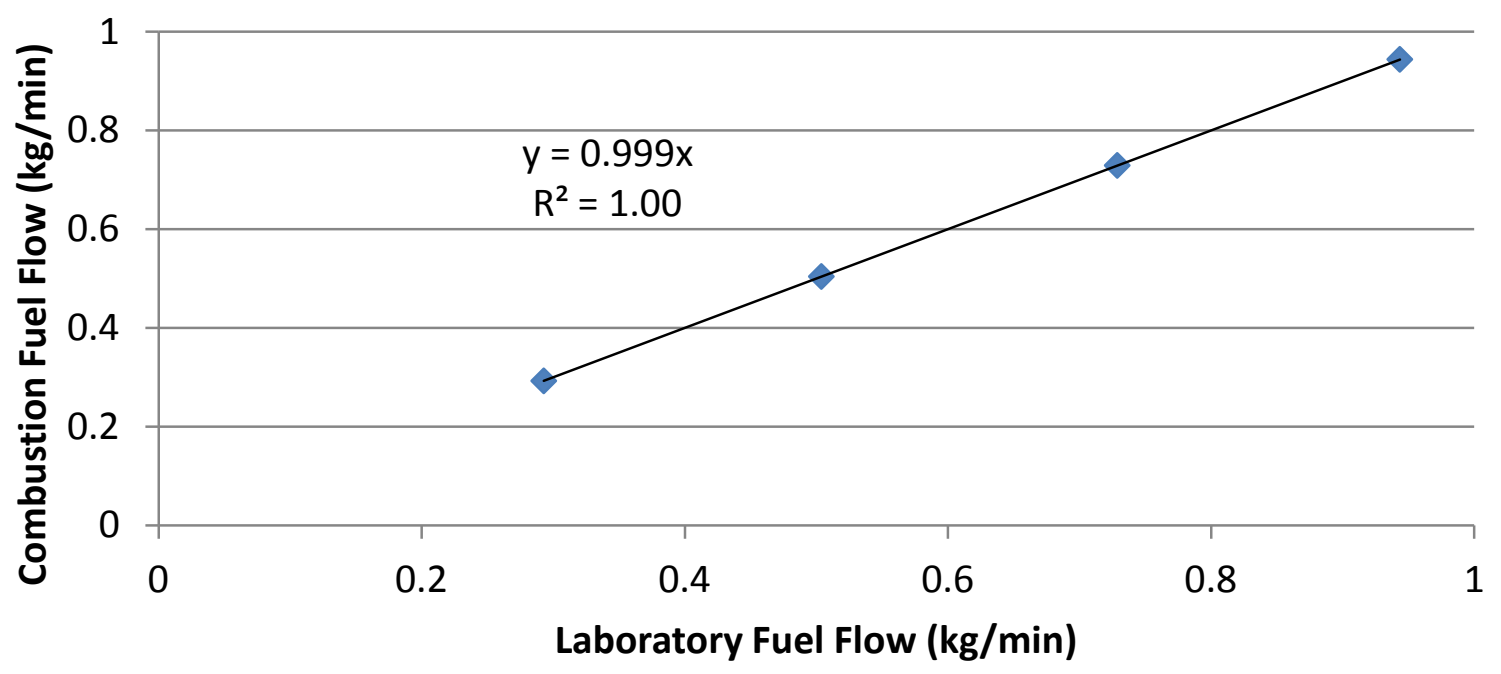

Figure 29 - Fuel Flow Linear Regression for 2005 Mercedes OM-460LA Steady-State Diesel-Only Operation 




Figure 30 - Fuel Flow Linear Regression for 2005 Mercedes OM-460LA Steady-State Dual-Fuel Operation

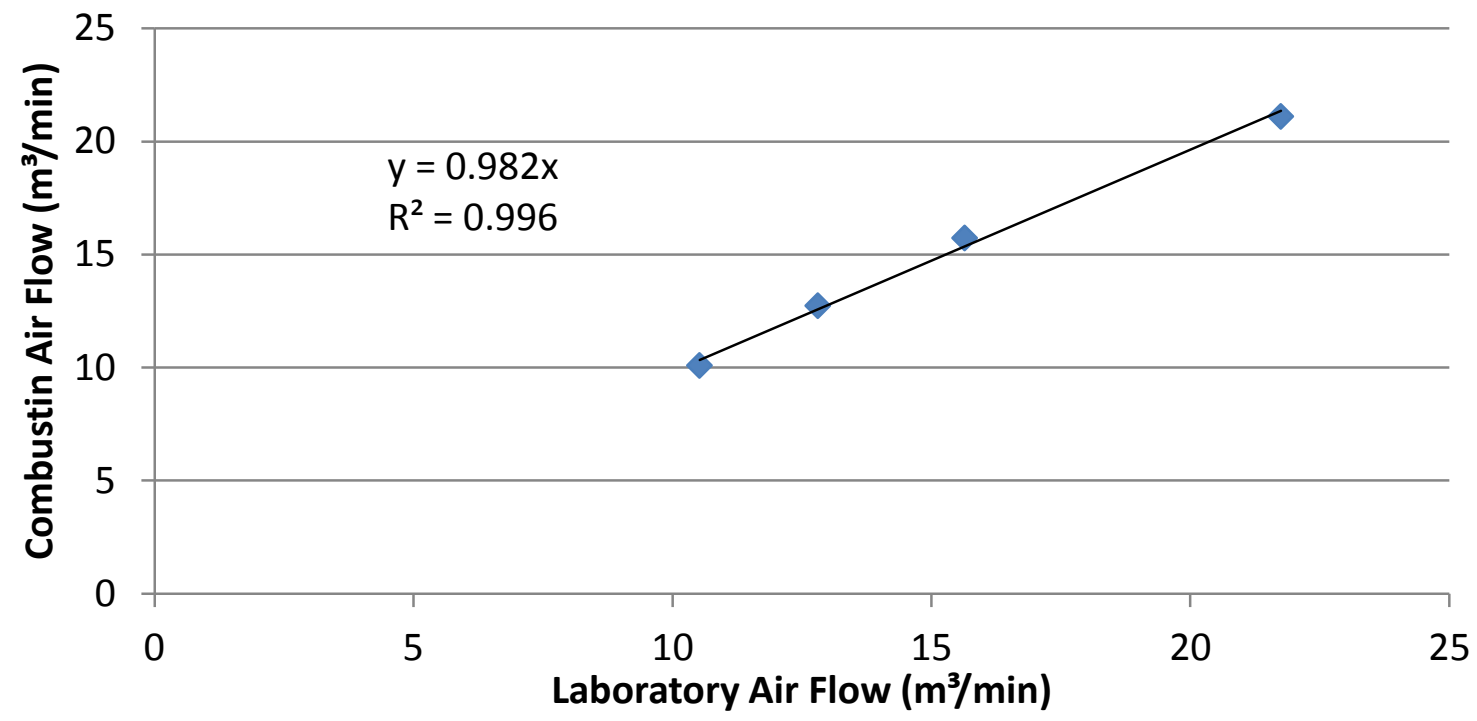

Figure 31 - Intake Air Flow Linear Regression for 2005 Mercedes OM-460LA Steady-State Diesel-Only Operation 


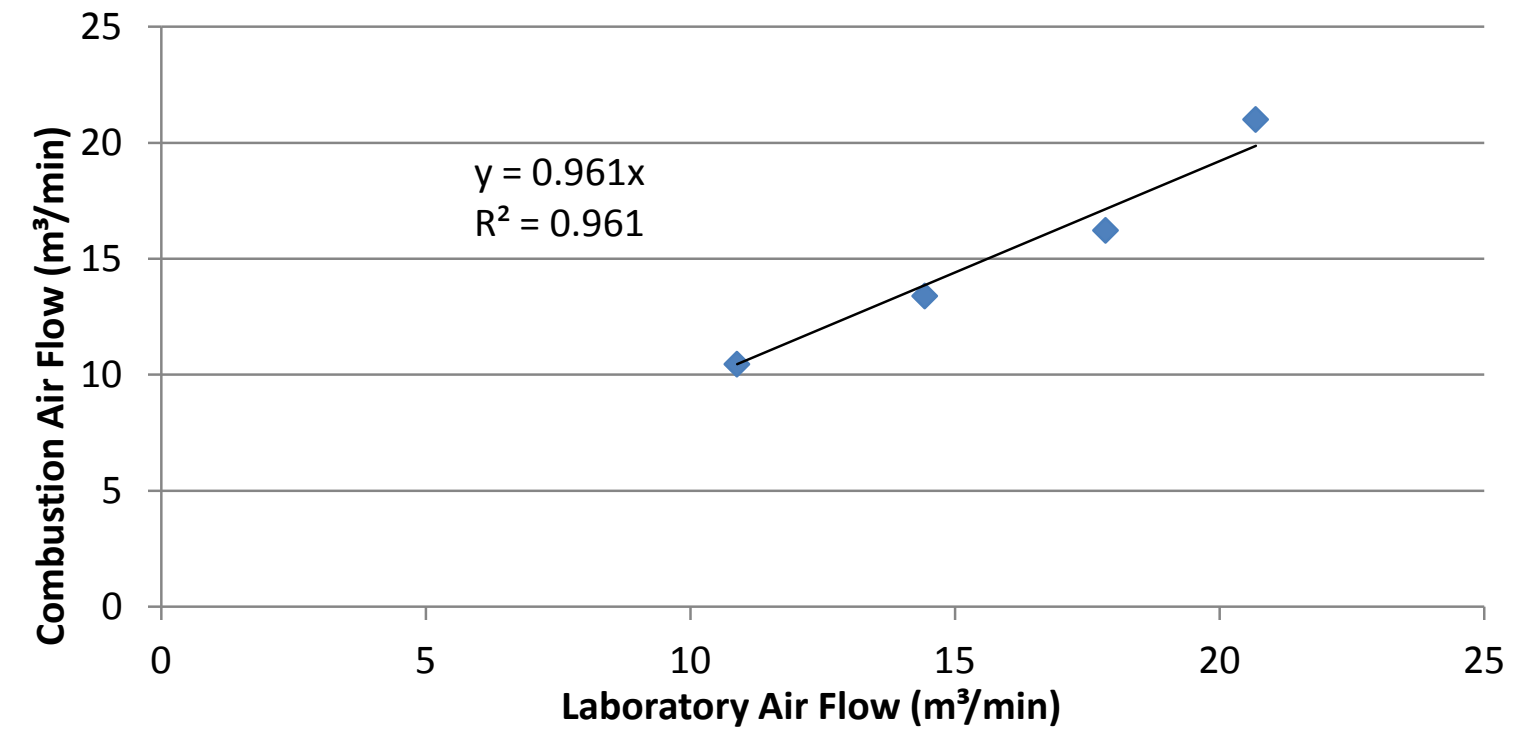

Figure 32 - Intake Air Flow Linear Regression for 2005 Mercedes OM-460LA Steady-State Dual-Fuel Operation

For diesel-only operation, $\mathrm{R}^{2}$ values were greater than 0.99 for mass fuel flow and volumetric air flow. For dual-fuel operation, the $\mathrm{R}^{2}$ value was greater than 0.96 for volumetric air flow. The $\mathrm{R}^{2}$ value dropped to 0.94 for mass fuel flow because of the combustion efficiency experienced during dual-fuel operation. Dual-fuel volumetric intake flow regression values were worse than diesel-only regression values because of CNG injection into the intake airstream. These values were considered acceptable for this research. To determine how efficiently the engine was utilizing the fuel supplied to produce power output, the brake specific fuel consumption (BSFC) was calculated using Equation 19.

$B S F C=\frac{\dot{m}_{\text {fuel }}}{\text { Power }}$

Equation 19

To determine how well the fuel was being utilized for combustion energy release, the combustion efficiency was calculated using Equation 20.

$\eta_{\text {comb }}=\frac{Q_{\text {gross }}}{m_{\text {fuel }}(L H V)}$ 


\section{Results and Discussions}

The following results compare diesel-only operation and dual-fuel operation on a heavy-duty diesel engine with a dual-fuel conversion kit designed with the intent to be mass produced and operated in transient over the road conditions. The 2005 Mercedes OM-460LA engine was used to collect in-cylinder pressure data and resultant emissions for steady-state SETs. This data offers insight and comparison between dual-fuel operation and diesel-only operation combustion characteristics and how they affect emissions. The 2005 Mack AC-460P engine was used to collect emissions over transient FTPs and steady-state SETs. The work completed on this engine was used to certify the dual-fuel conversion kit with the EPA's Clean Alternative Fuel Conversion Program. An outline will be given on the certification testing completed. Diesel and CNG consumption were measured for in-use demonstrations and the completion of a cost and MPG efficiency analysis. The repeatability results from RPT tests, daily operating conditions, and repeated transient FTPs are presented and explained. Standard deviation error bars are included on all emissions figures to show statistical significance of comparisons.

\subsection{Combustion and Exhaust Emissions}

Combustion characteristics, heat release rate curves, and the formation of emissions were determined for steady-state conditions from the analysis of the in-cylinder pressure data and measured emissions data from the 2005 Mercedes OM-460LA engine. In-cylinder pressure data and emissions for diesel-only operation and dual-fuel operation were collected at a single engine speed and four load points ranging from light to heavy. PM emissions were continuously collected over an entire steady-state SET cycle and then gravimetrically analyzed. Combustion and emission testing was completed with Guttman Oil diesel fuel and Matheson Chemically Pure $\mathrm{CH}_{4}$. For the following calculations the lower heating values for diesel and $\mathrm{CNG}$ were 43,326 $\mathrm{kJ} / \mathrm{kg}$ and $50,050 \mathrm{~kJ} / \mathrm{kg}$ respectively.

\subsubsection{5\% Load Operation}

At light load conditions, the engine was operating at $1596 \mathrm{rpm}$ and $25 \%$ load resulting in an output torque of $307 \mathrm{ft}-1 \mathrm{~b}$ for diesel-only operation and dual-fuel operation. With a brake mean effective pressure (BMEP) of $204 \mathrm{kPa}$, the BSFC increased by $24.2 \%$ from $252 \mathrm{~g} / \mathrm{kW}$-h for diesel-only operation to $313 \mathrm{~g} / \mathrm{kW}$-h for dual-fuel operation. The brake thermal efficiency (BTE) decreased by $25.5 \%$ from $32.9 \%$ for diesel-only operation to $24.5 \%$ for dual-fuel operation indicating more fuel energy was needed to produce the same power output. The MAP increased 
by $4.48 \%$ from $134 \mathrm{kPa}$ for diesel-only operation to $140 \mathrm{kPa}$ for dual-fuel operation. This explains the deviation in in-cylinder pressure during the compression stroke observed in Figure 33.

In-cylinder pressure and heat release rates were compared between diesel-only operation and dual-fuel operation at 25.0\% load in Figure 33 and Figure 34. Diesel-only operation and dualfuel operation had start of injection (SOI) signals at 24.0 deg before top dead center (BTDC) which does not indicate when the actual start of injection occurs due to needle lift lag time within the injector. The same start of injection signal does indicate that the start of injection occurs at the same point allowing the ignition delay to be compared by an increase or delay in the start of combustion (SOC). The SOC was $3.50 \mathrm{deg}$ after top dead center (ATDC) for diesel-only operation and 4.50 deg ATDC for dual-fuel operation indicating an increase in ignition delay by $1 \mathrm{deg}$. The increase in ignition delay can be partly attributed to the decrease in temperature at the SOC by $2.68 \%$ from $857 \mathrm{~K}$ for diesel-only operation to $834 \mathrm{~K}$ for dual-fuel operation. The increase in ignition delay with an increase in temperature can be visualized by Equation 1. An increase in ignition delay can also be attributed to the increase in the fuel/air equivalence ratio by $31.6 \%$ from 0.326 for diesel-only operation to 0.429 for dual-fuel operation indicating a more fuel rich mixture. During dual-fuel operation it takes longer for the pilot diesel fuel to mix with air to combustible limits due to air displacement during CNG injection in the intake airstream. Also, the deterioration in oxidation of diesel by $\mathrm{CNG}$ present in the cylinder may have increased the ignition delay 


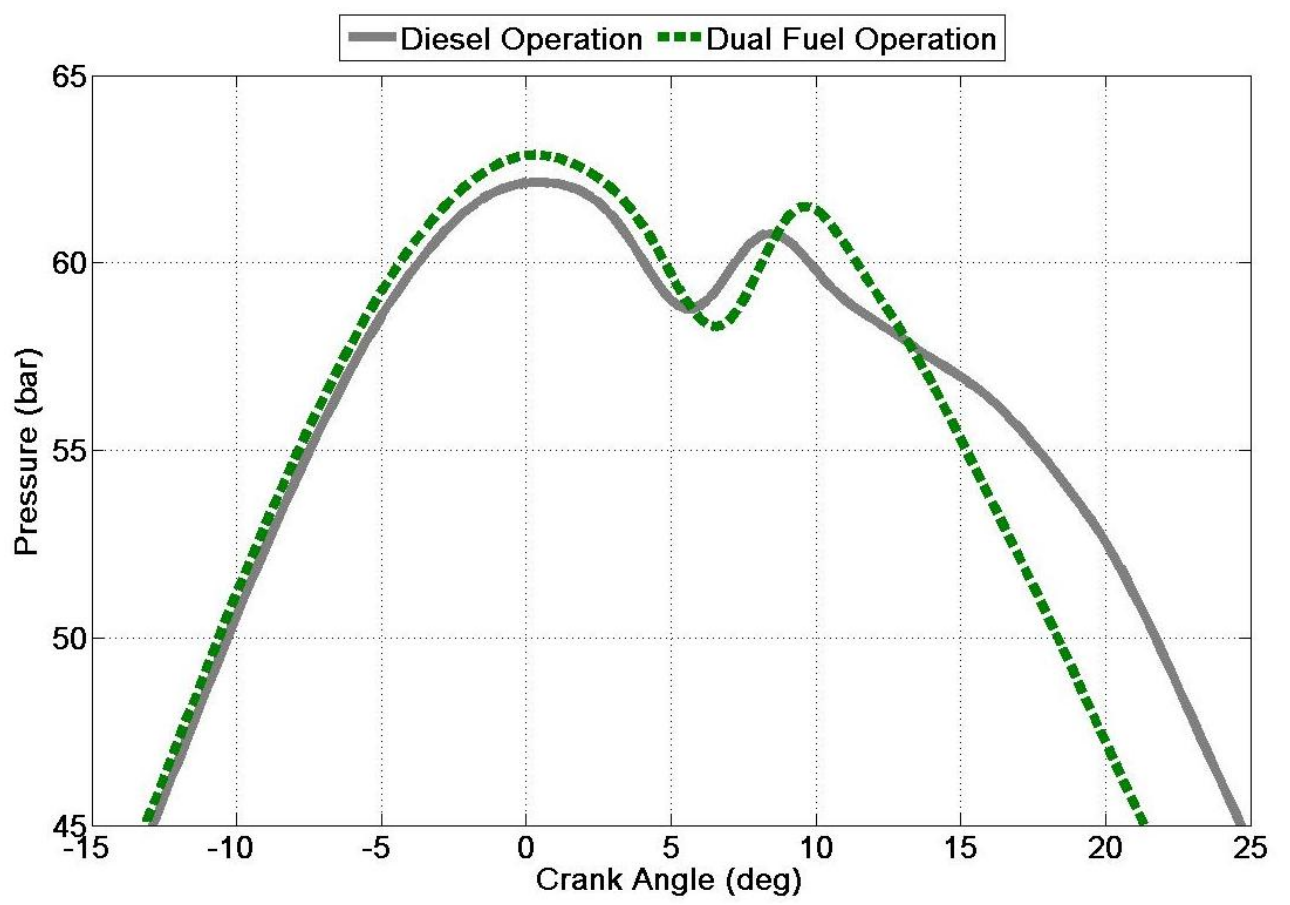

Figure 33 - In-Cylinder Pressure (25\% Load)

The amount of heat released during premixed combustion increased by $32.7 \%$ from $0.407 \mathrm{~kJ}$ for diesel-only operation to $0.540 \mathrm{~kJ}$ for dual-fuel operation. The increased amount of premixed energy released during dual-fuel operation indicates there was $\mathrm{CNG}$ entrained in the pilot diesel injection spray. As the pilot diesel injection is mixing with air to reach combustible limits, it is also mixing with $\mathrm{CNG}$ because of the $\mathrm{CNG} /$ air mixture within the cylinder. Due to the injection strategy of the dual-fuel ECU, the pilot diesel injection quantity is never reduced further than the quantity of diesel that would take place in premixed combustion during diesel-only operation. With this strategy, during dual-fuel operation the same amount of diesel fuel is injected in the pilot stage as would be injected during diesel-only operation to take place in premixed combustion. 


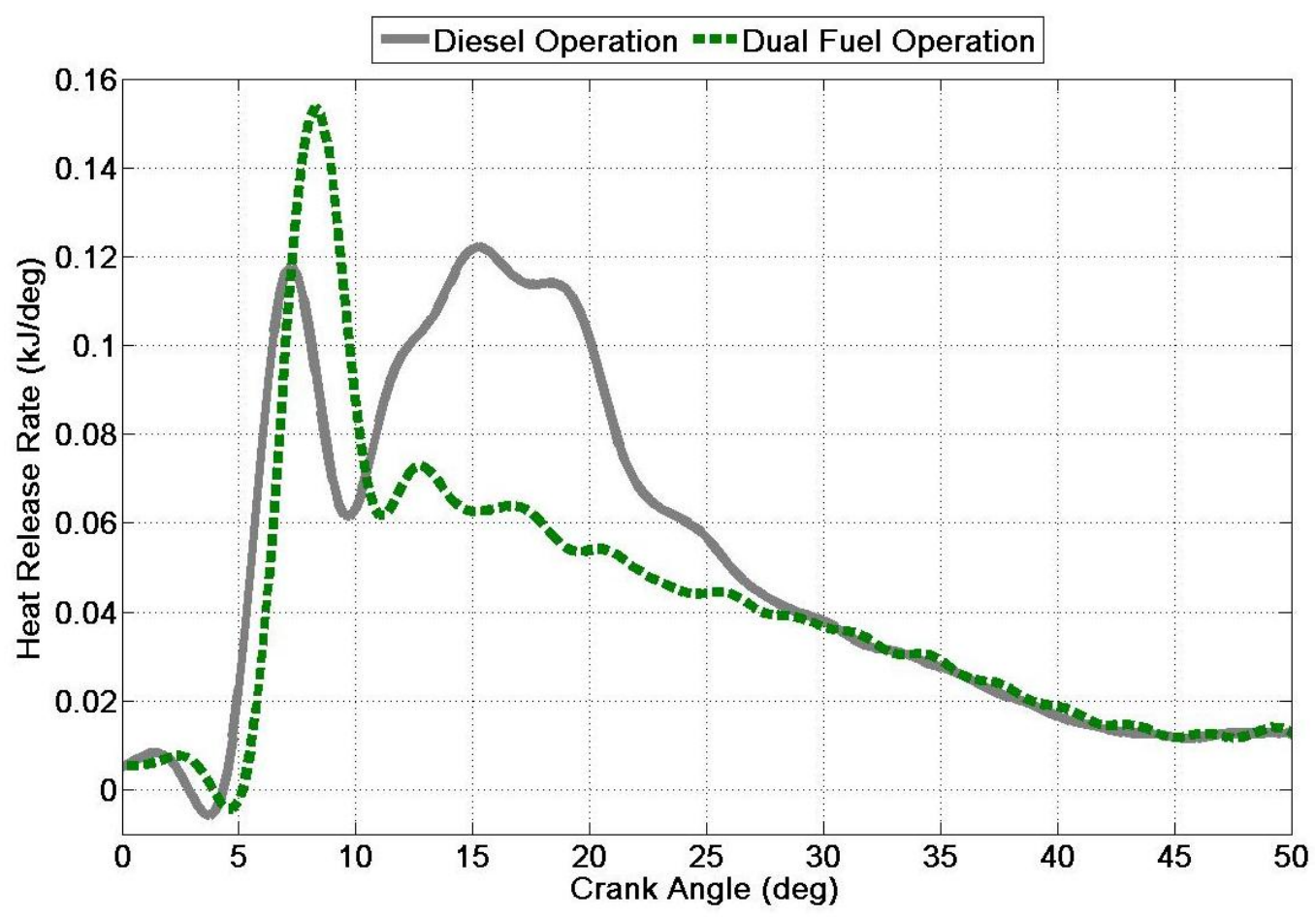

Figure 34 - Heat Release Rate (25\% Load)

The amount of heat released during diffusion combustion decreased by $29.3 \%$ from $2.15 \mathrm{~kJ}$ for diesel-only operation to $1.52 \mathrm{~kJ}$ for dual-fuel operation. The reduction in diffusion combustion energy release indicates that flame propagation during dual-fuel combustion did not reach the $\mathrm{CNG} /$ air mixture at locations away from the pilot diesel injection vicinity. The combustion efficiency decreased by $39.9 \%$ from $96.7 \%$ for diesel-only operation to $58.1 \%$ for dual-fuel operation also indicating that flame propagation did not reach the $\mathrm{CNG} /$ air mixture away from the pilot diesel vicinity.

\subsubsection{0\% Load Operation}

At medium/light load conditions the engine was operating at $1596 \mathrm{rpm}$ and $50 \%$ load resulting in an output torque of $613 \mathrm{ft}-\mathrm{lb}$ for diesel operation and dual-fuel operation. With a BMEP of 408 $\mathrm{kPa}$, the BSFC increased by $8.72 \%$ from $218 \mathrm{~g} / \mathrm{kW}$-h for diesel-only operation to $237 \mathrm{~g} / \mathrm{kW}$-h for dual-fuel operation. The BTE decreased by $13.9 \%$ from $38.2 \%$ for diesel-only operation to $32.9 \%$ for dual-fuel operation indicating more fuel energy was needed to produce the same power output. The MAP increased by $5.95 \%$ from $168 \mathrm{kPa}$ for diesel-only operation to $178 \mathrm{kPa}$ for dual-fuel operation. This explains the deviation in in-cylinder pressure during the compression stroke observed in Figure 35 
In-cylinder pressure and heat release rate are compared between diesel-only operation and dualfuel operation at 50\% load in Figure 35 and Figure 36. Diesel-only operation and dual-fuel operation had SOI signals at 26.0 deg BTDC. The SOC was $1.50 \mathrm{deg}$ BTDC for diesel-only operation and $0.750 \mathrm{deg}$ ATDC for dual-fuel operation indicating an increase in ignition delay by $2.25 \mathrm{deg}$. The increase in ignition delay can be attributed to the decrease in temperature at the start of combustion by $1.75 \%$ from $858 \mathrm{~K}$ for diesel-only operation to $843 \mathrm{~K}$ for dual-fuel operation. An increase in ignition delay can also be attributed to the increase in the fuel/air equivalence ratio by $4.56 \%$ from 0.461 for diesel-only operation to 0.482 for dual-fuel operation for reasons explained in Section 4.1.1 for 25\% load operation.

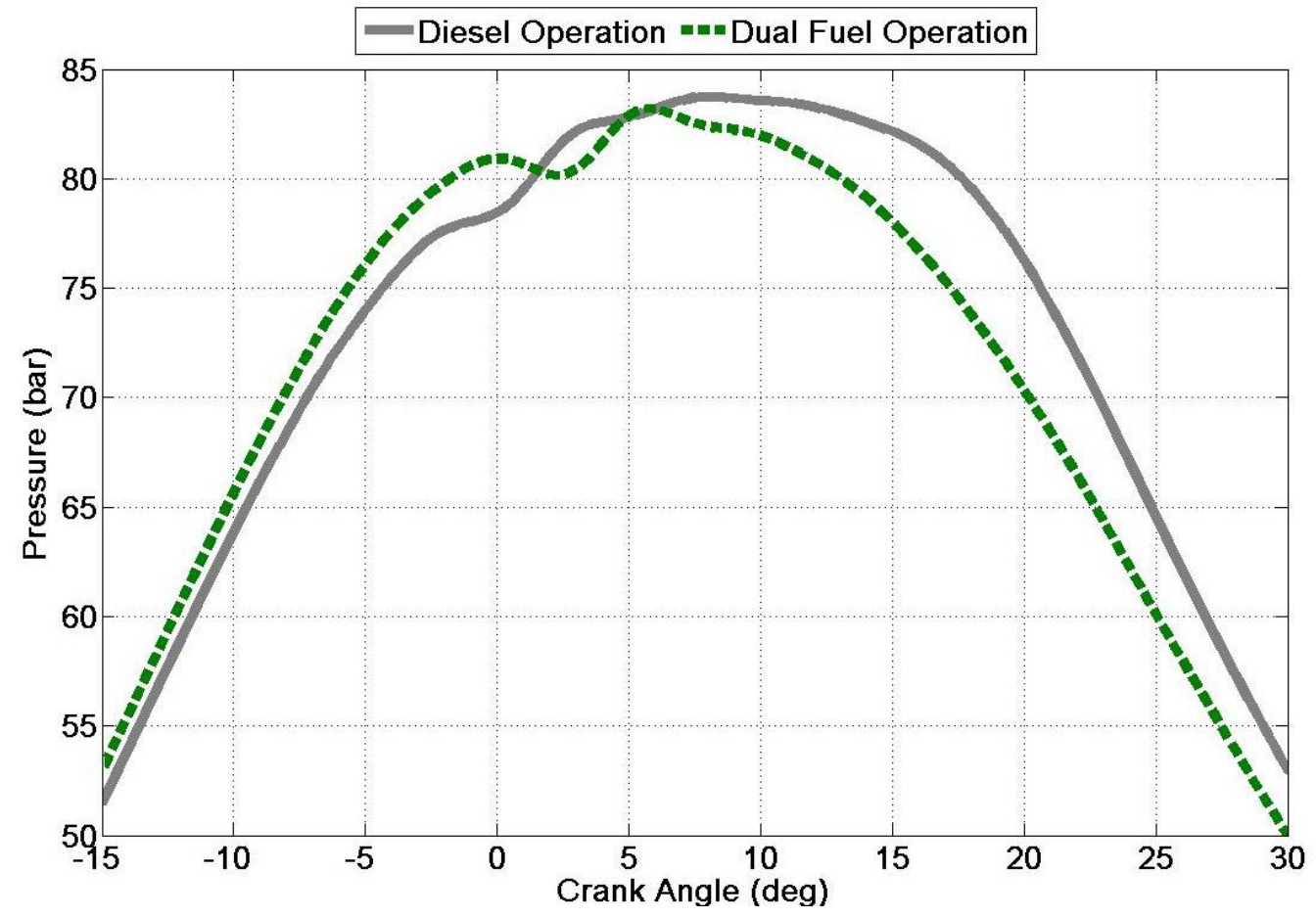

Figure 35 - In-Cylinder Pressure (50\% Load)

The amount of heat released during premixed combustion increased by $47.4 \%$ from $0.272 \mathrm{~kJ}$ for diesel-only operation to $0.401 \mathrm{~kJ}$ for dual-fuel operation. The increased amount of premixed energy released is due to the same reasons explained in Section 4.1 .1 for $25 \%$ load operation. The amount of heat released during diffusion combustion decreased by $11.1 \%$ from $4.23 \mathrm{~kJ}$ for diesel-only operation to $3.76 \mathrm{~kJ}$ for dual-fuel operation. The reduction in diffusion combustion energy is due to the same reasons outlined in Section 4.1 .1 for $25 \%$ load. The combustion 
efficiency decreased by $20.3 \%$ from $98.8 \%$ for diesel-only operation to $78.7 \%$ for dual-fuel operation due to the same reasons outlined in Section 4.1 .1 for $25 \%$ load.

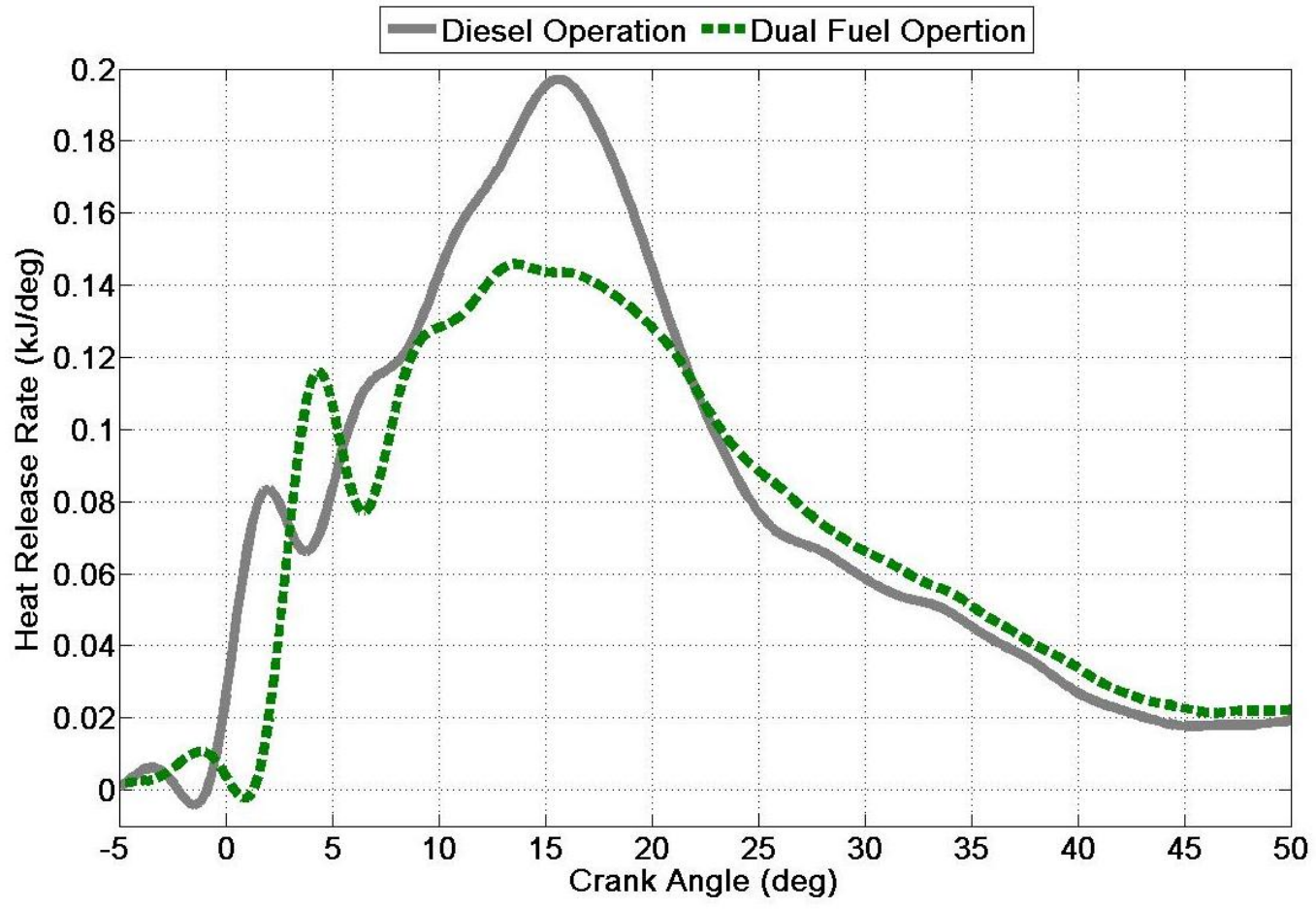

Figure 36 - Heat Release Rate (50\% Load)

\subsubsection{5\% Load Operation}

At medium/heavy load conditions the engine was operating at $1596 \mathrm{rpm}$ and $75 \%$ load resulting in an output torque of $920 \mathrm{ft}-\mathrm{lb}$ for diesel operation and dual-fuel operation. With a BMEP of 612 $\mathrm{kPa}$ the BSFC increased by $2.38 \%$ from $210 \mathrm{~g} / \mathrm{kW}$-h for diesel-only operation to $215 \mathrm{~g} / \mathrm{kW}$-h for dual-fuel operation. The BTE decreased by $6.81 \%$ from $39.6 \%$ for diesel-only operation to $36.9 \%$ for dual-fuel operation indicating more fuel energy was needed to produce the same power output. The MAP increased by $3.79 \%$ from $211 \mathrm{kPa}$ for diesel-only operation to $219 \mathrm{kPa}$ for dual-fuel operation This explains the deviation in in-cylinder pressure during the compression stroke observed in Figure 37.

In-cylinder pressure and heat release rate are compared between diesel-only operation and dualfuel operation at $75 \%$ load in Figure 37 and Figure 38. Diesel-only operation and dual-fuel operation had SOI signals at 28.0 deg BTDC. The SOC was 4.00 deg BTDC for diesel-only operation and $1.50 \mathrm{deg}$ BTDC for dual-fuel operation indicating an increase in ignition delay by 2.50 deg. The increase in ignition delay can be attributed to the decrease in temperature at the 
SOC by $.346 \%$ from $867 \mathrm{~K}$ for diesel-only operation to $864 \mathrm{~K}$ for dual-fuel operation. The increase in ignition delay due to other reasons is explained in Section 4.1 .1 for $25 \%$ load operation.

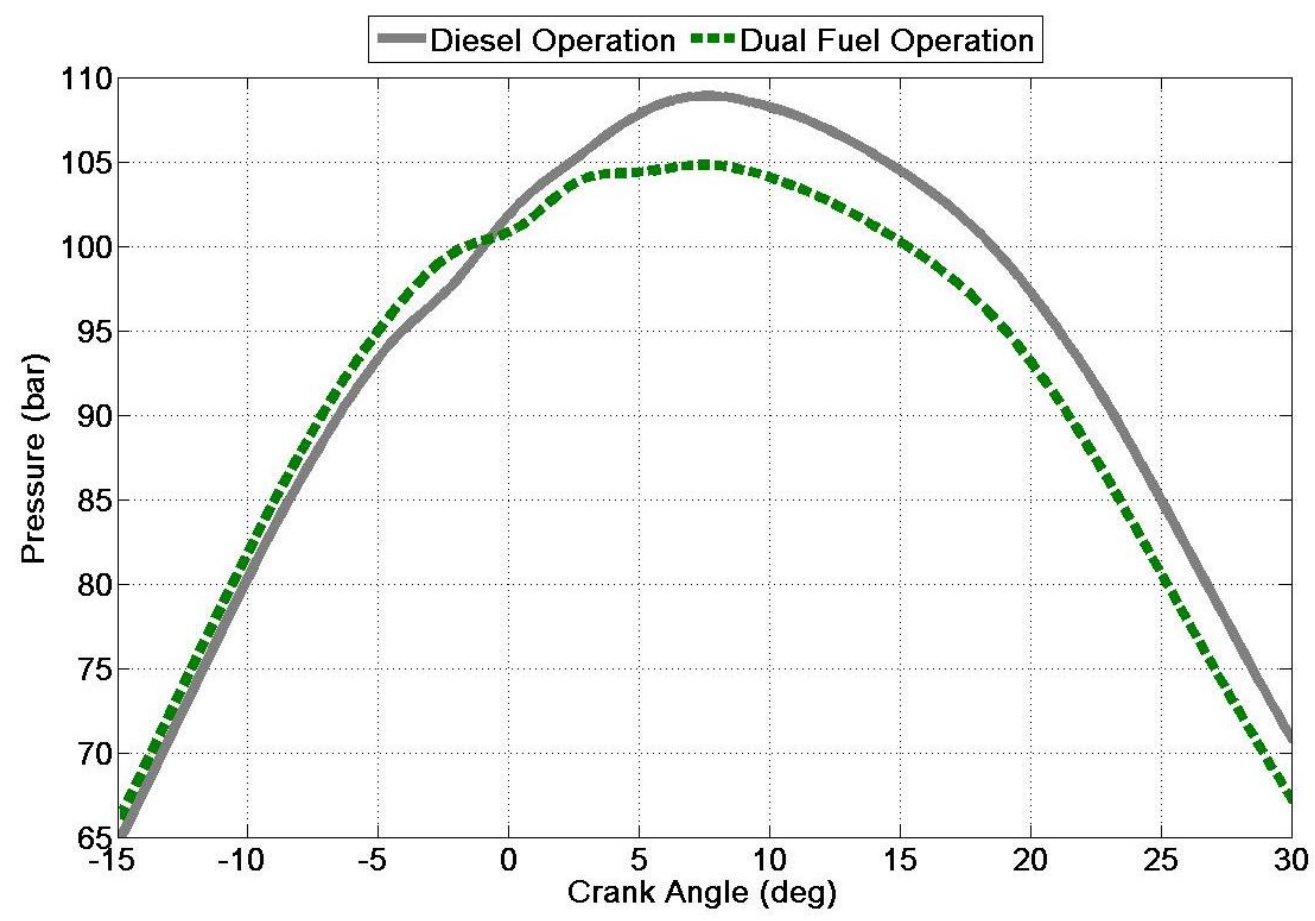

Figure 37 - In-Cylinder Pressure (75\% Load)

The amount of heat released during premixed combustion increased by $54.9 \%$ from $.175 \mathrm{~kJ}$ for diesel-only operation to $.271 \mathrm{~kJ}$ for dual-fuel operation. The increased amount of premixed energy released is due to the same reasons explained in Section 4.1 .1 for $25 \%$ load operation. The amount of heat released during diffusion combustion decreased by $8.19 \%$ from $6.35 \mathrm{~kJ}$ for diesel-only operation to $5.83 \mathrm{~kJ}$ for dual-fuel operation. The reduction in diffusion combustion energy release is due to the same reasons explained in Section 4.1.2 for 50\% load operation. The combustion efficiency decreased by $12.9 \%$ from $99.0 \%$ for diesel-only operation to $86.2 \%$ for dual-fuel operation due to the same reasons explained in Section 4.1 .2 for $50 \%$ load operation. 


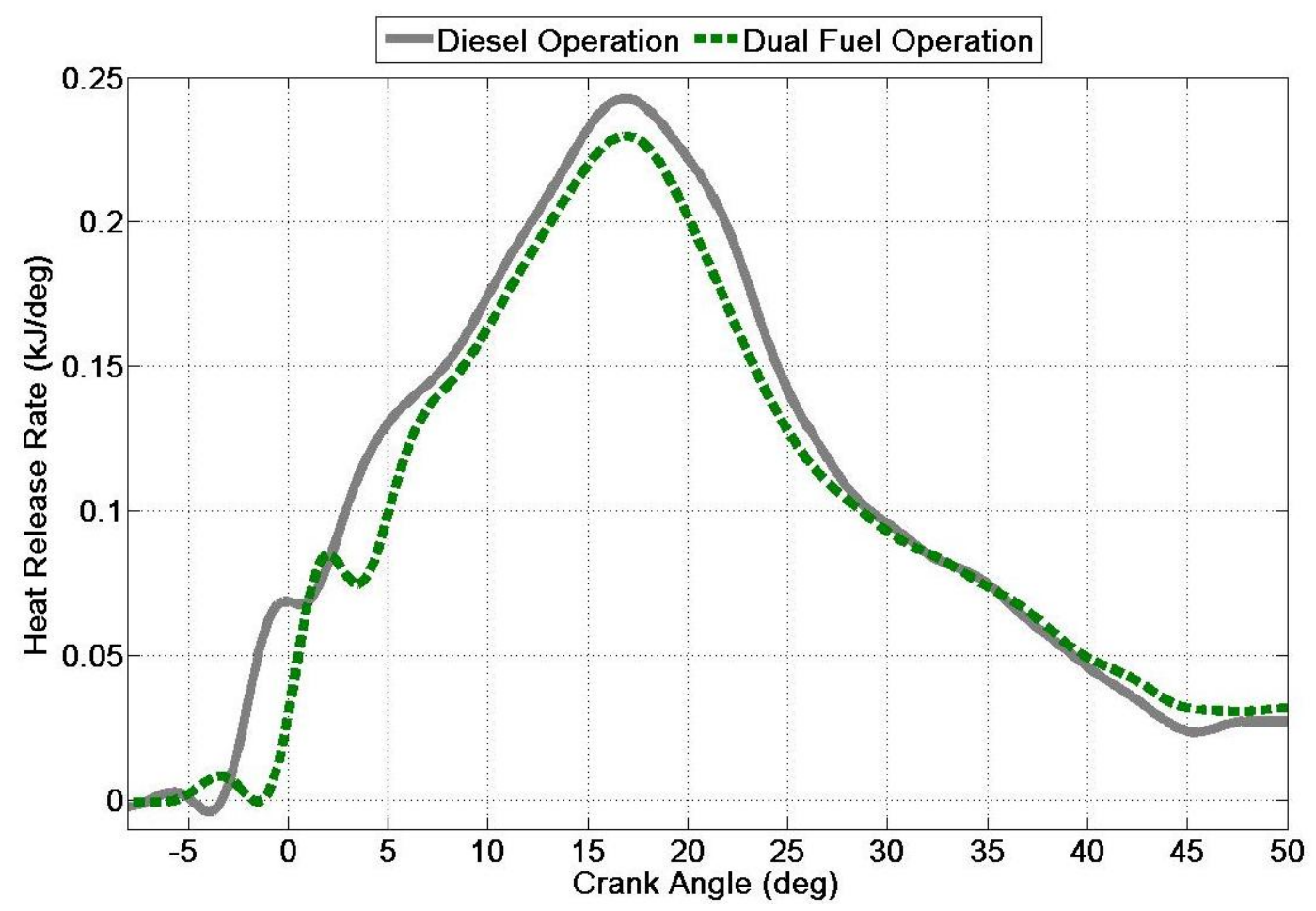

Figure 38 - Heat Release Rate (75\% Load)

\subsubsection{0\% Load Operation}

At heavy load conditions, the engine was operating at $1596 \mathrm{rpm}$ and $100 \%$ load resulting in an output torque of $1238 \mathrm{ft}-1 \mathrm{~b}$ for diesel operation and dual-fuel operation. With a BMEP of 824 $\mathrm{kPa}$, the BSFC increased by $0.495 \%$ from $202 \mathrm{~g} / \mathrm{kW}$-h for diesel-only operation to $203 \mathrm{~g} / \mathrm{kW}-\mathrm{h}$ for dual-fuel operation. The BTE decreased by $4.37 \%$ from $41.2 \%$ for diesel-only operation to $39.4 \%$ for dual-fuel operation indicating more fuel energy was needed to produce the same power output. The MAP increased by $1.58 \%$ from $252 \mathrm{kPa}$ for diesel-only operation to $256 \mathrm{kPa}$ for dual-fuel operation.

In-cylinder pressure and heat release rate are compared between diesel-only operation and dualfuel operation at $100 \%$ load in Figure 39 and Figure 40. Diesel-only operation and dual-fuel operation had SOI signals at 30.0 deg BTDC. The SOC was 6.00 deg BTDC for diesel-only operation and 4.25 deg BTDC for dual-fuel operation indicating an increase in ignition delay by $1.75 \mathrm{deg}$. The increase in ignition delay can be attributed to the decrease in temperature at the SOC by $0.341 \%$ from $880 \mathrm{~K}$ for diesel-only operation to $877 \mathrm{~K}$ for dual-fuel operation. The increase in ignition delay due to other reasons is explained in Section 4.1 .1 for $25 \%$ load operation. 
The amount of heat released during premixed combustion increased by $11.1 \%$ from $0.108 \mathrm{~kJ}$ for diesel-only operation to $0.120 \mathrm{~kJ}$ for dual-fuel operation. The increased amount of premixed energy released is due to the same reasons explained in Section 4.1 .1 for $25 \%$ load operation. The amount of heat released during diffusion combustion decreased by $5.16 \%$ from $8.33 \mathrm{~kJ}$ for diesel-only operation to $7.90 \mathrm{~kJ}$ for dual-fuel operation. The reduction in diffusion combustion energy release is due to the same reasons explained in Section 4.1 .2 for 50\% load operation. The combustion efficiency decreased by $8.91 \%$ from $98.8 \%$ for diesel-only operation to $90.0 \%$ for dual-fuel operation due to the same reasons explained in Section 4.1 .2 for $50 \%$ load operation.

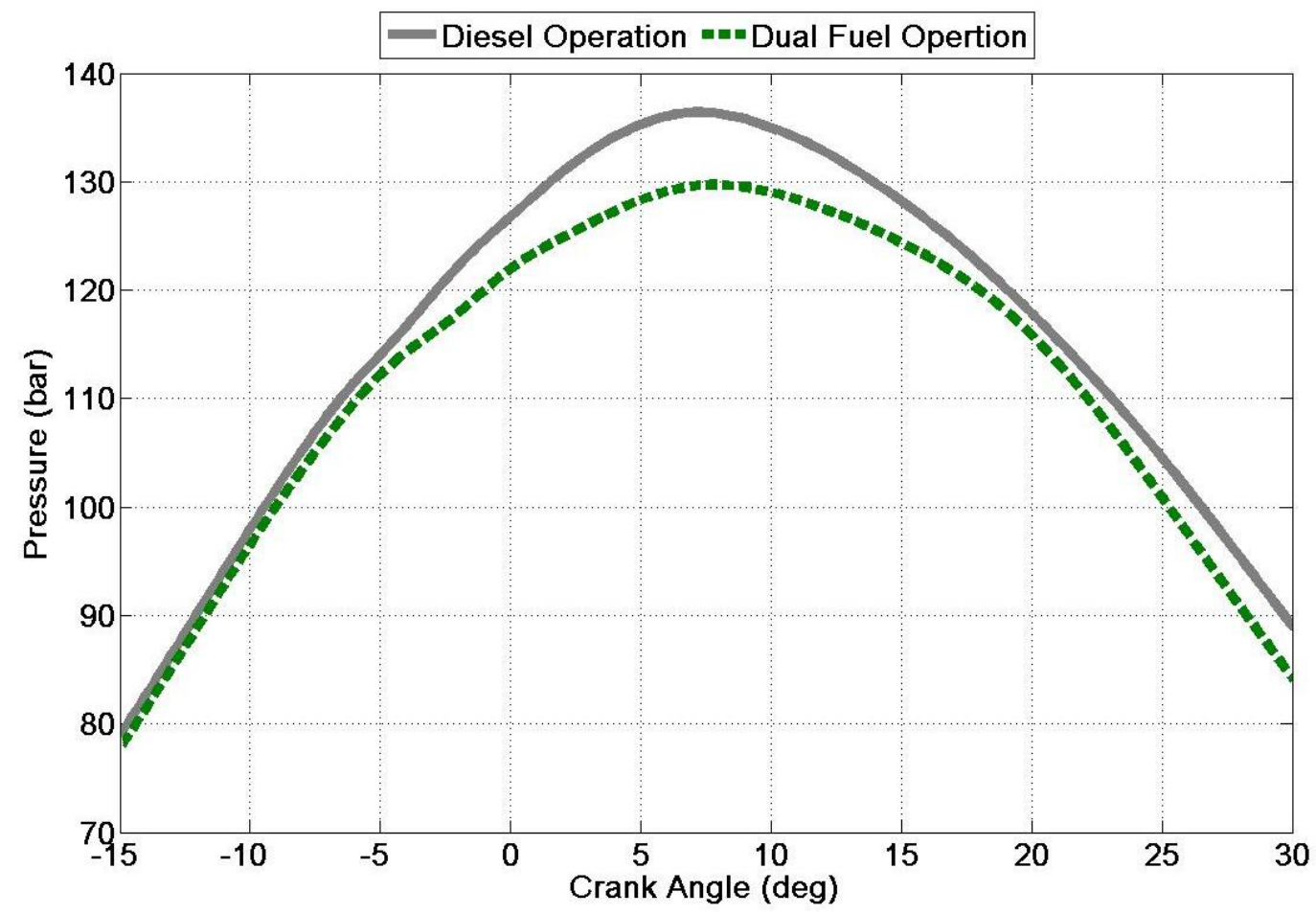

Figure 39 - In-Cylinder Pressure (100\% Load) 


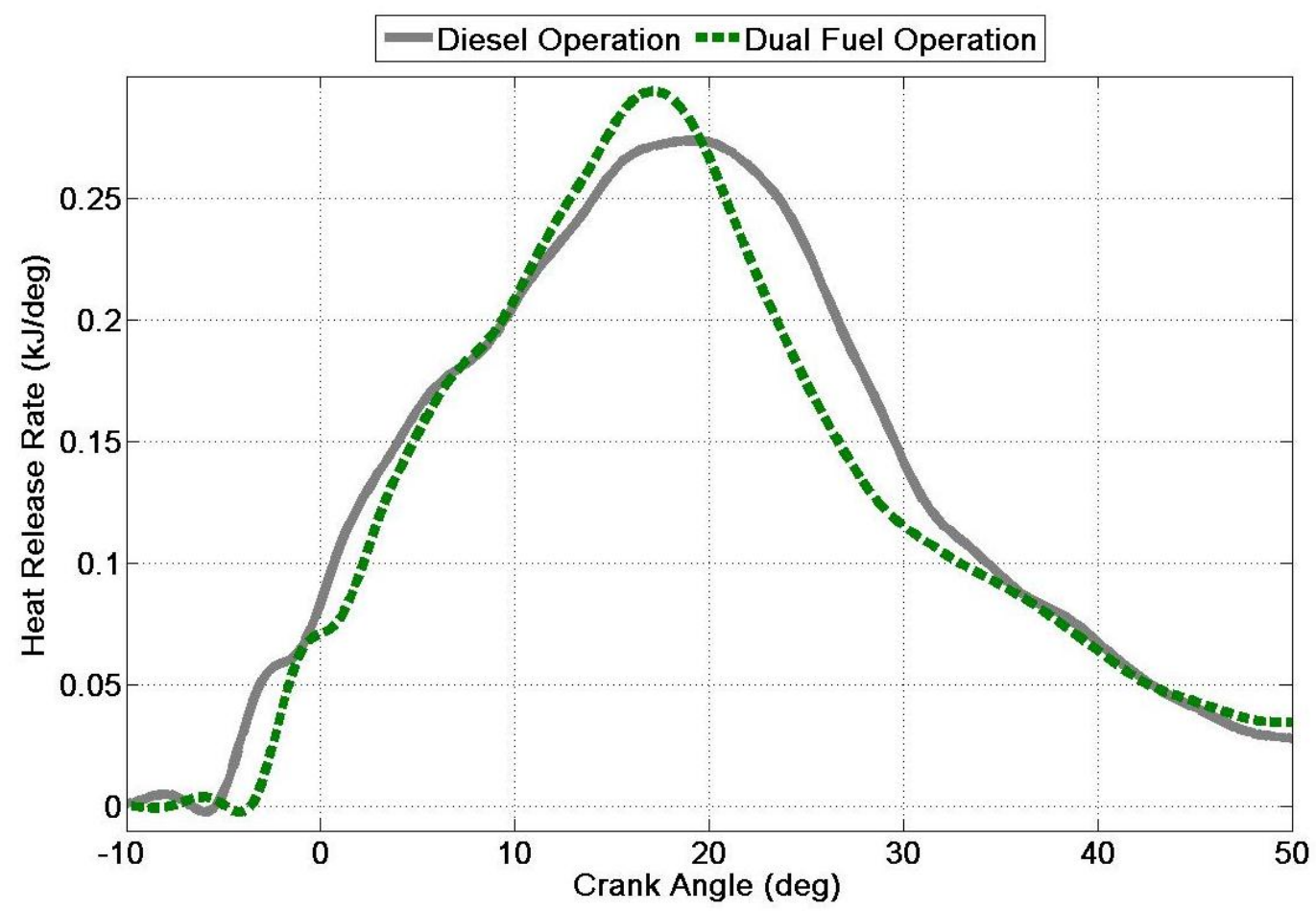

Figure 40 - Heat Release Rate (100\% Load)

\subsubsection{HC Emissions}

MHC and NMHC emissions for diesel-only operation and dual-fuel operation can be observed in Figure 41 and Figure 42. Diesel-only operation had no MHC emissions for all load points while dual-fuel operation did produce MHC emissions, more significantly at low loads. The MHC emissions produced for dual-fuel operation can be found in Table 3. MHC emissions indicate that $\mathrm{CNG}$ escapes the combustion process unburned. From Figure 41 it can be observed that MHC emissions decrease as load increases for dual-fuel operation. The decrease of MHC emissions correlates to the increase in combustion efficiency for dual-fuel operation as load increases. This also correlates to a decrease in reduction of diffusion combustion energy release for dual-fuel operation when compared to diesel-only operation as load increases.

Table 3 - MHC Emissions Comparison

\begin{tabular}{ccc}
\hline Load (\%) & MHC Diesel (g/bhp-hr) & MHC Dual-fuel (g/bhp-hr) \\
\hline 25 & N/A & 36.8 \\
\hline 50 & N/A & 12.2 \\
\hline 75 & N/A & 4.02 \\
\hline 100 & N/A & 1.49 \\
\hline
\end{tabular}


As load increases, in-cylinder gas temperatures increase allowing flame propagation to reach the $\mathrm{CNG}$ /air mixture further into the cylinder during dual-fuel operation. This is indicated by the increase in combustion efficiency with engine loading and the increase in diffusion combustion energy release to be comparable to the diffusion combustion energy release during diesel-only operation.

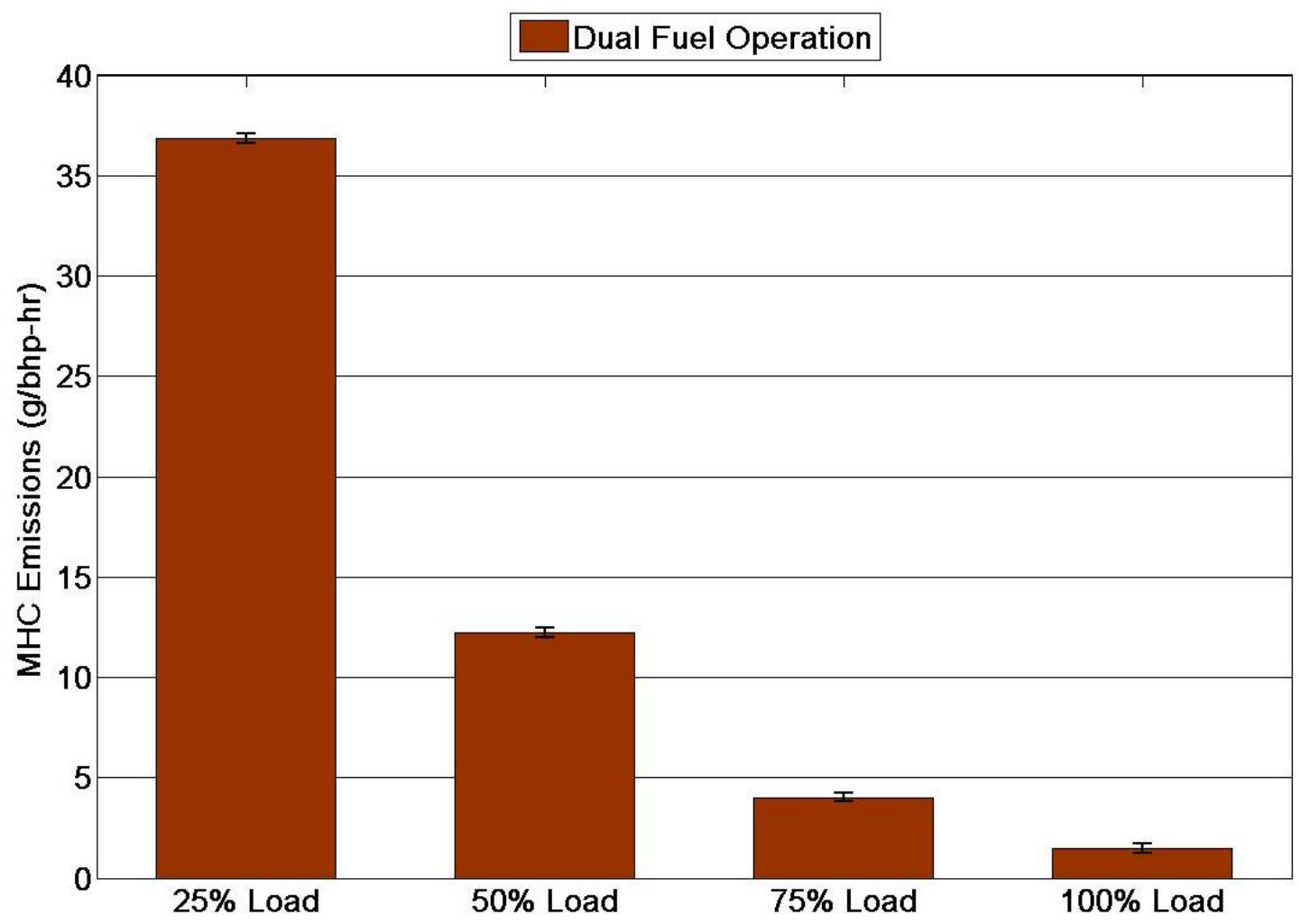

Figure 41 - MHC Emissions

The NMHC emissions produced for dual-fuel operation and diesel-only operation can be found in Table 4 along with the percentage change with respect to diesel-only NMHC emissions. Dualfuel operation had increased NMHC emissions compared to diesel-only operation. For dieselonly operation and dual-fuel operation, NMHC emissions decreased with increased engine load. NMHC emissions are $\mathrm{HC}$ emissions with a larger molecular weight than $\mathrm{CH}_{4}$ emissions indicating they come from the pilot diesel fuel. It is assumed that the amount of lubricating oil present in the cylinder during combustion is constant between diesel-only and dual-fuel operations because the $\mathrm{CNG}$ used was Matheson Chemically Pure $\mathrm{CH}_{4}$ with no compressor lubricating oils present. This indicates that the addition of $\mathrm{CNG}$ in the cylinder during dual-fuel combustion results in incomplete combustion of the pilot diesel fuel. This may be caused by 
locally fuel/air rich regions during premixed combustion and diffusion combustion in which diesel fuel participates. Similar to the MHC emissions explanation, as load increases, in-cylinder gas temperatures increase allowing improved flame propagation for more complete combustion. The decrease of MHC emissions correlates to the increase in combustion efficiency for dual-fuel operation.

Table 4 - NMHC Emissions Comparison

\begin{tabular}{cccc}
\hline Load (\%) & NMHC Diesel (g/bhp-hr) & NMHC Dual-fuel (g/bhp-hr) & \% Change \\
\hline 25 & 0.137 & 2.86 & $1990 \%$ \\
\hline 50 & 0.0384 & 0.945 & $2360 \%$ \\
\hline 75 & 0.0215 & 0.299 & $1290 \%$ \\
\hline 100 & 0.0221 & 0.111 & $402 \%$ \\
\hline
\end{tabular}

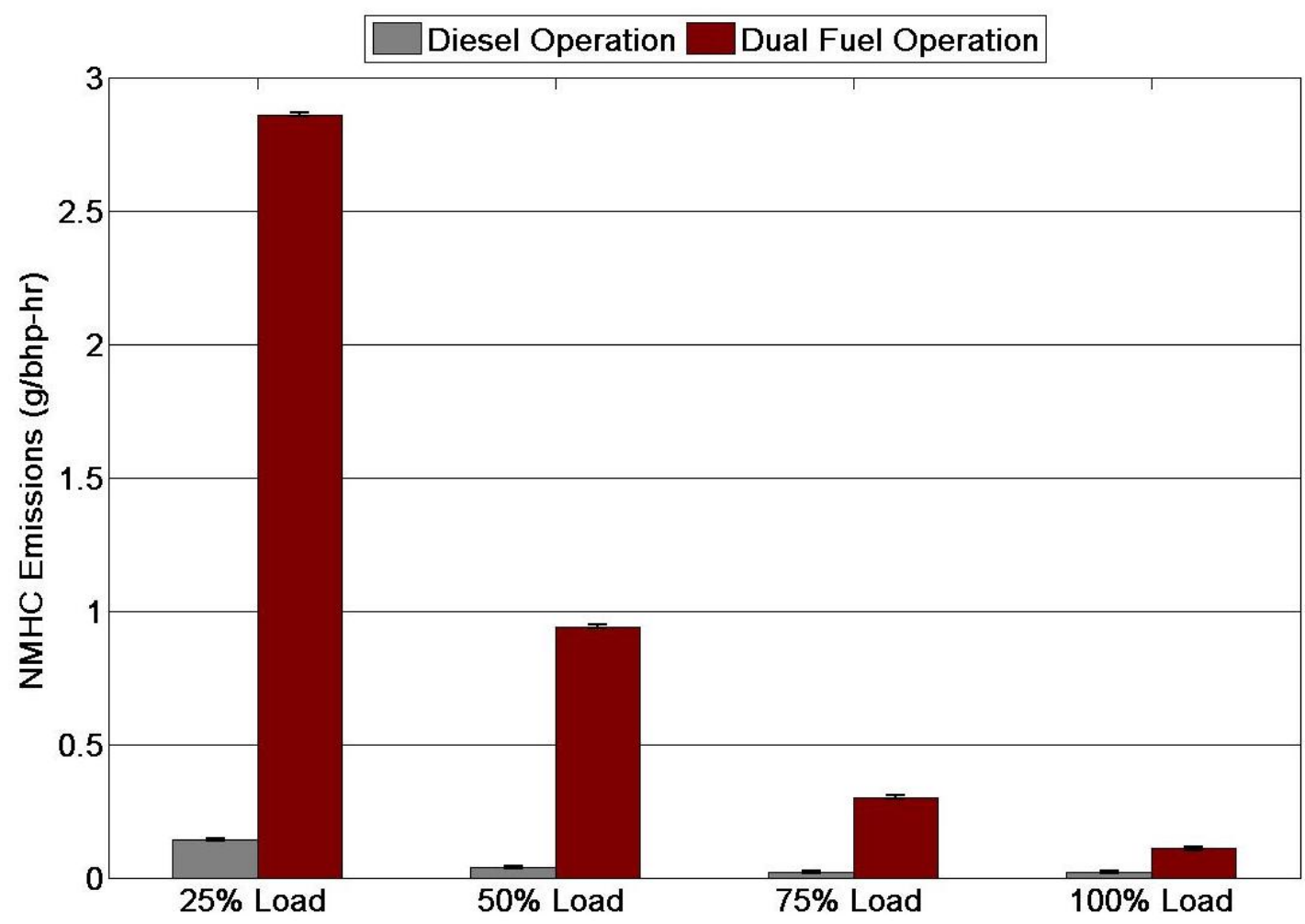

Figure 42 - NMHC Emissions Comparison

\subsubsection{Oxides of Nitrogen Emissions}

NOx and NO emissions for diesel-only operation and dual-fuel operation can be observed in Figure 43 and Figure 44. NOx emissions increase for dual-fuel operation and diesel-only operation as load increases except between $50 \%$ load and $70 \%$ load for diesel-only operation. With combustion temperatures expected to rise with engine load, it was assumed that increased 
EGR flow kept NOx levels steady between 50\% load and 75\% load for diesel-only operation. The NOx emissions produced for dual-fuel operation and diesel-only operation can be found in Table 5 along with the percentage change with respect to diesel-only NOx emissions.

Table 5 - NOx Emissions Comparison

\begin{tabular}{cccc}
\hline Load (\%) & NOx Diesel (g/bhp-hr) & NOx Dual-fuel (g/bhp-hr) & \% Change \\
\hline 25 & 1.61 & 0.956 & $-40.6 \%$ \\
\hline 50 & 1.71 & 1.12 & $-34.5 \%$ \\
\hline 75 & 1.70 & 1.25 & $-26.5 \%$ \\
\hline 100 & 2.39 & 1.28 & $-46.4 \%$ \\
\hline
\end{tabular}

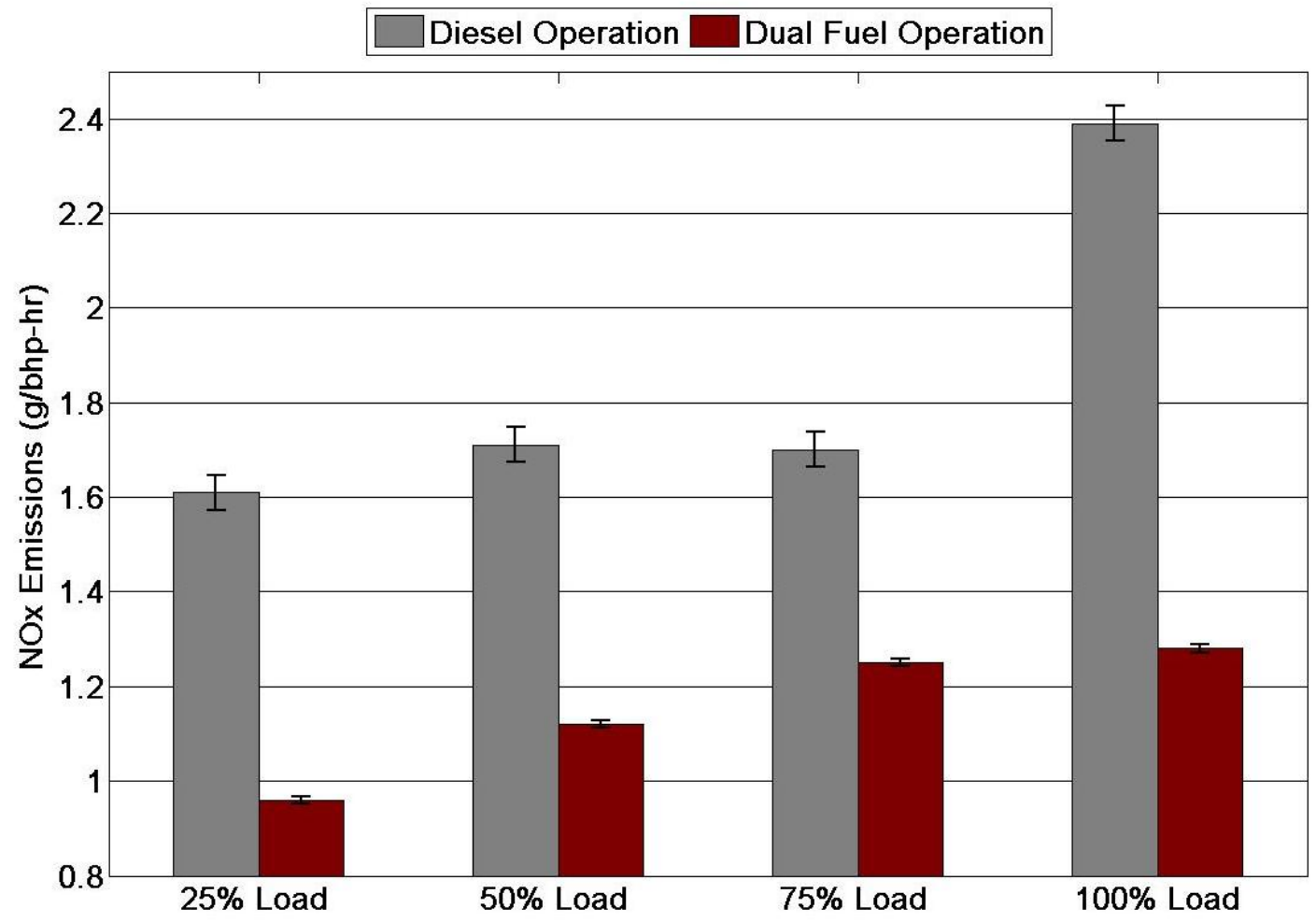

Figure 43 - NOx Emissions Comparison

Increased NOx emissions for diesel-only operation compared to dual-fuel operation can be attributed to increased temperatures experienced during combustion. In-cylinder gas temperatures were calculated for diesel-only operation and dual-fuel operation and can be observed in Figure 45 for light load operation and Figure 46 for heavy load operation. The maximum and averaged calculated in-cylinder gas temperatures for diesel and dual-fuel 
operation can be found in Table 6 along with their percentage change with respect to diesel-only operation.

Table 6 - Maximum and Average Calculated In-Cylinder Gas Temperatures Comparison

\begin{tabular}{ccccccc}
\hline & \multicolumn{3}{c}{ Maximum Temperature } & \multicolumn{3}{c}{ Average Temperature } \\
\hline Load (\%) & Diesel (K) & Dual-fuel (K) & \% Change & Diesel (K) & Dual-fuel (K) & \% Change \\
\hline 25 & 1250 & 1060 & $-15.2 \%$ & 695 & 623 & $-10.4 \%$ \\
\hline 50 & 1440 & 1280 & $-11.1 \%$ & 774 & 719 & $-7.11 \%$ \\
\hline 75 & 1550 & 1430 & $-7.74 \%$ & 828 & 787 & $-4.95 \%$ \\
\hline 100 & 1640 & 1550 & $-5.49 \%$ & 861 & 840 & $-2.43 \%$ \\
\hline
\end{tabular}

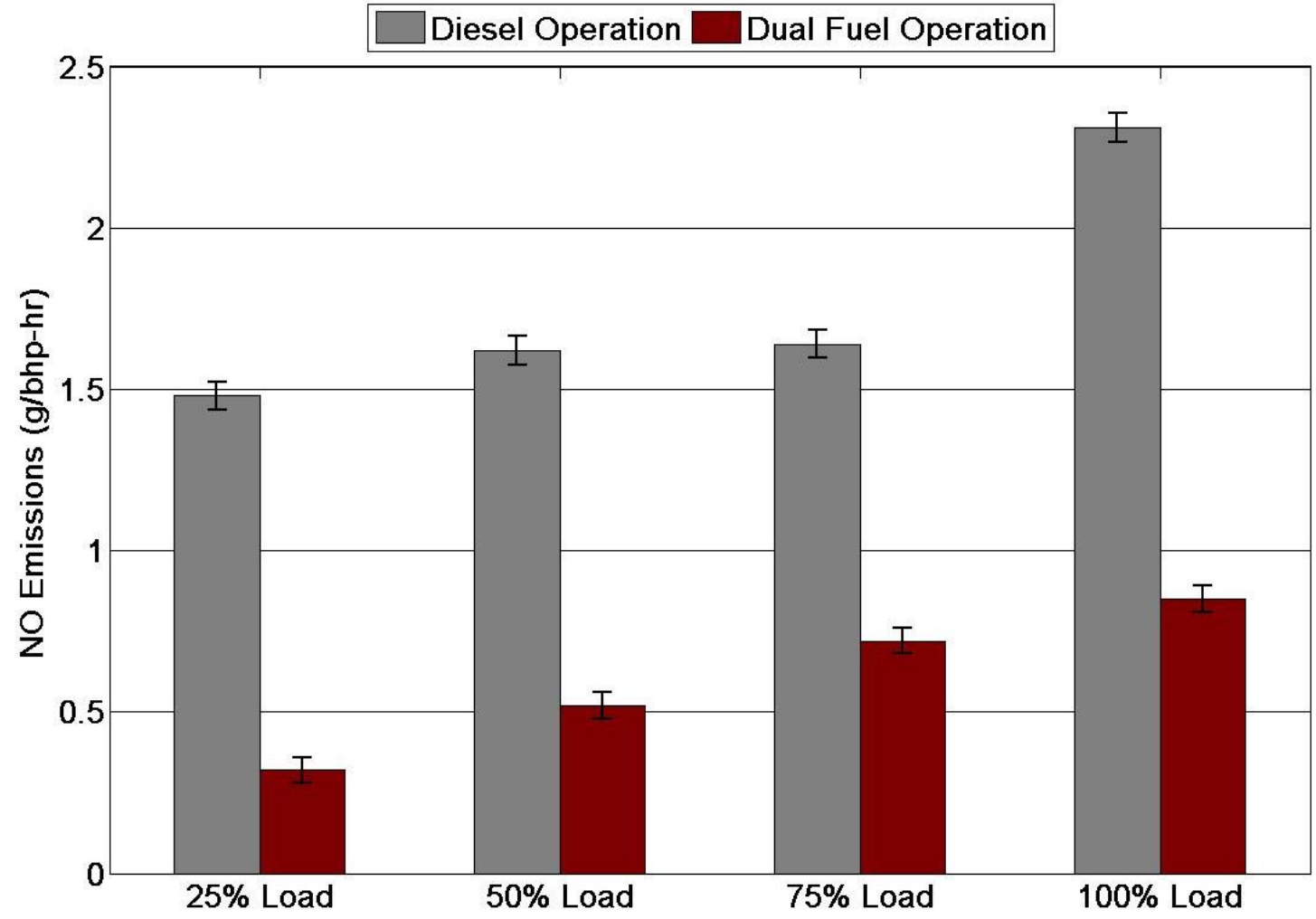

Figure 44 - NO Emissions Comparison

The calculated in-cylinder gas temperatures represent a global temperature within the cylinder and never exceeds $1650 \mathrm{~K}$ for diesel-only operation and dual-fuel operation at all load points. A well-known temperature for NOx formation according to the "Zeldovich Mechanism" is $1900 \mathrm{~K}$ which is higher than the global temperatures calculated for dual-fuel operation and diesel-only operation. NOx formation occurs due to local flame temperatures within the combustion process exceeding $1700 \mathrm{~K}$. Adiabatic flame temperatures for diesel fuel at stoichiometric combustion is 
$\sim 2500 \mathrm{~K}$ while $\mathrm{CNG}$ fuel at stoichiometric combustion is $\sim 2220 \mathrm{~K}$. This indicates that localized combustion temperatures will be above $1900 \mathrm{~K}$ for diesel-only operation and dual-fuel operation where fuel/air mixtures are stoichiometric. However, the in-cylinder pressure/temperature derived values are not capable of determining these local temperatures.

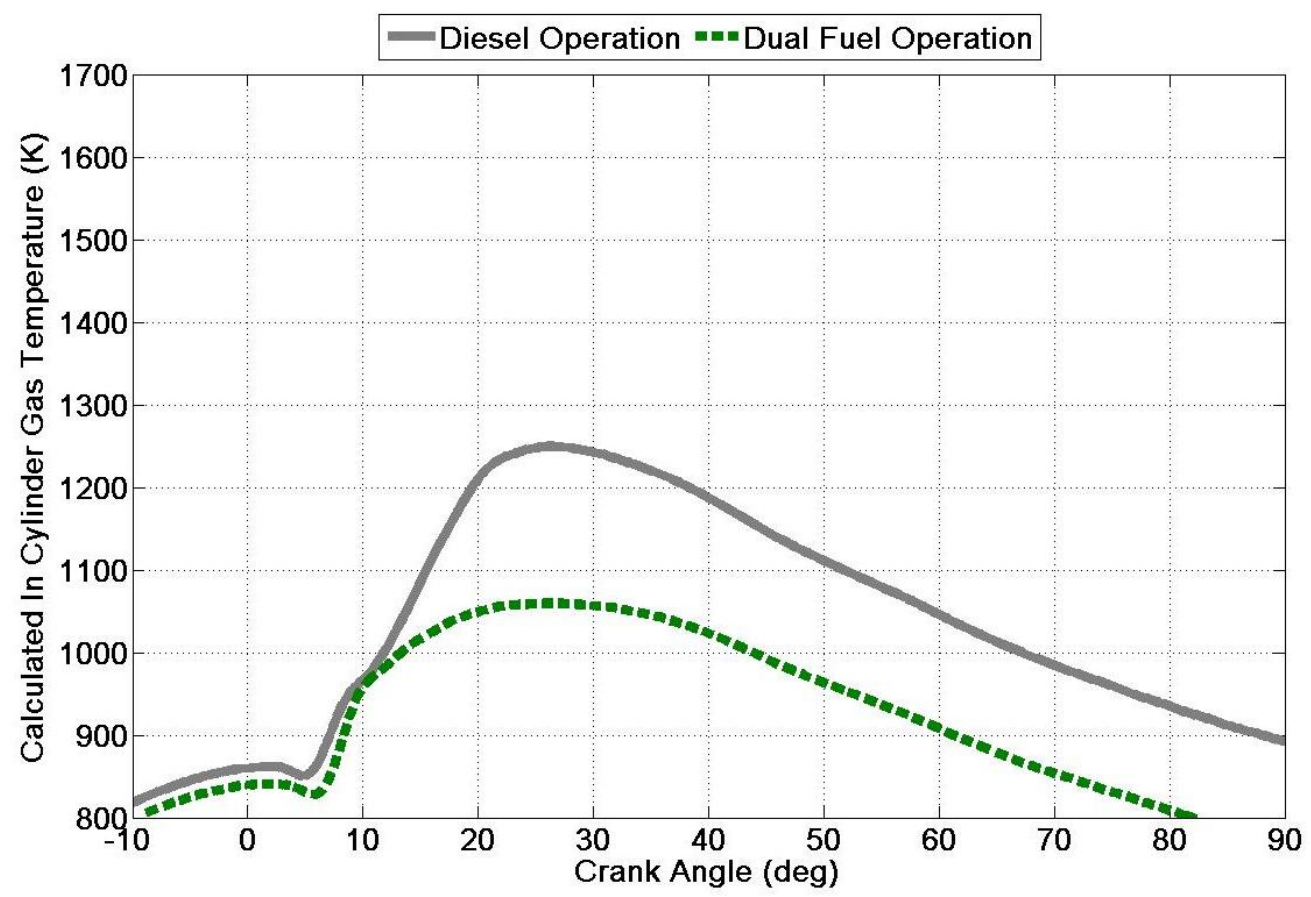

Figure 45 - Calculated In-Cylinder Gas Temperatures At 25\% Load

With increased global in-cylinder gas temperatures and increased localized in-cylinder gas temperatures for diesel-only operation, NOx emissions are increased at all loads. As loads increase for both modes of operation, combustion durations are increased to meet the load requirements and combustion temperatures increase due to increased fueling. The increase in calculated in-cylinder gas temperatures can be observed by comparing Figure 45 and Figure 46. With increased temperatures and increased combustion durations resulting in increased residence time for NOx formation to occur, NOx emissions increase with load.

Table 7 shows the percentage of NO emissions within total NOx emissions. NO concentrations in NOx is larger for diesel-only operation as compared to dual-fuel operation. During combustion $\mathrm{NO}$ is oxidized to $\mathrm{NO}_{2}$ following the path specified in Equation 9. If temperatures remain high, $\mathrm{NO}_{2}$ will convert back to $\mathrm{NO}$ following the path specified in Equation 10. Lower in-cylinder gas temperatures during dual-fuel combustion results in flame quenching which 
causes $\mathrm{NO}_{2}$ to remain in its present state rather than converting back to NO. Flame quenching results in less flame propagation and is experienced in incomplete combustion. As combustion efficiency increases with load during dual-fuel combustion, the percentage of NO within NOx also increases indicating decreased flame quenching and increased flame propagation. Dieselonly combustion efficiencies are over $96 \%$ at all loads indicating complete combustion and higher percentages of NO within NOx.

Table 7 - NO Percentage in NOx Comparison

\begin{tabular}{ccc}
\hline Load (\%) & NO Fraction Diesel & NO Fraction Dual-fuel \\
\hline 25 & $92.0 \%$ & $33.8 \%$ \\
\hline 50 & $95.1 \%$ & $46.7 \%$ \\
\hline 75 & $96.4 \%$ & $57.6 \%$ \\
\hline 100 & $96.8 \%$ & $65.9 \%$ \\
\hline
\end{tabular}

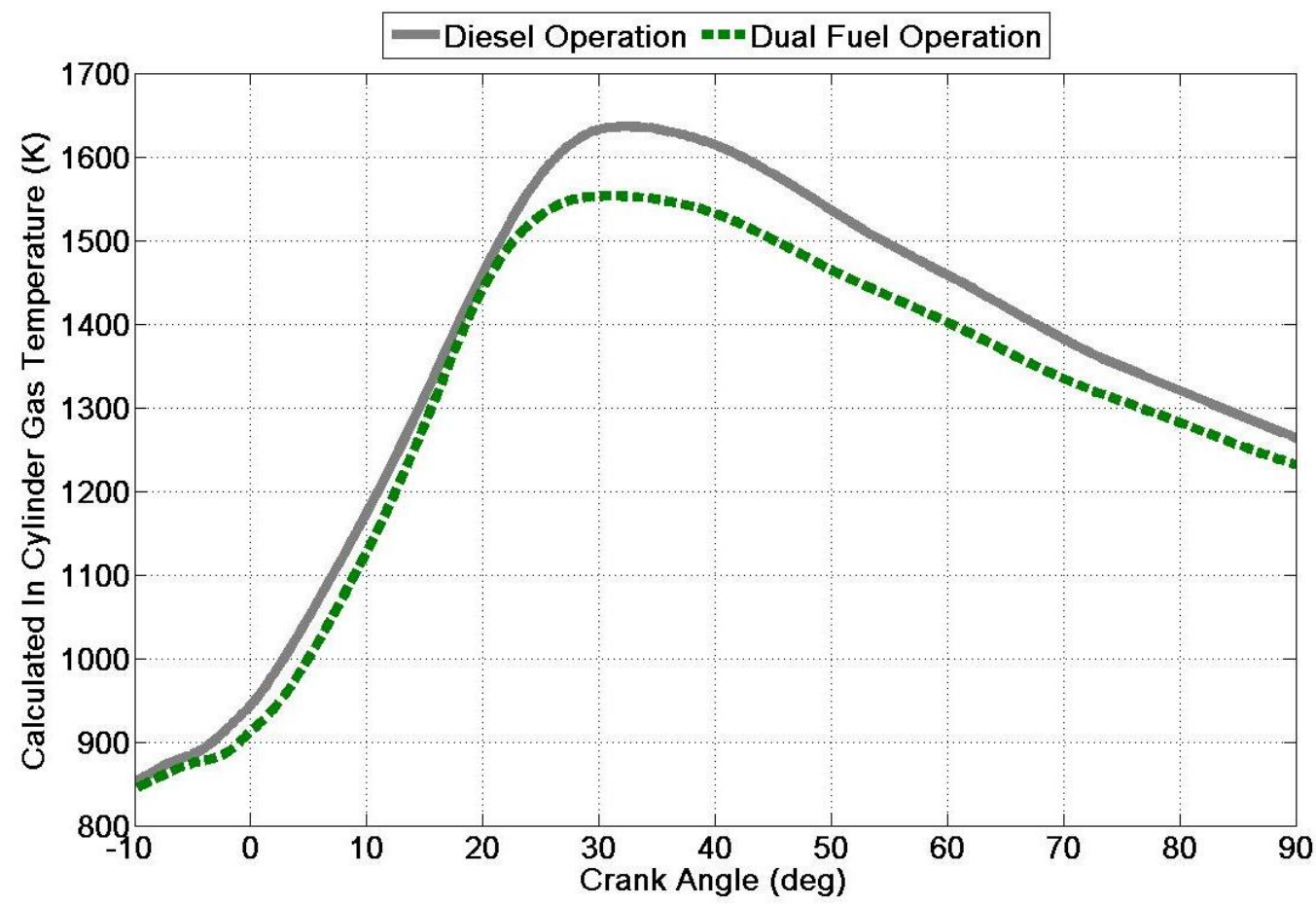

Figure 46 - Calculated In-Cylinder Gas Temperatures At 100\% Load

\subsubsection{Carbon Monoxide and Carbon Dioxide Emissions}

$\mathrm{CO}$ and $\mathrm{CO}_{2}$ emissions from diesel-only operation and dual-fuel operation can be observed in Figure 47 and Figure 48 respectively. $\mathrm{CO}$ emissions decrease for dual-fuel operation and dieselonly operation as load increases. Dual-fuel operation had increased CO emission when compared 
to diesel-only operation. The $\mathrm{CO}$ emissions produced for dual-fuel operation and diesel-only operation can be found in Table 8 along with the percentage change with respect to diesel-only $\mathrm{CO}$ emissions. $\mathrm{CO}$ is formed from incomplete combustion due to the lack of oxidants, low combustion temperatures, and inadequate residence time. During complete combustion CO proceeds towards $\mathrm{CO}_{2}$ by Equation 11. $\mathrm{CO}$ emissions for dual-fuel operation and diesel-only operation correlate to each engine loads combustion efficiency.

Table 8 - CO Emissions Comparison

\begin{tabular}{cccc}
\hline Load (\%) & CO Diesel (g/bhp-hr) & CO Dual-fuel (g/bhp-hr) & \% Change \\
\hline 25 & 1.01 & 17.8 & $1660 \%$ \\
\hline 50 & 0.621 & 12.4 & $1900 \%$ \\
\hline 75 & 0.361 & 7.13 & $1880 \%$ \\
\hline 100 & 0.215 & 4.71 & $2090 \%$ \\
\hline
\end{tabular}

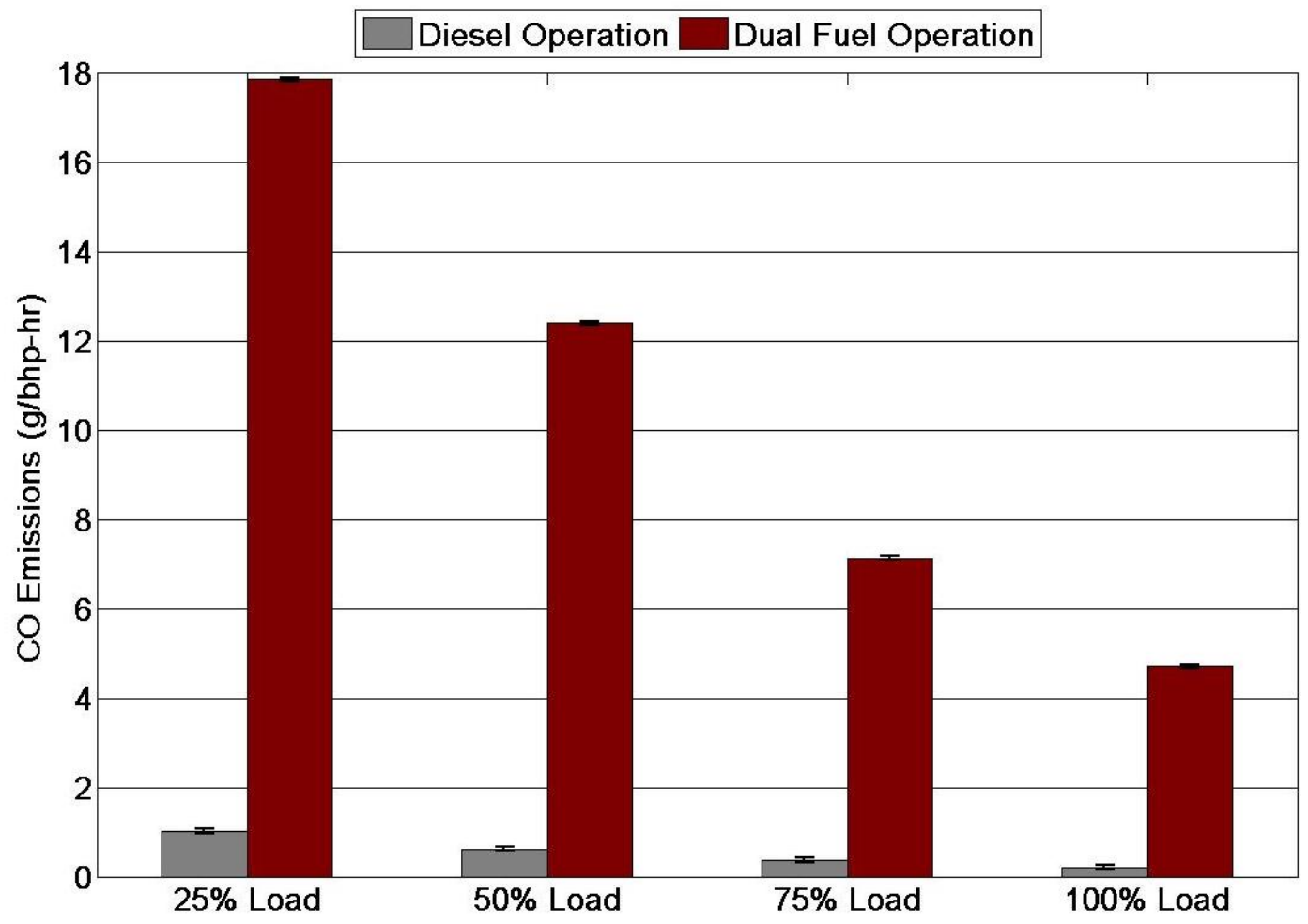

Figure 47 - CO Emissions Comparison

Dual-fuel operation experienced lower combustion efficiencies than diesel-only operation, especially at light loads, resulting in increased $\mathrm{CO}$ emissions. The production of $\mathrm{CO}$ emissions indicates that oxidation of the CNG/air mixture is taking place incompletely. As load increases, 
cylinder pressures and temperatures increase allowing flame propagation to reach the $\mathrm{CNG} /$ air mixture and properly oxidize $\mathrm{CO}$ to $\mathrm{CO}_{2}$. This is indicated by the increase in combustion efficiency with engine loading and the increase in diffusion combustion energy release from dual-fuel operation to be comparable to the diffusion combustion energy release observed during diesel-only operation. Dual-fuel operation had decreased $\mathrm{CO}_{2}$ emissions when compared to diesel-only operation. This is due to large amounts of $\mathrm{CO}$ not being converted to $\mathrm{CO}_{2}$ with the decrease of in-cylinder gas temperatures. This is also due to $\mathrm{CNG}$ containing less $\mathrm{C}$ than diesel fuel.

Table 9 - $\mathrm{CO}_{2}$ Emissions Comparison

\begin{tabular}{cccc}
\hline Load (\%) & $\mathbf{C O}_{\mathbf{2}}$ Diesel (g/bhp-hr) & $\mathbf{C O}_{\mathbf{2}}$ Dual-fuel (g/bhp-hr) & \% Change \\
\hline 25 & 550 & 505 & $-8.18 \%$ \\
\hline 50 & 481 & 443 & $-7.90 \%$ \\
\hline 75 & 468 & 443 & $-5.34 \%$ \\
\hline 100 & 468 & 441 & $-5.77 \%$ \\
\hline
\end{tabular}






\subsubsection{PM Emissions}

PM emissions from diesel-only operation and dual-fuel operation can be observed in Figure 49. PM emissions increased by $49.8 \%$ from $66.3 \mathrm{mg} / \mathrm{bhp}-\mathrm{hr}$ for diesel-only operation to 99.3 $\mathrm{mg} / \mathrm{bhp}-\mathrm{hr}$ for dual-fuel operation. The SOL portion of PM is formed mainly from elemental C. During dual-fuel operation the fuel/air mixture is more globally rich than during diesel-only operation. This can be observed by comparing the equivalence ratios in Section 4.1.1 through Section 4.1.4. With a more globally rich fuel/air mixture, it can be assumed there are more locally rich fuel zones as well. With increased locally rich fuel zones, inadequate amounts of oxygen are present to convert all elemental $\mathrm{C}$ to $\mathrm{CO}_{2}$ resulting in incomplete combustion. The effects of incomplete combustion during dual-fuel operation can be observed by increased HC emissions and $\mathrm{CO}$ emissions while combustion efficiencies are lower compared to diesel-only operation.

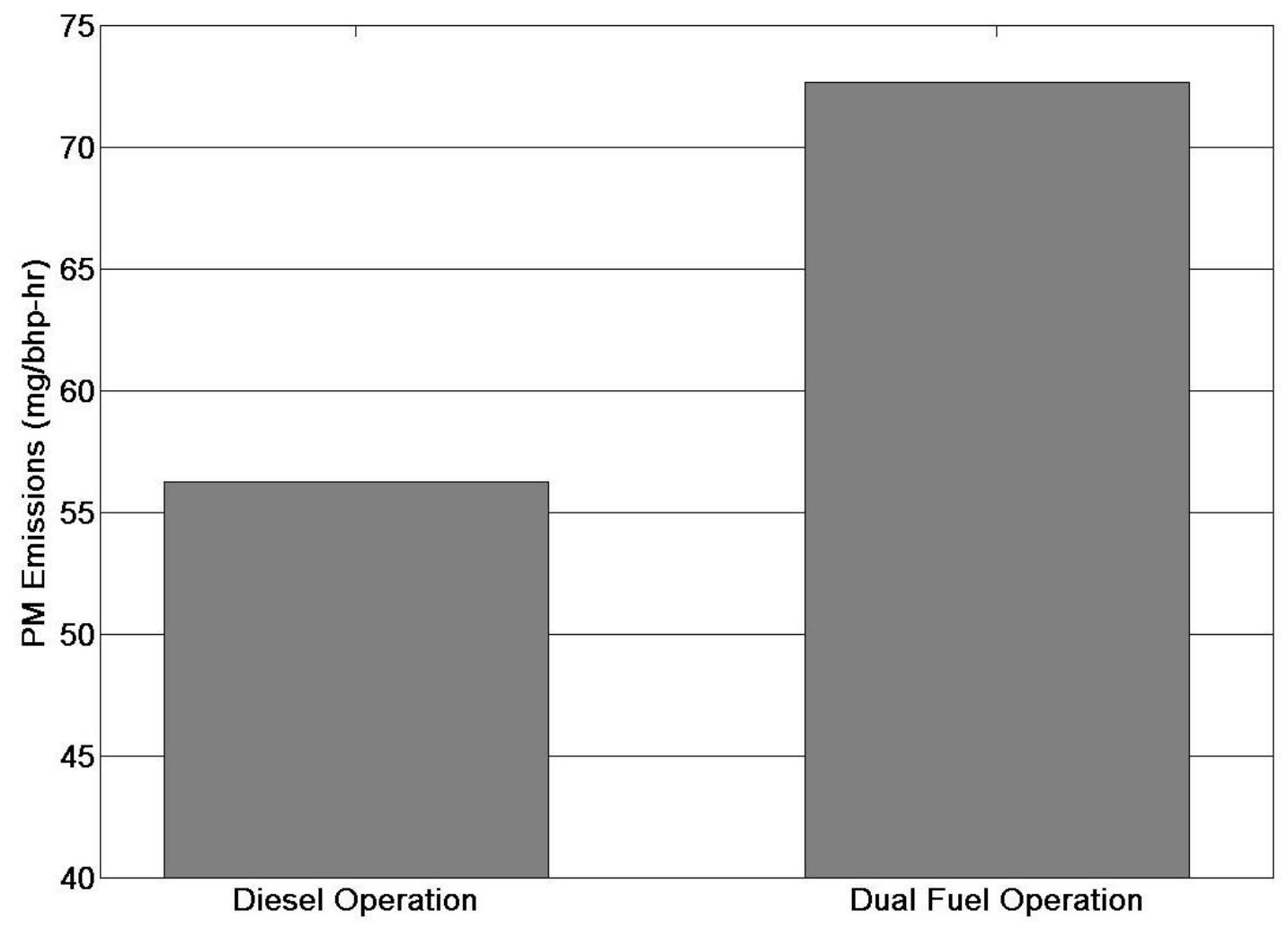

Figure 49 - PM Emissions Comparison

For diesel-only operation, a significant amount of elemental $\mathrm{C}$ can remix with the excess $\mathrm{O}_{2}$ within the cylinder and be consumed. Because of flame propagation limitations and low combustion efficiencies, there are indications of increased amounts of elemental $\mathrm{C}$ exiting the 
combustion chamber with exhaust gases which never react with excess $\mathrm{O}_{2}$. As elemental $\mathrm{C}$ exits the combustion chamber, organic material derived from fuel and lubricating oil absorbs onto the surface of elemental $\mathrm{C}$ particles, thereby contributing to the SOF. At high exhaust temperatures organic material does not absorb onto elemental $\mathrm{C}$ particles. At lower exhaust temperatures, organic material condenses, forming increased amounts of SOF within the exhaust. Dual-fuel operation experiences lower exhaust temperatures than diesel-only operation with the biggest difference being a $3.49 \%$ decrease from $631 \mathrm{~K}$ to $609 \mathrm{~K}$ at $25 \%$ load and $1596 \mathrm{rpm}$.

\subsection{Certification Work}

To meet the EPA's Clean Alternative Fuel Conversion Program certification requirements, developmental work had to be completed on the dual-fuel conversion kit being tested. To meet these requirements the engine had to meet the emissions limits specified by the EPA as observed in Table 1. Certification work to allow the dual-fuel conversion kit to be applied to 2004-2006 Mack AC engines was completed on the 2005 Mack AC-460P engine. The dual-fuel conversion kit was tested in baseline configuration on Haltermann Solutions certification diesel fuel and Matheson Chemically Pure $\mathrm{CH}_{4}$. The results from the transient FTPs and steady-state SETs can be found in Table 10 and Table 11. The dual-fuel conversion kit had the same operating characteristics as the dual-fuel conversion kit used for the combustion and resultant emissions study in Section 4.1, except for a timing retard. A pilot diesel injection delay was applied to the OEM diesel injection signal at all modes of operation. Emissions produced during transient operation followed the same trend as emissions produced during steady-state operation when comparing the difference between dual-fuel operation and diesel-only operation. This indicates that same combustion characteristics and emission formations explained in Section 4.1 are taking place during transient operations.

Table 10 - FTP Transient Operation Emissions (Haltermann Diesel Fuel)

\begin{tabular}{cccccccc}
\hline Emissions (g/bhp-hr) & MHC & NMHC & NOx & NO & CO & CO $_{2}$ & PM $^{*}$ \\
\hline Diesel & 0.000 & 0.103 & 2.44 & 2.26 & 0.574 & 551 & 84.5 \\
\hline Dual-fuel & 8.36 & 0.201 & 1.92 & 1.40 & 6.27 & 500 & 86.0 \\
\hline \% Change & N/A & $95.1 \%$ & $-21.3 \%$ & $-38.1 \%$ & $992 \%$ & $-9.26 \%$ & $1.78 \%$ \\
\hline \multicolumn{7}{c}{$*(\mathrm{mg} / \mathrm{bhp}-\mathrm{hr})$} \\
\hline
\end{tabular}


Table 11 - SET Steady-State Operation Composite Emissions (Haltermann Diesel Fuel)

\begin{tabular}{cccccccc}
\hline Emissions (g/bhp-hr) & MHC & NMHC & NOx & NO & CO & CO $_{2}$ & PM* $^{*}$ \\
\hline Diesel & 0.000 & 0.0512 & 2.43 & 2.30 & 0.497 & 511 & 78.4 \\
\hline Dual-fuel & 3.72 & 0.0738 & 1.96 & 1.51 & 4.15 & 461 & 117 \\
\hline \% Change & N/A & $44.1 \%$ & $-19.3 \%$ & $-34.3 \%$ & $735 \%$ & $-9.78 \%$ & $49.2 \%$ \\
\hline \multicolumn{7}{c}{$*(\mathrm{mg} / \mathrm{bhp}-\mathrm{hr})$} \\
\hline
\end{tabular}

In dual-fuel operation the engine met all emission standards set for by the EPA in Table 1 except for PM emissions during the steady-state SET. The steady-state SET was repeated with the pilot injection delay removed. With an expected increase of NOx and decrease in PM with timing delay removed, the global substitution ratio was increased. With the pilot injection delay removed, pilot injection occurs when the OEM ECU determines the start of injection should occur. The results from the steady-state SET can be found in Table 12 with the percentage change of the results with respect to the dual-fuel results found in Table 11.

Table 12 - SET Steady-State Operation Composite Emissions (Haltermann Diesel Fuel, No Injection Delay, Increased Substitution)

\begin{tabular}{cccccccc}
\hline Emissions (g/bhp-hr) & MHC & NMHC & NOx & NO & CO & CO $_{2}$ & PM* \\
\hline Dual-fuel & 5.57 & 0.0569 & 2.86 & 2.33 & 5.16 & 425 & 70.7 \\
\hline \% Change & $49.7 \%$ & $-22.9 \%$ & $45.9 \%$ & $53.8 \%$ & $24.3 \%$ & $-7.80 \%$ & $-39.5 \%$ \\
\hline \multicolumn{7}{c}{$(\mathrm{mg} / \mathrm{bhp}-\mathrm{hr})$} \\
\hline
\end{tabular}

As expected with the removal of pilot diesel injection delay, NOx emissions increased and PM emissions decreased due to higher combustion temperatures. MHC emissions increased with the increased average substitution ratio indicating the $\mathrm{CNG}$ /air mixture is not being reached by flame propagation. NMHC emissions decreased indicating more complete combustion of the pilot diesel fuel due to increased combustion temperatures with the removal of the pilot diesel injection delay. An increase of $\mathrm{CO}$ emissions indicates that the increase of CNG substitution resulted in lower combustion efficiencies. The decrease in combustion efficiency can also be observed by the increase of MHC emissions. It is expected that increased combustion temperatures allowed better combustion of the pilot diesel fuel, but flame propagation could still not reach the entire $\mathrm{CNG}$ /air mixture within the cylinder resulting in increased $\mathrm{CO}$ and $\mathrm{MHC}$ emissions. $\mathrm{CO}_{2}$ emissions decreased as more $\mathrm{CO}$ was formed and $\mathrm{CNG}$ was used as a fuel source. 
NOx emissions were higher than the emissions standards set forth by the EPA in Table 1. To bring NOx emissions to within acceptable limits, the diesel pilot injection timing was delayed when the OEM ECU advanced the injection timing at high loads. At light loads the dual-fuel controller did not retard injection timing to reduce PM emissions. To further reduce PM, CNG substitution was also decreased. The results from the steady-state SET can be found in Table 13 with the percentage change of the results with respect to the results in Table 12.

Table 13 - SET Steady-State Operation Composite Emissions (Haltermann Diesel Fuel, Altering Injection Delay, Decreased Substitution)

\begin{tabular}{cccccccc}
\hline Emissions (g/bhp-hr) & MHC & NMHC & NOx & NO & CO & CO $_{2}$ & PM* $^{*}$ \\
\hline Dual-fuel & 4.05 & 0.0688 & 2.18 & 1.68 & 4.25 & 465 & 89.6 \\
\hline \% Change & $-27.3 \%$ & $20.9 \%$ & $-23.7 \%$ & $-28.0 \%$ & $-17.7 \%$ & $9.40 \%$ & $26.7 \%$ \\
\hline \multicolumn{7}{c}{$*(\mathrm{mg} / \mathrm{bhp}-\mathrm{hr})$} \\
\hline
\end{tabular}

NOx emissions decreased due to the pilot diesel injection timing delay adjustments made at high loads. PM emissions decreased due to the decrease in $\mathrm{CNG}$ substitution and the pilot diesel injection timing delay removal made at light to medium loads. MHC emissions decreased with the decrease in CNG substitution. NMHC emissions increased, indicating incomplete combustion of the pilot diesel fuel with decreased combustion temperatures at heavy loads with the pilot diesel injection delay. CO emissions decreased with the decrease of CNG substitution indicating a global increase in combustion efficiency. $\mathrm{CO}_{2}$ emissions increased as more $\mathrm{CO}$ was transformed into $\mathrm{CO}_{2}$.

With PM emissions from the steady-state SET within acceptable limits, a transient FTP was run and the results are shown in Table 14. The percentage change of results in Table 14 are with respect to the dual-fuel results in Table 10. NOx emissions increased because no pilot diesel injection timing delay was used at light to medium loads. This produced higher combustion temperatures at light and medium loads, when compared to the baseline transient FTP. PM emissions decreased because the pilot diesel injection timing delay was only used at high loads. MHC emissions decreased due to the decrease in CNG substitution. NMHC emissions decreased indicating more complete combustion of the pilot diesel fuel with increased combustion temperatures at medium to light loads with the pilot diesel injection delay removed. $\mathrm{CO}$ 
emissions decreased with the decrease of CNG substitution indicating an increase in combustion efficiency. $\mathrm{CO}_{2}$ emissions increased as more $\mathrm{CO}$ was transformed into $\mathrm{CO}_{2}$.

Table 14 - FTP Transient Operation Emissions (Haltermann Diesel Fuel, Altering Injection Delay, Decreased Substitution)

\begin{tabular}{cccccccc}
\hline Emissions (g/bhp-hr) & MHC & NMHC & NOx & NO & CO & CO $_{2}$ & PM $^{*}$ \\
\hline Dual-fuel & 7.95 & 0.164 & 2.26 & 1.74 & 5.37 & 508 & 61.4 \\
\hline \% Change & $-4.90 \%$ & $-18.2 \%$ & $17.9 \%$ & $23.8 \%$ & $-14.3 \%$ & $1.70 \%$ & $-28.6 \%$ \\
\hline \multicolumn{7}{c}{$*(\mathrm{mg} / \mathrm{bhp}-\mathrm{hr})$} \\
\hline
\end{tabular}

With the dual-fuel conversion kit certified to the EPA's Clean Alternative Fuel Conversion Program requirements, it can be compared to diesel-only operation to determine the effect of the kit on emissions during testing (Table 15). For the transient FTP, NOx and PM decreased for dual-fuel operation when compared to diesel-only operation. This can be attributed to the balance of diesel injection timing adjustments and cylinder temperatures experienced during combustion. Cylinder temperatures decreased due to the substitution of CNG while timing was advanced far enough to keep cylinder temperatures hot enough to reduce PM emissions. For the steady-state SET, NOx emissions decreased but PM emissions increased. Steady-state operation required the engine to operate at low load conditions for long durations where excessive PM emissions were emitted. During transient operation the engine passed through low load conditions to higher loading conditions where PM was oxidized more effectively.

Table 15 - Certified Dual-Fuel Conversion Kit Operation Emissions Compared to Diesel-Only Operation Emissions

\begin{tabular}{cccccccc}
\hline Emissions & MHC & NMHC & NOx & NO & CO & CO2 & PM \\
\hline \% Change FTP & N/A & $59.3 \%$ & $-7.29 \%$ & $-23.1 \%$ & $836 \%$ & $-7.81 \%$ & $-27.4 \%$ \\
\hline \% Change SET & N/A & $34.4 \%$ & $-10.1 \%$ & $-27.1 \%$ & $754 \%$ & $-8.87 \%$ & $14.2 \%$ \\
\hline
\end{tabular}

\subsection{Global Warming Potential}

The amount of heat trapped by an emission is defined by its global warming potential (GWP). The GWP takes into consideration the lifetime of the emission when emitted and its infrared absorption capabilities. $\mathrm{MHC}$ and $\mathrm{CO}_{2}$ greenhouse gas emissions are of particular interest in this research. The global warming potential (GWP) of MHC emissions is 72 magnitudes larger than the GWP of $\mathrm{CO}_{2}$ emissions when analyzed in a 20 -year timeframe. The reduction of $\mathrm{CO}_{2}$ 
emissions is outweighed by the increase in MHC emissions during dual fuel operation to a GWP increase of $35 \%$ for the steady-state SET and $85.2 \%$ for the transient FTP.

\subsection{Repeatability}

The mean, standard deviation, and coefficient of variation (COV) for engine data collected during the RPT tests can be found in Table 16 in the Appendix. The largest COVs came from THC emissions during diesel-only operation (13.3\%), NO emissions during dual-fuel operation (8.48\%), and CO emissions during diesel-only operation (7.81\%). Dual-fuel operation exhibited increased concentrations of $\mathrm{THC}$ emissions and $\mathrm{CO}$ emissions compared to diesel-only operation. This resulted in higher spans needed for the THC FID and CO NDIA. Dual-fuel operation produced decreased concentrations of NO compared to diesel-only operation. When an analyzer is spanned to capture larger concentrations of particular pollutants, it will become less accurate at smaller concentrations. This resulted in the large COVs listed above.

Results from the analysis of variance between engine data collected for each RPT test can be found in Table 17 in the Appendix. Results indicated there were variations in the THC emissions, MHC emissions, and NO emissions for dual-fuel operation between the two RPT tests. An analysis of variance test compares within group variation and group-to-group variation to determine if the two groups of tests can be considered similar. For each of the emissions above, the COV for each RPT test analyzed separately was low meaning there was little within group variation. This was factored into the analysis of variance test making it more "strict" about group-to-group variation. The purpose of looking at emissions comparisons was to determine the change in operation of the engine. Looking at the COVs of means from each RPT test for the emissions listed above, it was determined comparisons could still be made.

The mean, standard deviation, and coefficient of variation for in-cylinder pressure data collected during the RPT tests can be found in Table 18 and Table 19 in the Appendix. The 2005 Mack OM-460LA engine used to collect in-cylinder pressure data utilized EGR and a VGT. With more operating components, it is expected the engine will be less repeatable. All COV's were determined acceptable to make the comparison made within this research.

Results from the analysis of variance between in-cylinder pressure data collected for each RPT test can be found in Table 20 and Table 21 in the Appendix. Results indicated increased variations in dual-fuel parameters between the two RPT tests when compared to diesel-only 
operation. This can be contributed to the addition of working components for dual-fuel operation and the fact the engine is not designed from the OEM to operate with dual-fuel combustion. The parameters that failed the analysis of variance test did so for the same reason explained when looking at the analysis of variance for the engine data in Table 17 in the Appendix. The results were determined repeatable after analyzing the COVs of means from each RPT test for the incylinder pressure parameters that failed the analysis of variance test.

Repeatability of operating conditions can be found in Table 22, Table 23, Table 24, and Table 25 in the Appendix. The operating conditions analyzed were barometric pressure, intake absolute humidity, and intake temperature. The analysis of variance tests (Table 23 and Table 25 in the Appendix) indicated group-to-group variation in all operating conditions for reasons explained when looking at the analysis of variance for the engine data in Table 17 in the Appendix. The largest group-to-group variations occurred for intake absolute humidity and intake temperature. These variations occur due to changes in atmospheric conditions. The mean, standard deviation, and COV calculations can be found in Table 22 and Table 24 in the Appendix. COVs were worse for certification work because testing was completed over a number of days. The results were considered acceptable meaning they would not alter engine performance significantly.

The mean, standard deviation, and coefficient of variation for measured engine data during transient operation (FTPs) can be found in Table 26 in the Appendix. All COVs were determined to be acceptable for this experiment.

\subsection{Cost Comparison}

The results of the operation cost comparison can be found in Table 27 in the Appendix. During Demonstration I the truck traveled approximately 91,246 highway miles a year which was 350 highway miles a day. The fuel efficiency of the truck decreased by $18.1 \%$ from $6.31 \mathrm{MPG}$ for diesel-only operation to 5.17 miles per diesel gallon equivalent (MPDGE) for dual-fuel operation. With the cost of the dual-fuel conversion kit it would take a 4.02-year period for a balanced return on investments and a 10 year cost savings of $\$ 61,283$ at $\$ 10,249$ savings per year. During Demonstration III the truck traveled approximately 135,772 highway miles a year which was 520 highway miles a day. The fuel efficiency of the truck decreased by $11.8 \%$ from 6.09 MPG for diesel-only operation to 5.37 MPDGE for dual-fuel operation. With the cost of the 
dual-fuel conversion kit it would take a 2.27-year period for a balanced return on investments and a 10 year cost savings of $\$ 138,642$ at $\$ 17,632$ savings per year.

During Demonstration II, the truck traveled approximately 25,578 highway miles a year which was 98 combined highway and rural miles a day. The fuel efficiency of the truck decreased by $10.9 \%$ from 4.85 MPG for diesel-only operation to 4.32 MPGDE for dual-fuel operation. With the cost of the dual-fuel conversion kit it would take a 10.21-years period for a balanced return in investments and a 10 year cost loss of $\$ 868$ at $\$ 3,919$ savings per year. The decrease of fuel efficiency from diesel-only operation to dual-fuel operation can be attributed to the increase in BSFC and the decrease in combustion efficiency experienced for dual-fuel combustion. The decrease in fuel efficiency for both modes of operation from Demonstration I and Demonstration III's MPG efficiencies to Client II's MPG efficiency can be attributed to the change from highway driving to combined highway and rural driving. A comparison of all the trucks indicates increased savings for the clients when miles traveled are increased per year. This indicates the dual-fuel conversion kit is cost effectively suited for high yearly mileage trucks that travel highway routes.

There are a limited number of stations for a dual-fuel truck to refuel at during a highway haul. In terms of refueling, the dual-fuel conversion kit is best suited for a truck that can slow fill over night and complete its route the next day. Trucks that operate under these conditions usually travel local routes with some highway miles. These trucks do not operate under high yearly mileage conditions when compared to an over-the-road highway traveling truck. An ideal situation for a dual-fuel conversion would be a truck that travels highway miles for a majority of its operation and slow refuels during its down time. 


\section{Conclusions and Recommendations}

The objective of this work is to investigate dual-fuel combustion characteristics and resultant emissions to determine if the partial replacement of diesel fuel with CNG is a applicable technology in the transportation industry. To accomplish this, a dual-fuel capable 2005 Mercedes OM-460LA 12.8 liter engine was outfitted with in-cylinder pressure and exhaust emissions measurement capabilities and operated at steady-state conditions to compare combustion characteristics and emissions formation between dual-fuel and diesel operation. Also, research and development work was completed on a 2005 Mack AC-460P 12.0 liter engine to certify a dual-fuel conversion kit with the (EPA's) Clean Alternative Fuel Conversion Program. Exhaust emissions were collected over steady-state and transient conditions. In-use operation cost and MPG efficiency comparisons were then completed with the certified conversion kit.

\subsection{Conclusions}

The in-cylinder pressure analysis of dual-fuel operation compared to diesel-only operation showed reductions in combustion efficiencies and increases in BSFCs. An increase of premixed combustion energy release and a decrease in diffusion combustion energy release was observed. Ignition delays increased while mean and maximum pressure derived in-cylinder gas temperatures decreased. To meet the EPA's Clean Alternative Fuel Conversion Program, pilot diesel injection timing was retarded at high loads. Repeatability was assessed by calculating means, standard deviations, COVs, and analyses of variance of emissions data and in-cylinder pressure data. All results were determined to be satisfactory to make the necessary comparisons between dual-fuel operation and diesel-only operation. The EPA certified dual-fuel conversion kit was in-use tested for clients to show operation cost savings and MPG efficiencies. Demonstrations with high yearly highway miles showed significant savings per year $(\leq \$ 17,632$ per vehicles converted) with a 2.27-year period for a balanced return on investment timeframe. Demonstrations with low yearly rural and highway miles showed decreased savings (\$3.919) with a 10.21 year period for a balanced return on investment. MPG efficiencies decreased up to $18 \%$.

The EPA certified dual-fuel conversion kit showed reduction in NOx emissions during the steady-state SET and transient FTP. A reduction in NOx emissions is desirable considering they are a major contributor in photochemical smog which is linked to respiratory health issues. PM 
emissions increased during the steady-state SET and decreased during the transient FTP. The reduction of $\mathrm{PM}$ emissions during transient operation is desirable considering they are also linked to respiratory health issues. NMHC emissions increased during the steady-state SET and transient FTP. An increase in NMHC emissions is non-desirable because they can cause cancer or other adverse health effects. CO emissions increased during the steady-state SET and transient FTP. An increase in $\mathrm{CO}$ emissions is undesirable because they are colorless, odorless, and poisonous. $\mathrm{CO}_{2}$ emissions decreased during the steady-state SET and transient FTP. A decrease in $\mathrm{CO}_{2}$ emissions is desirable because they are linked to global warming. MHC emissions increased during the steady-state SET and transient FTP. A increase in $\mathrm{CO}_{2}$ emissions is nondesirable because they are a cause of global warming. The reduction of $\mathrm{CO}_{2}$ emissions is outweighed by the increase in MHC emissions due to a GWP increase of 35\% for the steadystate SET and $85.2 \%$ for the transient FTP.

The dual-fuel conversion kit demonstrated compliance with the EPA's Clean Alternative Fuels Conversion Program and potential savings in operation costs. In-use testing resulted in reductions of diesel consumed $(\leq 63.2 \%)$ indicating a potential to decrease the amount of petroleum imported by the United States. The CNG refueling infrastructure needs development to provide more refueling locations for natural gas operating vehicles. Dual-fuel operation cost savings proved to be most effective when the vehicle was operated on highways and accumulated high yearly mileages.

\subsection{Recommendations}

Future research should be aimed to improve combustion efficiencies. A comparison of direct $\mathrm{CNG}$ injection to sequential CNG injection could prove to be beneficial. Future studies could investigate how to improve flame spread limits to reach $\mathrm{CNG}$ /air mixtures at locations away from the pilot diesel vicinity. The same study should also explore approaches to increase substitution at high loads without creating engine knock. For future research it is recommended that modal PM data is collected with increased sampling times during the SETs. It is also recommended the dual-fuel conversion kit is in-use tested with more driving scenarios to determine a wider spectrum of cost comparisons. Diesel oxidation catalyst's (DOCs) should be tested to reduce $\mathrm{CO}$ and $\mathrm{HC}$ emissions produced during dual-fuel operation. 


\section{References}

[1] September 2003 Report: National Air Quality and Emissions Trends Report, 2003 Special Studies Edition, Environmental Protection Agency, Washington, DC, USEPA \#454/R03-005, 2003.

[2] Karim, G.A., "Combustion in Gas Fuel Compression: Ignition Engines of the Dual-fuel Type," Journal of Engineering for Gas Turbines and Power, Vol. 125 pp. 827-836, 2003.

[3] Wagemakers, A.M.L.M and Leermakers, C.A.J, "Review on the Effects of Dual-Fuel Operation, Using Diesel and Gaseous Fuels, on Emissions and Performance," SAE Paper no. 2012-01-0869, 2012.

[4] Shen, J., Qin, J., and Yao, M., "Turbocharged Diesel/CNG Dual-Fuel Engines with Intercooler: Combustion, Emissions, and Performance," SAE Paper no. 2003-01-3082, 2003.

[5] Shah, A., Thipse, S.S., Tyagi, A., Rairikar, S.D., Kavthekar, K.P., and Mrathe, N.V., "Literature Review and Simulation of Dual-fuel Diesel-CNG Engines," SAE Paper no. 2011-260001, 2011.

[6] Heywood, J.B., Internal Combustion Engine Fundamentals, McGraw-Hill, New York, NY, 1988.

[7] Khair, M. and Jaaskelained, H., DieselNet Technology Guide - Combustion in Diesel Engines [Online, January 2013]. http://dieselnet.com/tech/diesel_comb.php

[8] Badr, O., Karim, G.A., and Liu, B., "An Examination of the Flame Spread Limits in a Dual-fuel Engine," Applied Thermal Engineering, Vol. 19 pp. 1071-1080, 1999.

[9] Li, H., Karim, A., and Sohrabi, A., "Knock and Combustion Characteristics of $\mathrm{CH}_{4}, \mathrm{CO}$, $\mathrm{H}_{2}$, and Their Binary Mixtures," SAE Paper no. 2003-01-3088, 2003.

[10] Papagiannakis, R.G., Hountalas, D.T., and Kotsiopoulos, P.N., "Experimental and Theoretical Analysis of the Combustion and Pollutants Formation Mechanisms in Dual-fuel DI Diesel Engines," SAE Paper no. 2005-01-1726, 2005.

[11] Liu, Z. and Karim, G.A., "The Ignition Delay Period in Dual-fuel Engines," SAE Paper no. $950466,1995$.

[12] Liu, S., Li, H., Gatts, T., Liew, C., Clark, N., and Nuszkowski, J., "An Investigation of Combustion Process of a Heavy-Duty Dual-fuel Engine Supplemented with Natural Gas and Hydrogen," Personal Communications.

[13] Karim, G.A., C. Eng., Klat, S.R., and Moore, N.P.W., "Knock in Dual-fuel Engines," Proceeding's of the Institution of Mechanical Engineers, Vol. 181 pp. 453-466, 1966.

[14] Papagiannakis, R.G., Rakopoulos, C.D., Hountalas, D.T., and Rakopoulos, D.C., "Emission Characteristics of High Speed, Dual-fuel, Compression Ignition Engine Operating in a Wide Range of Natural Gas/Diesel Fuel Proportions," Fuel, Vol. 89 pp. 1397-1406, 2010.

[15] Majewski,W.A., (2013, May) DieselNet Technology Guide - Diesel Particulate Matter [Online]. http://dieselnet.com/tech/dpm.php

[16] Pulkrabek, W.W., Engineering Fundamentals of the Internal Combustion Engine, Pearson Prentice-Hall, Upper Saddle River, NJ, 2004. 
[17] Papagiannakis, R.G. and Hountalas, D.T., "Combustion and Exhaust Emission Characteristics of a Dual-fuel Compression Ignition Engine Operated with Pilot Diesel Fuel and Natural Gas,” Energy Conversion and Management, Vol. 45 pp. 2971-2987, 2004.

[18] Shiyu, L., Li, H., Chetmun, L., Wayne, S., Thompson, G., Clark, N., and Nuzkowski, J., "An Investigation of $\mathrm{NO}_{2}$ Emissions From a Heavy-Duty Diesel Engine Fumigated with $\mathrm{H}_{2}$ and Natural Gas,” Combust. Sci. Technol. no. 2008-2035, 2012.

[19] DieselNet, Emission Standards - Heavy-Duty Truck and Bus Engines [Online, May 2013]. http://dieselnet.com/standards/us/hd.php

[20] Nuszkowski, J., "The Effects of Fuel Additives on Diesel Engine Emissions during Steady State and Transient Operation," West Virginia University, Morgantown, WV, Dissertation 2008.

[21] Sayers, A., "Investigation of Performance Degradation of a Johnson Matthey SCRT," West Virginia University, Morgantown, WV, Thesis 2012.

[22] Jahnke, J.A., Continuous Emission Monitoring, Can Nostrand Reinhold, 115 Fifth Avenue, New York, 1993.

[23] Papagiannakis, R.G., Hountalas, D.T., Rakopoulos, C.D., and Rakopoulos, D.C., "Combustion and Performance Characteristics of a DI Diesel Engine Operating from Low to High Natural Gas Supplement Ratios at Various Operating Conditions," SAE Paper no. 2008-011392, 2008.

[24] Collantes, G. and Melaina, M.W., "The Co-Evolution of Alternative Fuel Infrastructure and Vehicles: A Study of the Experience of Argentina with Compressed Natural Gas," Energy Policy, Vol. 39 pp. 664-675, 2011.

[25] Sahoo, B.B., Sahoo, N., and Saha, U.K., "Effect of Engine Parameters and Type of Gaseous Fuel on the Performance of Dual-Fuel Gas Diesel Engines - A Critical Review," Renewable and Sustainable Energy Reviews, Vol. 13 pp. 1151-1184, 2009.

[26] Abdelghaffar, W.A., "Performance and Emissions of a Diesel Engine Converted to Dual Diesel-CNG Fuelling," European Journal of Scientific Research, Vol. 56 pp. 279-293, 2011.

[27] Hountalas, D.T. and Papagiannakis, R.G., "Theoretical and Experimental Investigation of a Direct Injection Dual-fuel Diesel-Natural Gas Engine," SAE Paper no. 2002-01-0868, 2002.

[28] Wang, M. and Dongquan, H., "Full Fuel-Cycle Greenhouse Gas Emission Impacts of Transportation Fuels Produced from Natural Gas," SAE Paper no. 2000-01-1505, 2000.

[29] Singh, M.K. and Moore Jr., J.S., "Preliminary Assessment of the Availability of U.S. Natural Gas Resources to Meet U.S. Transportation Energy Demand," SAE Paper no. 2002-011926, 2002

[30] Park, T., "Dual-fuel Conversion of a Direct Injection Diesel Engine," West Virginia University, Morgantown, WV, Thesis 1999.

[31] Natural Gas Supply Association, Natural Gas [Online, December 2012]. http://www.naturalgas.org/

[32] TIAX, "U.S. and Canadian Natural Gas Vehicle Market Analysis: Compressed Natural Gas Infrastructure,” America's Natural Gas Alliance, 2012. 
[33] U.S. Energy Information Administration, Independent Statistics and Analysis [Online, December 2012]. http://www.eia.gov/

[34] Yoshimoto, Y., Kinoshita, E., Luge, S., and Ohmura, T., "Combustion Characteristics of a Dual-fuel Diesel Engine with Natural Gas (Lower Limit of Cetane Number for Ignition of the Fuel," SAE Paper no. 2012-01-1690, 2012.

[35] Selim, M.Y.E., "A Study of Some Combustion Characteristics of Dual-fuel Engine Using EGR,” SAE Paper no. 2003-01-0766, 2003.

[36] Yusaf, T.F., Buttsworth, D., and Al-Atabi, M.T., "Engine Performance and Exhaust Gas Emissions Characteristics of (CNG/Diesel) Dual-Fuel Engine," SAE Paper no. 2001-011808/4228, 2001.

[37] Lim, O., Iida, N., Gyubaek, C., and Narankhuu, J., "The Research about Engine Optimization and Emission Characteristic of Dual-fuel Engine Fueled with Natural Gas and Diesel,” SAE Paper no. 2012-32-0008, 2012.

[38] Addy, J.M., Bining, A., Norton, P., Peterson E., Campbell, K., and Bevillaque, O., "Demonstration of Caterpillar C10 Dual-fuel Natural Gas Engines in Commuter Buses," SAE Paper no. 2000-01-1386, 2000.

[39] Mustafi, N.N. and Raine, R.R., "A Study of the Emissions of a Dual-fuel Engine Operating with Alternative Gaseous Fuels," SAE Paper no. 2008-01-1394, 2008.

[40] Shengua, L., Longbao, Z., Ziyan, W., and Jiang, R., "Combustion Characteristics of Compressed Natural Gas/Diesel Dual-Fuel Turbocharged Compressed Ignition Engine," Proceedings of the Institution of Mechanical Engineers, Part D: Journal of Automobile Engineering, 2003 217:833, 2003.

[41] Ahmad, N., Babu, M.K.G., and Ramesh, A., "Experimental Investigation of Different Parameters Affecting the Performance of a CNG-Diesel Dual-fuel Engine," SAE Paper No. 2005-01-3767, 2005.

[42] DieselNet, DieselNet Technology Guide - Gaseous Emissions [Online, May 2013]. http://dieselnet.com/tech/emi_gas.php

[43] Khair, M. and Jaaskelained, H., DieselNet Technology Guide - Emission Formation in Diesel Engines [Online, May 2013]. http://dieselnet.com/tech/diesel_emiform.php

[44] Cozzolini, A., Littera, D., Ryskamp, R., Besch, M., Velardi, M., Kappana, H., Carder, D., Gautam, M., and Smallwood, J., "Characteristics of Exhaust Emissions from a Heavy-Duty Diesel Engine Retrofitted to Operate in CNG/Diesel Dual-Fuel Mode," SAE Paper no. 13ICE0108, 2013.

[45] CNGNOW!, Average Price - Average Prices Across the United States [Online, June 2013]. http://www.cngnow.com/average-cng-prices/pages/default.aspx

[46] EPA, "Clean Alternative Fuel Vehicle and Engine Conversions," Environmental Protection Agency, Washington, DC, Final Register/Vol. 76, No. 68/Friday, April 8, 2011/Rules and Regulations, 2011. 


\section{Appendices}

Table 16 - Mean, Standard Deviation, and COV of RPT Tests for Engine Data

\begin{tabular}{|c|c|c|c|}
\hline \multicolumn{2}{|c|}{ Engine Data Repeatability } & Diesel & Dual-fuel \\
\hline \multirow{3}{*}{$\frac{\sqrt{\pi}}{0} \frac{4}{3}$} & Average (bhp-hr) & 3.88 & 3.88 \\
\hline & Std Dev (bhp-hr) & 0.001 & 0.002 \\
\hline & $\mathrm{COV}$ & $0.030 \%$ & $0.041 \%$ \\
\hline \multirow{3}{*}{ 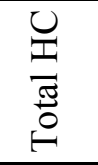 } & Average (g/bhp-hr) & 0.031 & 16.5 \\
\hline & Std Dev (g/bhp-hr) & 0.004 & 0.232 \\
\hline & $\mathrm{COV}$ & $13.3 \%$ & $1.41 \%$ \\
\hline \multirow{3}{*}{$\stackrel{U}{\stackrel{U}{\Sigma}}$} & Average (g/bhp-hr) & N/A & 15.3 \\
\hline & Std Dev (g/bhp-hr) & N/A & 0.230 \\
\hline & $\mathrm{COV}$ & N/A & $1.50 \%$ \\
\hline \multirow{3}{*}{$\stackrel{\star}{ٍ}$} & Average (g/bhp-hr) & 1.69 & 1.06 \\
\hline & Std Dev (g/bhp-hr) & 0.037 & 0.008 \\
\hline & $\mathrm{COV}$ & $2.19 \%$ & $0.740 \%$ \\
\hline \multirow{3}{*}{$\stackrel{O}{Z}$} & Average (g/bhp-hr) & 1.59 & 0.474 \\
\hline & Std Dev (g/bhp-hr) & 0.044 & 0.040 \\
\hline & $\mathrm{COV}$ & $2.75 \%$ & $8.48 \%$ \\
\hline \multirow{3}{*}{ O } & Average (g/bhp-hr) & 0.652 & 13.9 \\
\hline & Std Dev (g/bhp-hr) & 0.051 & 0.038 \\
\hline & $\mathrm{COV}$ & $7.81 \%$ & $0.272 \%$ \\
\hline \multirow{3}{*}{$\stackrel{N}{0}$} & Average (g/bhp-hr) & 485 & 436 \\
\hline & Std Dev (g/bhp-hr) & 2.60 & 0.865 \\
\hline & $\mathrm{COV}$ & $0.537 \%$ & $0.198 \%$ \\
\hline \multirow{3}{*}{$\begin{array}{l}\overline{0} \\
\stackrel{0}{0} \\
\stackrel{0}{0}\end{array}$} & Average $(\mathrm{kg} / \mathrm{min})$ & 0.507 & 0.274 \\
\hline & Std Dev (kg/min) & 0.002 & 0.002 \\
\hline & $\mathrm{COV}$ & $0.356 \%$ & $0.435 \%$ \\
\hline \multirow{3}{*}{$\bigcup_{\circlearrowright}^{\circlearrowright}$} & Average (kg/min) & N/A & 0.285 \\
\hline & Std Dev $(\mathrm{kg} / \mathrm{min})$ & N/A & 0.001 \\
\hline & $\mathrm{COV}$ & N/A & $0.451 \%$ \\
\hline
\end{tabular}


Table 17 - ANOVA of RPT Tests for Engine Data

\begin{tabular}{|c|c|c|c|}
\hline \multicolumn{2}{|c|}{ Engine Data Repeatability } & Diesel & Dual-fuel \\
\hline \multirow{3}{*}{ 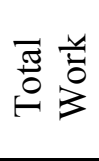 } & P Value & 0.916 & 0.588 \\
\hline & F Value & 0.013 & 0.346 \\
\hline & Variation of Means & No Sig Diff & No Sig Diff \\
\hline \multirow{3}{*}{ 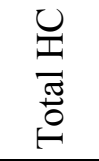 } & P Value & 0.166 & 0.002 \\
\hline & F Value & 2.86 & 56.1 \\
\hline & Variation of Means & No Sig Diff & $1.76 \%$ \\
\hline \multirow{3}{*}{$\stackrel{\circlearrowright}{\Xi}$} & P Value & N/A & 0.001 \\
\hline & F Value & $\mathrm{N} / \mathrm{A}$ & 61.4 \\
\hline & Variation of Means & $\mathrm{N} / \mathrm{A}$ & $1.87 \%$ \\
\hline \multirow{3}{*}{$\stackrel{\varkappa}{Z}$} & P Value & 0.931 & 0.989 \\
\hline & F Value & 0.009 & 0.000 \\
\hline & Variation of Means & No Sig Diff & No Sig Diff \\
\hline \multirow{3}{*}{ Z } & P Value & 0.432 & 0.003 \\
\hline & F Value & 0.762 & 40.0 \\
\hline & Variation of Means & No Sig Diff & $10.4 \%$ \\
\hline \multirow{3}{*}{ O } & P Value & 0.160 & 0.153 \\
\hline & F Value & 2.97 & 3.09 \\
\hline & Variation of Means & No Sig Diff & No Sig Diff \\
\hline \multirow{3}{*}{ Oే } & P Value & 0.471 & 0.901 \\
\hline & F Value & 0.633 & 0.018 \\
\hline & Variation of Means & No Sig Diff & No Sig Diff \\
\hline \multirow{3}{*}{$\begin{array}{l}\bar{\nabla} \\
\ddot{\theta} \\
\ddot{\theta}\end{array}$} & $\mathrm{P}$ Value & 0.496 & 0.098 \\
\hline & F Value & 0.559 & 4.61 \\
\hline & Variation of Means & No Sig Diff & No Sig Diff \\
\hline \multirow{3}{*}{$\underset{\mho}{Z}$} & P Value & $\mathrm{N} / \mathrm{A}$ & 0.653 \\
\hline & F Value & $\mathrm{N} / \mathrm{A}$ & 0.235 \\
\hline & Variation of Means & N/A & No Sig Diff \\
\hline
\end{tabular}


Table 18 - Mean, Standard Deviation, and COV of RPT Tests for In-Cylinder Pressure Data

\begin{tabular}{|c|c|c|c|}
\hline \multicolumn{2}{|c|}{ In-Cylinder Data Repeatability } & \multirow{2}{*}{$\begin{array}{c}\text { Diesel } \\
0.200\end{array}$} & \multirow{2}{*}{$\begin{array}{c}\text { Dual-fuel } \\
0.128\end{array}$} \\
\hline \multirow{3}{*}{ 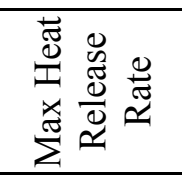 } & Average $(\mathrm{kJ} / \mathrm{deg})$ & & \\
\hline & Std Dev (kJ/deg) & 0.001 & 0.003 \\
\hline & $\mathrm{COV}$ & $0.341 \%$ & $2.18 \%$ \\
\hline \multirow{3}{*}{ 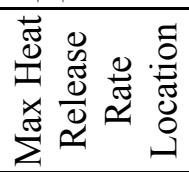 } & Average (deg) & 15.7 & 11.5 \\
\hline & Std Dev (deg) & 0.112 & 5.05 \\
\hline & $\mathrm{COV}$ & $\mathrm{N} / \mathrm{A}$ & $\mathrm{N} / \mathrm{A}$ \\
\hline \multirow{3}{*}{ 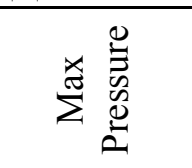 } & Average $(\mathrm{kPa})$ & 8340 & 8370 \\
\hline & Std Dev $(\mathrm{kPa})$ & 51.9 & 80.0 \\
\hline & $\mathrm{COV}$ & $0.622 \%$ & $0.956 \%$ \\
\hline \multirow{3}{*}{ 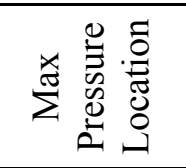 } & Average (deg) & 8.00 & 6.08 \\
\hline & Std Dev (deg) & 0.177 & 0.376 \\
\hline & $\mathrm{COV}$ & $\mathrm{N} / \mathrm{A}$ & $\mathrm{N} / \mathrm{A}$ \\
\hline \multirow{3}{*}{ 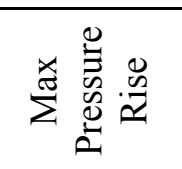 } & Average $(\mathrm{kPa} / \mathrm{deg})$ & 157 & 155 \\
\hline & Std Dev $(\mathrm{kPa} / \mathrm{deg})$ & 3.73 & 19.8 \\
\hline & $\mathrm{COV}$ & $2.38 \%$ & $12.8 \%$ \\
\hline \multirow{3}{*}{ 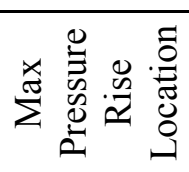 } & Average (deg) & 1.50 & 4.29 \\
\hline & Std Dev (deg) & 0.000 & 0.534 \\
\hline & $\mathrm{COV}$ & $\mathrm{N} / \mathrm{A}$ & $\mathrm{N} / \mathrm{A}$ \\
\hline \multirow{3}{*}{ 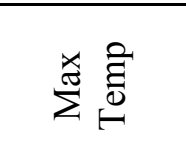 } & Average $(\mathrm{K})$ & 1450 & 1240 \\
\hline & Std Dev $(\mathrm{K})$ & 12.2 & 25.9 \\
\hline & $\mathrm{COV}$ & $0.839 \%$ & $2.09 \%$ \\
\hline \multirow{3}{*}{ 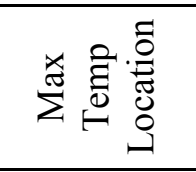 } & Average (deg) & 26.8 & 32.6 \\
\hline & Std Dev (deg) & 0.433 & 0.736 \\
\hline & $\mathrm{COV}$ & $\mathrm{N} / \mathrm{A}$ & $\mathrm{N} / \mathrm{A}$ \\
\hline \multirow{3}{*}{ 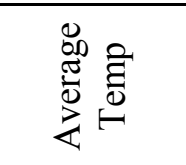 } & Average $(\mathrm{K})$ & 791 & 728 \\
\hline & Std Dev $(\mathrm{K})$ & 7.20 & 10.0 \\
\hline & $\mathrm{COV}$ & $0.910 \%$ & $1.38 \%$ \\
\hline \multirow{3}{*}{ 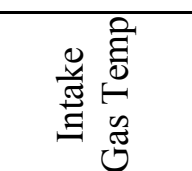 } & Average (K) & 322 & 323 \\
\hline & Std Dev $(\mathrm{K})$ & 1.35 & 1.50 \\
\hline & $\mathrm{COV}$ & $0.421 \%$ & $0.464 \%$ \\
\hline \multirow{3}{*}{ 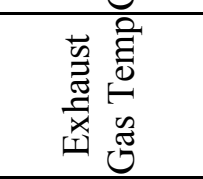 } & Average $(\mathrm{K})$ & 712 & 699 \\
\hline & Std Dev $(\mathrm{K})$ & 3.09 & 7.72 \\
\hline & $\mathrm{COV}$ & $0.434 \%$ & $1.10 \%$ \\
\hline
\end{tabular}


Table 19 - Mean, Standard Deviation, and COV of RPT Tests for In-Cylinder Pressure Data Continued

\begin{tabular}{|c|c|c|c|}
\hline \multicolumn{2}{|c|}{ In-Cylinder Data Repeatability } & \multirow{2}{*}{$\begin{array}{c}\text { Diesel } \\
-1.65 \\
\end{array}$} & \multirow{2}{*}{$\begin{array}{c}\text { Dual-fuel } \\
0.958 \\
\end{array}$} \\
\hline \multirow{3}{*}{ 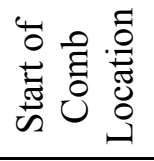 } & Average (deg) & & \\
\hline & Std Dev (deg) & 0.137 & 0.621 \\
\hline & $\mathrm{COV}$ & $\mathrm{N} / \mathrm{A}$ & $\mathrm{N} / \mathrm{A}$ \\
\hline \multirow{3}{*}{ 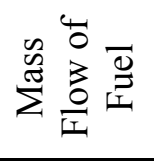 } & Average $(\mathrm{kg} / \mathrm{min})$ & 0.084 & 0.086 \\
\hline & Std Dev (kg/min) & 0.000 & 0.001 \\
\hline & $\mathrm{COV}$ & $0.414 \%$ & $1.34 \%$ \\
\hline \multirow{3}{*}{$\sum_{i}^{2}$} & Average $(\mathrm{kPa})$ & 168 & 181 \\
\hline & Std Dev $(\mathrm{kPa})$ & 1.47 & 0.657 \\
\hline & $\mathrm{COV}$ & $0.878 \%$ & $0.363 \%$ \\
\hline \multirow{3}{*}{ 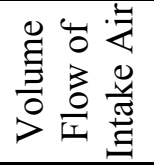 } & Average $\left(\mathrm{m}^{3} / \mathrm{min}\right)$ & 12.7 & 13.6 \\
\hline & Average $\left(\mathrm{m}^{3} / \mathrm{min}\right)$ & 0.009 & 0.121 \\
\hline & $\mathrm{COV}$ & $0.858 \%$ & $0.892 \%$ \\
\hline \multirow{3}{*}{ 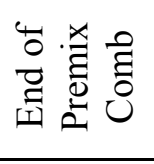 } & Average (deg) & 3.75 & 6.75 \\
\hline & Std Dev (deg) & 0.000 & 0.592 \\
\hline & $\mathrm{COV}$ & $0.000 \%$ & $8.76 \%$ \\
\hline \multirow{3}{*}{ 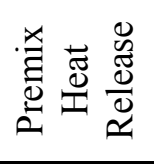 } & Average $(\mathrm{kJ})$ & 0.280 & 0.427 \\
\hline & Std Dev $(\mathrm{kJ})$ & 0.003 & 0.007 \\
\hline & $\mathrm{COV}$ & $0.914 \%$ & $1.57 \%$ \\
\hline \multirow{3}{*}{ 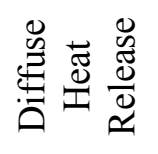 } & Average $(\mathrm{kJ})$ & 4.22 & 3.53 \\
\hline & Std Dev $(\mathrm{kJ})$ & 0.044 & 0.130 \\
\hline & $\mathrm{COV}$ & $1.05 \%$ & $3.69 \%$ \\
\hline
\end{tabular}


Table 20 - ANOVA of RPT Tests for In-Cylinder Pressure Data

\begin{tabular}{|c|c|c|c|}
\hline \multicolumn{2}{|c|}{ In-Cylinder Repeatability } & \multirow{2}{*}{$\begin{array}{c}\text { Diesel } \\
0.295\end{array}$} & \multirow{2}{*}{$\begin{array}{c}\text { Dual-fuel } \\
0.143\end{array}$} \\
\hline \multirow{3}{*}{ 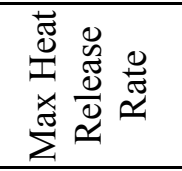 } & P Value & & \\
\hline & F Value & 1.60 & 3.31 \\
\hline & Variation of Means & No Sig Diff & No Sig Diff \\
\hline \multirow{3}{*}{ 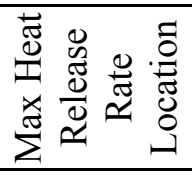 } & P Value & 0.272 & 0.074 \\
\hline & F Value & 1.80 & 5.76 \\
\hline & Variation of Means* & No Sig Diff & No Sig Diff \\
\hline \multirow{3}{*}{ 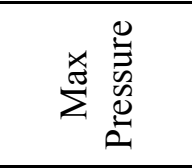 } & P Value & 0.215 & 0.013 \\
\hline & F Value & 2.46 & 17.9 \\
\hline & Variation of Means & No Sig Diff & $1.12 \%$ \\
\hline \multirow{3}{*}{ 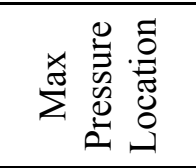 } & P Value & 1.00 & 0.001 \\
\hline & F Value & 0.000 & 64.0 \\
\hline & Variation of Means* & No Sig Diff & 0.667 \\
\hline \multirow{3}{*}{ 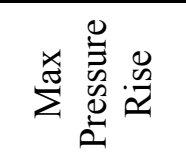 } & P Value & 0.486 & 0.035 \\
\hline & F Value & 0.629 & 9.91 \\
\hline & Variation of Means & No Sig Diff & $13.9 \%$ \\
\hline \multirow{3}{*}{ 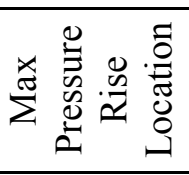 } & P Value & No Variance & 0.005 \\
\hline & F Value & No Variance & 30.3 \\
\hline & Variation of Means* & No Sig Diff & 0.917 \\
\hline \multirow{3}{*}{ 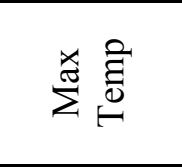 } & P Value & 0.003 & 0.006 \\
\hline & F Value & 83.7 & 28.0 \\
\hline & Variation of Means & $1.01 \%$ & $2.53 \%$ \\
\hline \multirow{3}{*}{ 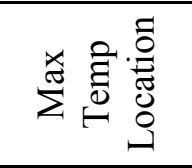 } & P Value & 0.361 & 0.000 \\
\hline & F Value & 1.15 & 256 \\
\hline & Variation of Means* & No Sig Diff & 1.33 \\
\hline \multirow{3}{*}{ 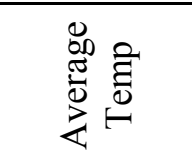 } & P Value & 0.016 & 0.005 \\
\hline & F Value & 24.0 & 31.5 \\
\hline & Variation of Means & $0.949 \%$ & $1.68 \%$ \\
\hline \multirow{3}{*}{ 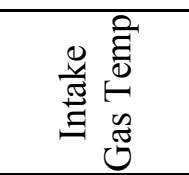 } & P Value & 0.314 & 0.059 \\
\hline & F Value & 1.46 & 6.83 \\
\hline & Variation of Means & No Sig Diff & No Sig Diff \\
\hline \multirow{3}{*}{ 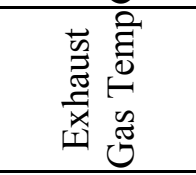 } & P Value & 0.015 & 0.007 \\
\hline & F Value & 26.1 & 25.8 \\
\hline & Variation of Means & $0.601 \%$ & $1.33 \%$ \\
\hline \multicolumn{4}{|c|}{ Significant Difference if "Variation of Means" Shows COV of Means } \\
\hline & erence of Means Rathe & $\mathrm{V}$ of Means & \\
\hline
\end{tabular}


Table 21 - ANOVA of RPT Tests for In-Cylinder Pressure Data Continued

\begin{tabular}{|c|c|c|c|}
\hline \multicolumn{2}{|c|}{ In-Cylinder Data Repeatability } & \multirow{2}{*}{$\begin{array}{c}\text { Diesel } \\
0.000\end{array}$} & \multirow{2}{*}{$\begin{array}{c}\text { Dual-fuel } \\
0.003 \\
\end{array}$} \\
\hline \multirow{3}{*}{ 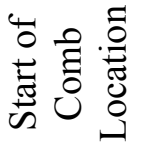 } & P Value & & \\
\hline & F Value & 0.000 & 42.3 \\
\hline & Variation of Means* & 0.250 & 1.08 \\
\hline \multirow{3}{*}{ 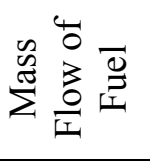 } & P Value & 0.506 & 0.054 \\
\hline & F Value & 0.569 & 7.25 \\
\hline & Variation of Means & No Sig Diff & No Sig Diff \\
\hline \multirow{3}{*}{$\sum_{i}$} & P Value & 0.090 & 0.071 \\
\hline & F Value & 6.08 & 5.97 \\
\hline & Variation of Means & No Sig Diff & No Sig Diff \\
\hline \multirow{3}{*}{ 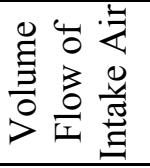 } & P Value & 0.001 & 0.000 \\
\hline & F Value & 198 & 305 \\
\hline & Variation of Means & $1.10 \%$ & $1.14 \%$ \\
\hline \multirow{3}{*}{ 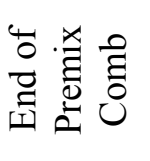 } & P Value & No Variance & 0.008 \\
\hline & F Value & No Variance & 24.0 \\
\hline & Variation of Means* & No Sig Diff & 1.00 \\
\hline \multirow{3}{*}{  } & P Value & 0.822 & 0.477 \\
\hline & F Value & 0.060 & 0.615 \\
\hline & Variation of Means & No Sig Diff & No Sig Diff \\
\hline \multirow{3}{*}{ 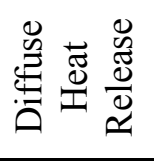 } & P Value & 0.295 & 0.030 \\
\hline & F Value & 1.60 & 10.8 \\
\hline & Variation of Means & No Sig Diff & $4.08 \%$ \\
\hline \multicolumn{4}{|c|}{ Significant Difference if "Variation of Means" Shows COV of Means } \\
\hline
\end{tabular}


Table 22 - Mean, Standard Deviation, and COV of Operating Conditions

\begin{tabular}{cccc}
\hline Op Conditions Repeatability & Barometric Pressure & Intake Abs. Hum. & Intake Temperature \\
\hline $\mathrm{Avg}\left(\mathrm{kPa}, \mathrm{kg} \mathrm{H}{ }_{2} \mathrm{O} / \mathrm{kg}\right.$ air, $\left.{ }^{\circ} \mathrm{C}\right)$ & 97.4 & 0.010 & 23.1 \\
\hline $\mathrm{Std}\left(\mathrm{kPa}, \mathrm{kg} \mathrm{H} \mathrm{O}_{2} \mathrm{O} / \mathrm{kg}\right.$ air, $\left.{ }^{\circ} \mathrm{C}\right)$ & 0.100 & 0.000 & 0.641 \\
\hline $\mathrm{COV}$ & $0.103 \%$ & $1.96 \%$ & $2.77 \%$ \\
\hline
\end{tabular}

Table 23 - ANOVA of Operating Conditions

\begin{tabular}{cccc}
\hline Op Conditions Repeatability & Barometric Press & Intake Abs. Hum. & Intake Temp \\
\hline P Value & 0.000 & 0.000 & 0.000 \\
\hline F Value & 2400000 & 231000 & 174000 \\
\hline Variation of Means & $0.145 \%$ & $2.72 \%$ & $3.81 \%$ \\
\hline Significant Difference if "Variation of Means" Shows COV of Means & \\
\hline
\end{tabular}

Table 24 - Mean, Standard Deviation, and COV of Certification Work

\begin{tabular}{cccc}
\hline Op Conditions Repeatability & Barometric Pressure & Intake Abs. Hum. & Intake Temperature \\
\hline $\mathrm{Avg}\left(\mathrm{kPa}, \mathrm{kg} \mathrm{H}{ }_{2} \mathrm{O} / \mathrm{kg}\right.$ air, $\left.{ }^{\circ} \mathrm{C}\right)$ & 97.9 & 0.010 & 25.4 \\
\hline $\mathrm{Std}\left(\mathrm{kPa}, \mathrm{kg} \mathrm{H} \mathrm{O} / \mathrm{kg}\right.$ air, $\left.{ }^{\circ} \mathrm{C}\right)$ & 0.548 & 0.001 & 1.48 \\
\hline $\mathrm{COV}$ & $0.559 \%$ & $7.14 \%$ & $5.83 \%$ \\
\hline
\end{tabular}

Table 25 - ANOVA of Certification Work

\begin{tabular}{cccc}
\hline Op Conditions Repeatability & Barometric Press & Intake Abs. Hum . & Intake Temp \\
\hline P Value & 0.000 & 0.000 & 0.000 \\
\hline F Value & 7880000 & 244000 & 387000 \\
\hline Variation of Means & $0.645 \%$ & $8.08 \%$ & $3.11 \%$ \\
\hline Significant Difference if "Variation of Means" Shows COV of Means & \\
\hline
\end{tabular}


Table 26 - Mean, Standard Deviation, and COV of Repeated FTPs

\begin{tabular}{|c|c|c|c|}
\hline & Engine Repeatability Data & Diesel & Dual-fuel \\
\hline \multirow{3}{*}{$\begin{array}{l}\frac{y}{0} \\
\dot{0}\end{array}$} & Avg (bhp-hr) & 29.9 & 30.5 \\
\hline & Std (bhp-hr) & 0.008 & 0.009 \\
\hline & $\mathrm{COV}$ & $0.027 \%$ & $0.030 \%$ \\
\hline \multirow{3}{*}{$\underset{⿱ 乛}{\stackrel{U}{\mid}}$} & $\operatorname{Avg}(g / b h p-h r)$ & 0.102 & 9.86 \\
\hline & Std (g/bhp-hr) & 0.005 & 0.131 \\
\hline & $\mathrm{COV}$ & $4.63 \%$ & $1.33 \%$ \\
\hline \multirow{3}{*}{$\underset{⿱}{\stackrel{U}{\Sigma}}$} & $\operatorname{Avg}(g / b h p-h r)$ & $\mathrm{N} / \mathrm{A}$ & 9.34 \\
\hline & Std (g/bhp-hr) & N/A & 0.484 \\
\hline & $\mathrm{COV}$ & N/A & $5.19 \%$ \\
\hline \multirow{3}{*}{$\stackrel{x}{z}_{z}$} & Avg (g/bhp-hr) & 2.32 & 1.78 \\
\hline & Std (g/bhp-hr) & 0.024 & 0.029 \\
\hline & $\mathrm{COV}$ & $1.02 \%$ & $1.65 \%$ \\
\hline \multirow{3}{*}{ Z } & $\operatorname{Avg}(g / b h p-h r)$ & 2.15 & 1.26 \\
\hline & Std (g/bhp-hr) & 0.024 & 0.029 \\
\hline & $\mathrm{COV}$ & $1.13 \%$ & $2.27 \%$ \\
\hline \multirow{3}{*}{ O } & $\operatorname{Avg}(g / b h p-h r)$ & 0.424 & 6.12 \\
\hline & Std (g/bhp-hr) & 0.001 & 0.054 \\
\hline & $\mathrm{COV}$ & $0.304 \%$ & $0.882 \%$ \\
\hline \multirow{3}{*}{ ठิ } & Avg (g/bhp-hr) & 540 & 494 \\
\hline & Std (g/bhp-hr) & 0.111 & 1.05 \\
\hline & $\mathrm{COV}$ & $0.021 \%$ & $0.213 \%$ \\
\hline \multirow{3}{*}{$\sum_{\Omega}$} & Avg (mg/bhp-hr) & 64.0 & 66.8 \\
\hline & Std (mg/bhp-hr) & 0.760 & 0.138 \\
\hline & $\mathrm{COV}$ & $1.19 \%$ & $0.206 \%$ \\
\hline
\end{tabular}


Table 27 - Cost Comparison

\begin{tabular}{cccc}
\hline Client Demonstration & I & II & III \\
\hline Days & 5 & 1 & 5 \\
\hline Distance (miles) & 1748 & 98 & 2601 \\
\hline Diesel Used (gallons) & 277 & 20.2 & 427 \\
\hline Dual-Fuel Diesel Used (gallons) & 102 & 8.67 & 176 \\
\hline Diesel Reduction (gallons) & 175 & 11.5 & 251 \\
\hline \% Diesel Reduction & $63.2 \%$ & $57.1 \%$ & $58.8 \%$ \\
\hline Dual-Fuel CNG Used (DGE) & 236 & 14.0 & 309 \\
\hline Diesel-Only MPG & 6.31 & 4.85 & 6.09 \\
\hline Dual-Fuel MPDGE & 5.17 & 4.32 & 5.37 \\
\hline Fuel Cost Savings Demo & $\$ 196$ & $\$ 16.2$ & $\$ 344$ \\
\hline Fuel Cost Savings Year & $\$ 10,249$ & $\$ 4,219$ & $\$ 17,932$ \\
\hline Miles/Year & 91246 & 25578 & 135772 \\
\hline Yearly Maintenance Costs & $\$ 300$ & $\$ 300$ & $\$ 300$ \\
\hline Yearly Operation Savings & $\$ 9,949$ & $\$ 3,919$ & $\$ 17,632$ \\
\hline Conversion Cost & $\$ 40,000$ & $\$ 40,000$ & $\$ 40,000$ \\
\hline Years to Return & 4.02 & 10.21 & 2.27 \\
\hline 10 Year Savings & $\$ 61,283$ & $-\$ 868$ & $\$ 138,642$ \\
\hline
\end{tabular}

